\title{
ELETRÓLITOS POLIMÉRICOS GÉIS À BASE DE PECTINA
}

\author{
JULIANA RAMOS DE ANDRADE
}

Dissertação apresentada ao Instituto de Química de São Carlos, da Universidade de São Paulo, para obtenção do título de Mestre em Fisico-Química.

Orientadora:Profa Dra. Agnieszka Joanna Pawlicka Maule. 


\section{Este exemplar foi revisado e alterado em relação à versão original, sob a exclusiva responsabilidade do autor. \\ São Carlos, 051102010 \\ fuliona R. de Androde \\ Juliana Ramos de Andrade}

Ficha Catalográfica elaborada pela Seção de Referência e Atendimento ao Usuário do SBI/IQSC

Andrade, Juliana Ramos

Eletrólitos poliméricos géis à base de pectina. / Juliana Ramos Andrade. -São Carlos, IQSC, 2010.

$161 \mathrm{p}$.

Dissertação (Mestrado) - Instituto de Química de São Carlos /

Universidade de São Paulo, 2010.

Edição revisada

Orientadora: Profa. Dra.Agnieszka Joana Pawlicka Maule

1. Polímeros naturais. 2. Pectina. 3. Eletrólitos poliméricos géis. I.Título. 


\section{DEDICATÓRIA}

Á DEUS PELA VIDA, SAUDE E CAPACIDADE, AOS MEUS PAIS E AVÓS QUE NUNCA MEDIRAM ESFORÇOS PARA OBTENÇÃO DO MEU TITULO, PELO INCENTIVO, OPORTUNIDADE E CONFIANÇA E AOS MEUS AMIGOS PELO APOIO. 


\section{AGRADECIMENTOS}

Agradeço a Deus por estar em minha vida e me abençoar com tantas maravilhas.

Aos meus pais, Maria do Céu e Sérgio, pelo incentivo, apoio, educação e por me ensinar a nunca desistir dos meus sonhos.

Ás minhas avós Sara de Jesus dos Santos Ramos e Dirce Moreira, que sempre me apoiaram, incentivaram e me deram muito amor e carinho.

Ao meu avô João de Souza Ramos que em 23/08/07 nos deixou, mas aonde quer que ele esteja está orgulhoso, e me dando força para continuar minha caminhada.

Ao meu irmão, ao meu padrinho Clovis, e aos meus tios, que mesmo de longe estavam torcendo por mim.

A Profa ${ }^{\text {. Dra }}$. Agnieszka, pela oportunidade de desenvolver este trabalho, pela orientação, amizade e paciência.

Ao Giorgio que como aluno de iniciação me auxiliou muito no desenvolvimento do meu trabalho, pela sua dedicação, inteligência e amizade.

Aos colegas de grupo Ellen, Ritamara, Diogo, César, Fran, Yurika pela disposição em ajudar em tudo que foi necessário para o desenvolvimento deste trabalho, e para o crescimento intelectual. pesquisa.

A Gilmara Machado, que me orientou e norteou sobre o tema desta

Aos chefes do CCDM, José Donato Ambrósio, Marcelo A. Chinelatto, Rubens E. dos Santos, que acreditaram no meu potencial, e me deram a oportunidade de concluir mais uma etapa.

A todos meus amigos e amigas, que não citarei nomes, pois poderei me esquecer de algum, mas quero agradecer à todos pela amizade, apoio e companheirismo em todas as horas.

A todos os funcionários e professores do IQSC e do IFSQ.

A todos os funcionários desta Universidade, que de forma direta ou indireta contribuíram para a obtenção deste trabalho.

A indústria CP KELCO Brasil S/A, pela doação das pectinas.

Á todos que de alguma forma me ajudaram neste trabalho. 
"Tudo que chega, chega sempre por alguma razão" Fernando Pessoa 


\section{LISTA DE FIGURAS}

Figura 1-1: Representação do movimento dos segmentos do polímero que auxilia na difusão do íon $\mathrm{Li}^{+}$na matriz polimérica. Os círculos representam os oxigênios do tipo éter

Figura 1-2: Representação esquemática do modelo de saltos para transporte iônico. $O$ movimento do cátion ocorre através do salto entre um par de íons e os oxigênios do tipo éter da cadeia polimérica (a) e entre dois pares de íons coordenados ao oxigênio éter (b).....

Figura 1-3: Cadeia linear de $(1 \rightarrow 4)-\alpha$-D-ácido galacturônico.

Figura 1-4: Mudanças de estado físico de macromoléculas.

Figura 1-5: Esquema de janela eletrocrômica.

Figura 1-6: Visualização e esquema de funcionamento de uma janela eletrocrômica.

Figura 3-1: Fórmula molecular do perclorato de lítio. .55

Figura 3-2: Fórmula molecular do glicerol. .56

Figura 3-3: Fórmula molecular do etileno glicol.

Figura 3-4: Fotografia da obtenção da solução viscosa dos eletrólitos. .57

Figura 3-5: Diagrama de Impedância no plano complexo

Figura 3-6: Circuito RC//.

Figura 3-7: Diagrama de Bode |Z|, para um sistema eletroquímico simples.

Figura 3-8: Célula de medida utilizada nos experimentos de determinação de condutividade dos filmes: (1) contato do eletrodo superior (tubo de inox fechado na parte inferior); (2) eletrodo inferior feito em Kovar; (3) torneira para conectar a bomba de vácuo; (4) fio de cobre para estabelecer o contato com o metal, Kovar; (5) Porta amostra, (6) eletrodo inferior, (7) eletrodo superior e (8) guia do porta amostra $\left(\right.$ Teflon $\left.^{\circledR}\right)$.

Figura 3-9: Visão do porta-amostra no forno com a porta aberta.

Figura 3-10: Impedancímetro Solartron modelo 1260.

Figura 3-11: A clássica radiografia feita por Röntgen em 1895, mostrando a mão de sua esposa.

Figura 3-12: Representação da difração de Raios-X...

Figura 3-13: Geometria Bragg-Brentano de um difratômetro de raios- $X$, mostrando as diferentes fendas utilizadas.

Figura 3-14: Diagrama esquemático mostrando os principais componentes de um microscópio eletrônico de varredura. 
Figura 3-15: Micrografias eletrônicas de filamentos de (a) W, (b) $\mathrm{LaB}_{6}$ e (c) FEG.

Figura 3-16: Diagrama esquemático de uma lente eletromagnética.

Figura 3-17: Esquema da varredura do feixe de elétrons.

Figura 3-18: Simulação de Monte-Carlo para o volume de interação de amostra de Carbono (a), Ferro (b), Prata (c) e Ouro (d) com o feixe de elétrons primários de 20 $\mathrm{keV}$. .86

Figura 3-19: Volume de interação e origem de alguns sinais. .87

Figura 3-20: Ilustração do processo associado às medidas de EDS. 90

Figura 3-21: Esquema representativo de um analisador térmico. .93

Figura 3-22: Exemplos de cadinhos utilizados na TG .97

Figura 3-23: Esquema representativo de um Calorímetro. 104

Figura 3-24: Cadinhos utilizado no DSC (grafite, $\mathrm{ZrO}_{2}, \mathrm{Al}_{2} \mathrm{O}_{3}, \mathrm{Pt}+\mathrm{Al}_{2} \mathrm{O}_{3}$ inside layer $\mathrm{Pt}$, $\mathrm{Au})$....... 104

Figura 4-1: Espectros de FT-IR das pectinas USP e BRS-Z pura. 112

Figura 4-2: Difratogramas de raios-X das pectinas BRS-Z e USP em pó. 114

Figura 4-3: Análise elementar das amostras de pectina em pó 115

Figura 4-4: Curva de DSC para pectina BRS-Z 116

Figura 4-5: Curva de DSC para pectina USP 117

Figura 4-6: Curva de TG para pectina GENU ${ }^{\circledR}$ BRS-Z.

Figura 4-7: Curva de TG para pectina GENU ${ }^{\circledR}$ USP 118

Figura 4-8: Quantidade de glicerol (\%) versus quantidade de $\mathrm{LiClO}_{4}([\mathrm{O}] /[\mathrm{Li}])$... 120

Figura 4-9: Difração de raios-X dos filmes a base de pectina contendo $0,24 \mathrm{~g}$ de $\mathrm{LiClO}_{4} \mathrm{e}$ $37 \%, 64 \%$ e $70 \%$ em massa de glicerol e da pectina em pó..

Figura 4-10: Espectros de FT-IR dos filmes a base de pectina com 0,24g de $\mathrm{LiClO}_{4}$ e $37 \%$, $60 \%$ e $70 \%$ em massa de glicerol.

Figura 4-11: Curva de DSC do filme de ESGs a base de pectina com $70 \%$ de glicerol e $0,24 \mathrm{~g}$ de $\mathrm{LiClO}_{4}$. 125

Figura 4-12: Curvas de DTG (a) e TG (b) para a pectina em pó, e para os filmes ESGs a base de pectina plastificada com 64 e $70 \%$ de glicerol e contendo $0,24 \mathrm{~g}$ de $\mathrm{LiClO}_{4}$. 
Figura 4-13: Espectro de UV-vis dos ESGs a base de pectina.

Figura 4-14: Micrografias das amostras com (a) 37\% de glicerol aumento de 1000X e 5000X e (b) $70 \%$ de glicerol com aumento de $1000 \mathrm{X}$ e $5000 \mathrm{X}$ (respectivamente).

Figura 4-15: Log da condutividade em função do inverso da temperatura para amostras de pectina plastificada com glicerol e contendo $0,24 \mathrm{~g}$ de $\mathrm{LiClO}_{4}$ 128

Figura 4-16: Log da condutividade em função da variação da porcentagem de glicerol para amostras de pectina contendo $0,24 \mathrm{~g}$ de $\mathrm{LiClO}_{4}$ a $30^{\circ} \mathrm{C}$. 129

Figura 4-17: Diagrama de Nyquist do filme com $37 \%$ de glicerol e $0,24 \mathrm{~g}$ de $\mathrm{LiClO}_{4} \ldots \ldots \ldots . . . .131$

Figura 4-18: Diagrama de Nyquist do filme com $70 \%$ de glicerol e $0,24 \mathrm{~g}$ de $\mathrm{LiClO}_{4}$ .132

Figura 4-19: Energia de ativação em função da porcentagem de glicerol em massa 133

Figura 4-20: Diagrama de Bode do filme a base de pectina plastificada com $70 \%$ de glicerol e contendo $0,24 \mathrm{~g}$ de $\mathrm{LiClO}_{4}$

Figura 4-21: Variação de condutividade em função do potencial elétrico aplicado para os filmes com $60 \%$ de glicerol.

Figura 4-22: Variação de condutividade em função do potencial elétrico aplicado para os filmes com $70 \%$ de glicerol.

Figura 4-23: Voltametria cíclica da janela eletrocrômica ITO/ $\mathrm{WO}_{3} /$ eletrólito de pectina/ $/ \mathrm{CeO}_{2}$ $\mathrm{TiO}_{2} /$ ITO com eletrólito a base de pectina plastificada com $70 \%$ de glicerol e contendo $\mathrm{LiClO}_{4}$ na concentração de $0,24 \mathrm{~g}$ de $\mathrm{LiClO}_{4}$

Figura 4-24: Densidade de carga catódica/anódica com eletrólito a base de pectina plastificada $70 \%$ de glicerol e contendo $\mathrm{LiClO}_{4}$ na concentração de $0,24 \mathrm{~g}$ de

$\mathrm{LiClO}_{4}$.....

Figura 4-25: Difração de raios-X dos filmes a base de pectina com $\mathrm{LiClO}_{4}$ e com $37 \%$, e $70 \%$ de glicerol..

Figura 4-26: FT-IR dos ESGs variando a quantidade de glicerol e com 30[O]/[Li] 141

Figura 4-27: Curva de DSC do filme à base de pectina, com $37 \%$ de glicerol e $\mathrm{LiClO}_{4}$

Figura 4-28: Curva de DSC do filme de à base de pectina, com $60 \%$ de glicerol e $\mathrm{LiClO}_{4}$ .143

Figura 4-29: Curva de DSC do filme à base de pectina, com $70 \%$ de glicerol e $\mathrm{LiClO}_{4}$

Figura 4-30: Curvas de TG para a pectina em pó, e para os filmes EPGs a base de pectina plastificada com $37 \%, 60 \%, 64 \%$ e $70 \%$ de glicerol e $30[\mathrm{Li}] /[\mathrm{O}]$. 
Figura 4-31: Curvas de DTG para a pectina em pó, e para os filmes EPGs a base de pectina plastificada com $37 \%, 60 \%, 64 \%$ e $70 \%$ de glicerol e $30[\mathrm{O}] /[\mathrm{Li}]$

Figura 4-32: Espectro de UV-vis dos ESGs a base de pectina.

Figura 4-33: Foto do filme a base de pectina com $60 \%$ de glicerol e $30[\mathrm{O}] /[\mathrm{Li}]$

Figura 4-34: Micrografia das amostras com 37\% de glicerol (aumento de 1000X e $5000 X)$

Figura 4-35: Micrografia das amostras com 70\% de glicerol (aumento de 1000X e 5000X).

Figura 4-36: Medidas de log da condutividade em função da porcentagem em massa de glicerol a temperatura ambiente para as amostras com 30[O]/[Li] de $\mathrm{LiClO}_{4}$.

Figura 4-37: Logaritmo da condutividade em função do inverso da temperatura para amostras de pectina plastificada com glicerol, contendo 30 $[\mathrm{O}] /[\mathrm{Li}]$

0

Figura 4-38: Energia de ativação e log da condutividade versus concentração de glicerol.

Figura 4-39: Diagrama de Nyquist do filme com 64\% de glicerol, 30[O]/[Li]

Figura 4-40: Diagrama de Nyquist do filme a base de pectina plastificada com $70 \%$ de glicerol e contendo $\mathrm{LiClO}_{4}$ na concentração de 30[O]/[Li].

Figura 4-41: Diagrama de Bode do filme a base de pectina, contendo $\mathrm{LiClO}_{4}$, plastificado com $64 \%$ de glicerol.

Figura 4-42: Diagrama de Bode do filme a base de pectina, contendo $\mathrm{LiClO}_{4}$, plastificado com $70 \%$ de glicerol

Figura 4-43: Voltametria cíclica da janela eletrocrômica ITO/ $\mathrm{WO}_{3}$ /eletrólito de pectina/ $\mathrm{CeO}_{2}$ $\mathrm{TiO}_{2} / \mathrm{ITO}$ com eletrólito a base de pectina plastificada com $70 \%$ de glicerol e contendo $\mathrm{LiClO}_{4}$ na concentração de 30

$[\mathrm{O}] /[\mathrm{Li}]$ 156

Figura 4-44: Densidade de carga catódica/anódica com eletrólito a base de pectina plastificada $70 \%$ de glicerol e contendo $\mathrm{LiClO}_{4}$ na concentração de 30 $[\mathrm{O}] /[\mathrm{Li}]$

Figura 4-45: Fotos da janela eletrocrômica ITO/ $\mathrm{WO}_{3} /$ eletrólito de pectina/ $\mathrm{CeO}_{2}-\mathrm{TiO}_{2} / \mathrm{ITO}$ com eletrólito a base de pectina plastificada $70 \%$ de glicerol e contendo $\mathrm{LiClO}_{4}$ na concentração de $30[\mathrm{O}] /[\mathrm{Li}]$ 157

Figura 4-46: UV-Vis da janela eletrocrômica ITO/ $\mathrm{WO}_{3} /$ eletrólito de pectina/ $\mathrm{CeO}_{2}-\mathrm{TiO}_{2} / \mathrm{ITO}$ com eletrólito a base de pectina plastificada $70 \%$ de glicerol e contendo $\mathrm{LiClO}_{4}$ na concentração de 30 $[\mathrm{O}] /[\mathrm{Li}]$ 158 


\section{LISTA DE TABELAS}

Tabela 1-1: Tipos de plastificantes e propriedade alterada................................ 35

Tabela 1-2: Valores de constante dielétrica $(\varepsilon)$ de plastificantes comuns...............44

Tabela 3-1: Concentração de concentrações de

$\mathrm{LiClO}_{4}$ 57

Tabela 3-2: Classificações de algumas técnicas termo analíticas........................91

Tabela 4-1: Valores de DE teórico e calculado...........................................111

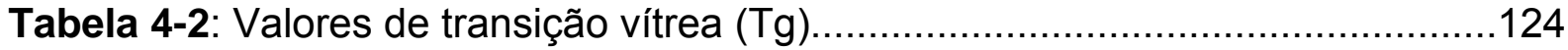




\section{LISTA DE ABREVIATURAS E SÍMBOLOS}

\begin{tabular}{|c|c|}
\hline PEO & Poli (Óxido de Etileno) \\
\hline ESP & Eletrólito Sólido Polimérico \\
\hline$T_{g}$ & Transição Vítrea \\
\hline$\varepsilon$ & Constante Dielétrica \\
\hline PPO & Poli(Óxido de Propileno) \\
\hline Z & Carga Efetiva do ĺon \\
\hline$\eta$ & Número de ĺons Móveis \\
\hline$e$ & Carga Elétrica Elementar \\
\hline$\mu$ & Mobilidade do Íon \\
\hline VTF & Vogel-Tammam-Fulcher \\
\hline WLF & Willians-Landel-Ferry \\
\hline CMC & Carboximetilcelulose \\
\hline $\mathrm{DE}$ & Grau de Esterificação \\
\hline $\mathrm{HM}$ & Alto Grau de Metoxilação \\
\hline LM & Baixo Grau de Metoxilação \\
\hline DOP & Dioctil-Ftalato \\
\hline PVC & Poli (Cloreto de Vinila) \\
\hline $\mathrm{T}_{\mathrm{m}}$ & Fusão Cristalina \\
\hline$T_{f}$ & Temperatura De Fusão \\
\hline$\delta$ & Solubilidade \\
\hline EPs & Eletrólitos Poliméricos \\
\hline FT-IR & Infravermelho por Transformada de Fourier \\
\hline ATR & Refletância Total Atenuada \\
\hline EIE & Espectroscopia de Impedância Eletroquímica \\
\hline ca & Corrente Alternada \\
\hline$c c$ & Corrente Contínua \\
\hline $\mathrm{R}$ & Resistência \\
\hline$\omega$ & Freqüência \\
\hline$Z^{\prime}$ & Componente Real \\
\hline Z" & Componente Imaginário \\
\hline$\Omega$ & Ohms \\
\hline $\mathrm{RC}$ & Resistor e Capacitor \\
\hline I & Espessura do Filme \\
\hline$s$ & Área Superficial \\
\hline C & Impedância Capacitiva \\
\hline $\mathrm{E}$ & Potencial \\
\hline$E_{p c}$ & Potencial de Pico Catódico \\
\hline$E_{p a}$ & Potencial do Pico Anódico \\
\hline$i_{p c}$ & Corrente de Pico Catódico \\
\hline $\mathrm{i}_{\mathrm{pa}}$ & Corrente de Pico Anódico \\
\hline$q_{a}$ & Cargas Anódica \\
\hline$q_{c}$ & Cargas Catódica \\
\hline UV-vis & Espectroscopia de Ultravioleta-Visível \\
\hline$\theta$ & Ângulo \\
\hline MEV & Microscopia Eletrônica De Varredura \\
\hline CRT & Tela do Tubo de Raios Catódicos \\
\hline ET & Everhart-Thornley \\
\hline ES & Elétrons Secundários \\
\hline
\end{tabular}




$\begin{array}{cl}\text { EDS } & \text { Espectroscopia de Energia Dispersiva de Raios-X } \\ \text { ICTA } & \text { Comitê de Nomenclatura da Confederação Internacional de } \\ & \text { Análises Térmicas } \\ \text { IUPAC } & \text { União Internacional de Química Pura e Aplicada } \\ \text { ASTM } & \text { Sociedade Americana de Testes de Materiais } \\ \text { TG } & \text { Termogravimetria } \\ \text { DTG } & \text { Derivada da Termogravimetria } \\ \text { DTA } & \text { Análise Térmica Diferencial } \\ \text { DSC } & \text { Calorimetria Exploratória Diferencial } \\ \text { TD } & \text { Termodilatometria } \\ \text { DMA } & \text { Analise Termomecânica Dinâmica } \\ \text { TMA } & \text { Analise Termomecânica } \\ \Delta T & \text { Diferença de Temperatura } \\ \Delta \Phi & \text { Fluxo de Calor } \\ \text { Tx } & \text { Temperatura de Cristalização } \\ { }^{1 H-N M R} & \text { Ressonância Magnética Nuclear de protón } \\ \text { EPG } & \text { Eletrólitos Poliméricos Géis } \\ \text { SEl } & \text { Eletrólito Sólido } \\ A & \text { Coeficiente Linear } \\ \Delta E & \text { Coeficiente Angular }\end{array}$




\section{SUMÁRIO}

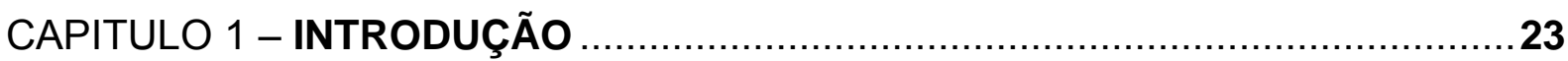

1.1 Polímeros e Polímeros Condutores lônicos ..............................................22

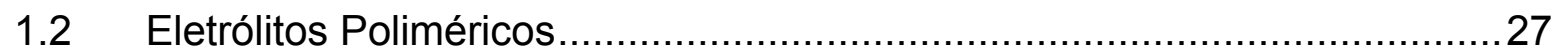

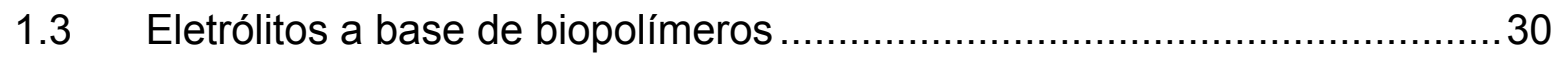

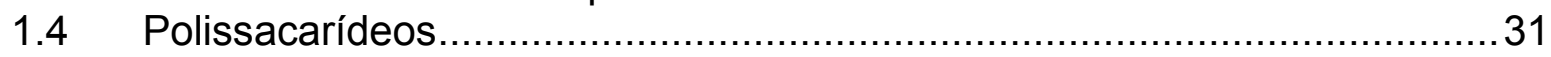

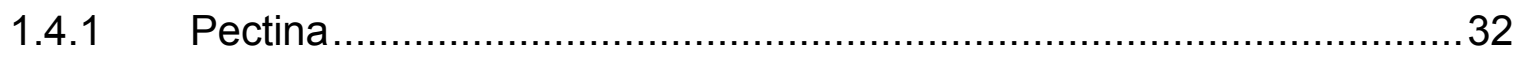

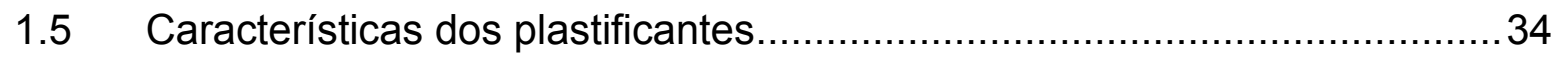

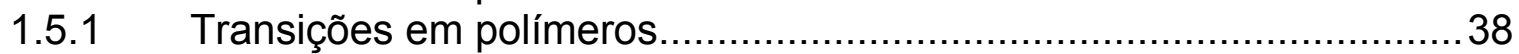

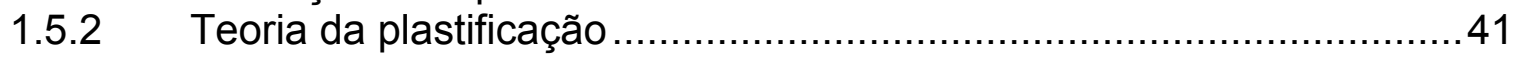

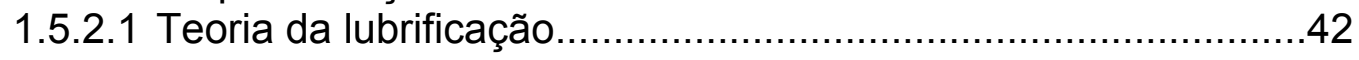

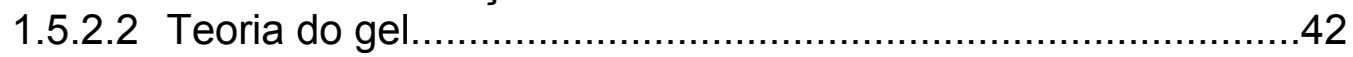

1.5.2.3 Teoria do volume livre...................................................42

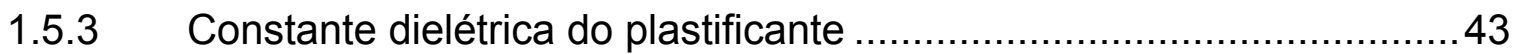

1.6 Dispositivos eletrocrômicos ........................................................ 44

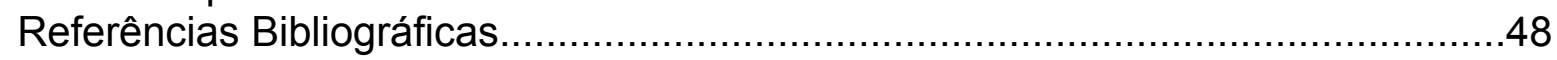

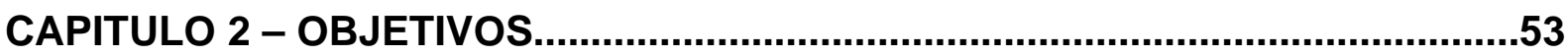

CAPITULO 3 - MATERIAIS E MÉTODOS.......................................................55

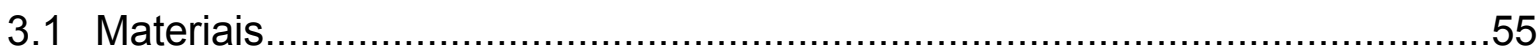

3.2 Obtenção dos eletrólitos a base de pectina............................................56

3.3 Técnicas utilizadas para a caracterização das pectinas e dos eletrólitos ......58

3.3.1 Espectroscopia na região do Infravermelho por transformada de

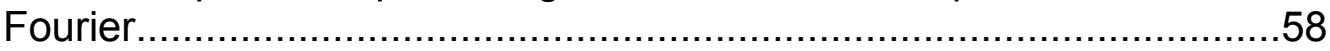

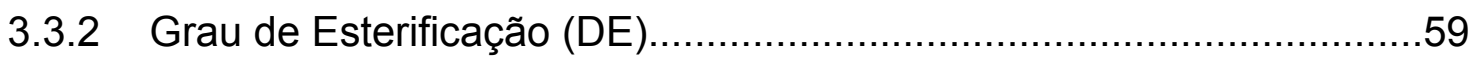

3.3.3 Espectroscopia de Impedância Eletroquímica (EIE)...........................60

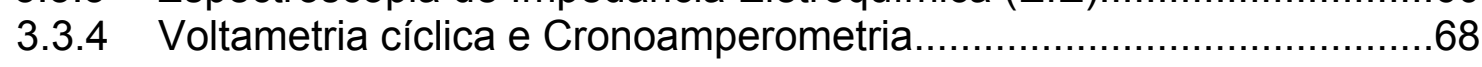

3.3.5 Espectroscopia no Ultravioleta-visível (UV-vis)................................69

3.3.6 Difração de Raios-X...................................................................

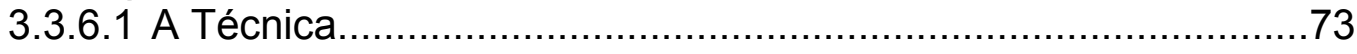

3.3.6.2 Difratômetro de Raios-X....................................................

3.3.7 Análise Elementar......................................................................

3.3.8 Microscopia Eletrônica de Varredura (MEV ou SEM) ..........................77

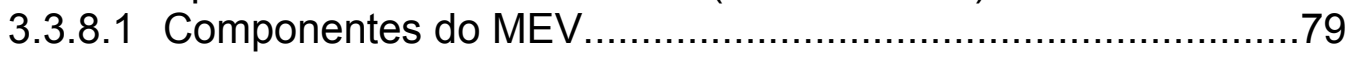

3.3.8.2 Varredura do Feixe de Elétrons............................................ 83

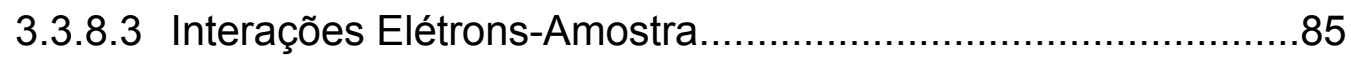

3.3.8.4 Resolução espacial.......................................................... 87

3.3.8.5 Espectroscopia de energia dispersiva de raios-X (EDS)..........89

3.3.9 Análise Térmica......................................................................91

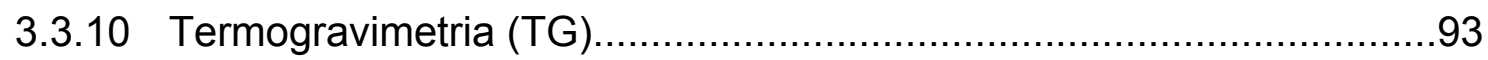

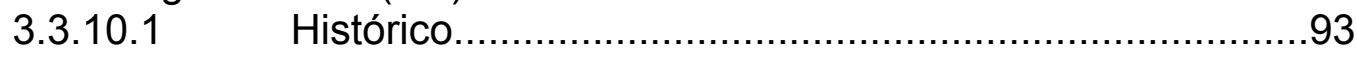

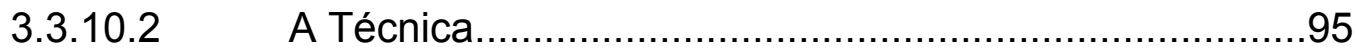

3.3.10.3 Aplicações da TG......................................................95

3.3.10.4 Cadinhos de TG...............................................................

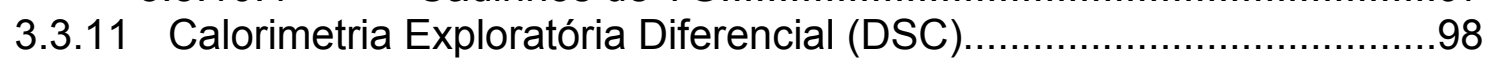


4.1 - Caracterização das pectinas utilizadas para preparação dos eletrólitos.

4.1.2 - Grau de esterificação (DE).

4.1.3 - Difração de Raios -X.

4.1.4 - Análise Elementar.

4.1.5 - Análises Térmicas - DSC e TG.

4.2 Eletrólitos Poliméricos Géis (EPG) a base de pectina...............................118

4.2.1 Eletrólitos Poliméricos Géis a base de pectina GENU ${ }^{\circledR}$ BRS-Z, contendo $0,24 \mathrm{~g}$ de sal em função da concentração do glicerol......

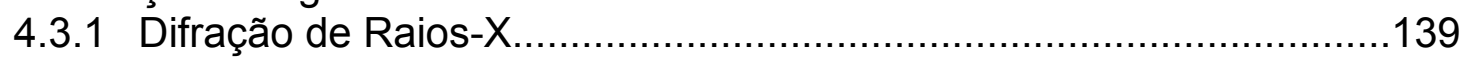

4.3.2 Espectroscopia de Infravermelho - FT-IR …...............................141

4.3.3 Calorimetria Exploratória Diferencial (DSC) ….............................142

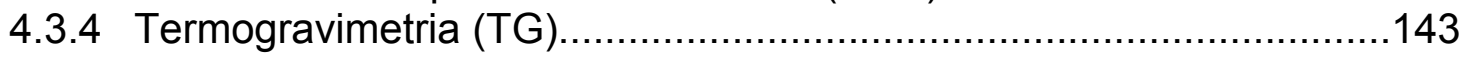

4.3.5 Medidas de Transmitância na Região do UV-vis.............................145

4.3.6 Microscopia Eletrônica de Varredura (MEV).................................147

4.3.7 Condutividade lônica dos Filmes à base de Pectina..........................149

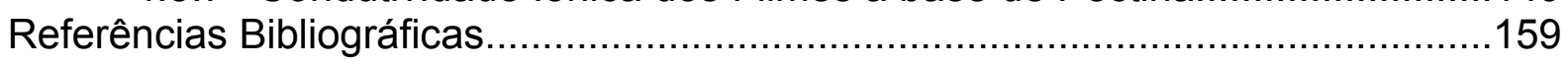

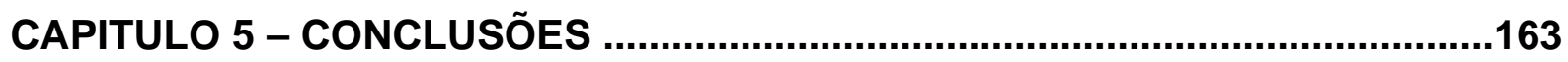




\section{RESUMO}

Esta dissertação apresenta a preparação e caracterização de eletrólitos poliméricos géis (EPGs) a partir de pectina comercial GENU ${ }^{\circledR}$, plastificada com glicerol e dopada com perclorato de lítio. O objetivo é a utilização de uma nova matéria-prima para a obtenção de eletrólitos poliméricos substituindo os polímeros sintéticos. A pectina é um polímero natural presente nas plantas; quimicamente é um polímero heterogêneo, e estruturalmente, é constituída unidades repetidas de (1 $\rightarrow 4)$ - $\alpha$-D-ácido galacturônico. Os eletrólitos foram preparados usando como sal $\mathrm{LiClO}_{4}(0,24 \mathrm{~g}$ ou $30[\mathrm{O}] /[\mathrm{Li}])$, e $0,6 \mathrm{~g}$ de pectina com diferentes quantidades de glicerol (0 g - 2,0 g; 0\% - 70\%) como plastificante. Os filmes foram caracterizados por espectroscopia de impedância, difração de raios-X, UV-Vis, FT-IR, análises térmicas (DSC e TG). Os melhores resultados foram apresentados pelos filmes constituídos com $70 \%$ de glicerol e 30 [O]/[Li] e $68 \%$ de glicerol e 0,24 g de $\mathrm{LiClO}_{4}$. Os filmes com $68 \%$ de glicerol apresentam valores de condutividade iônica de $1,61 \times 10^{-4} \mathrm{~S} . \mathrm{cm}^{-1} \mathrm{em}$ temperatura ambiente aumentando para $1,72 \times 10^{-3} \mathrm{~S}_{\mathrm{cm}} \mathrm{cm}^{-1}$ à $80^{\circ} \mathrm{C}$, e uma transmitância de $80 \%$ no intervalo do visível. Os valores da energia de ativação para este filme é em torno de $37 \mathrm{KJmol}^{-1}$. Também foi verificada a estabilidade eletroquímica em uma faixa de potencial que varia entre $-1,5$ a $+1,5 \mathrm{~V}$. Os filmes com $70 \%$ de glicerol apresentam os melhores valores de condutividade iônica de $3,08 \times 10^{-4} \mathrm{~S} . \mathrm{cm}^{-1} \mathrm{em}$ temperatura ambiente para $2,94 \times 10^{-3} \mathrm{~S} . \mathrm{cm}^{-1}$ à $80^{\circ} \mathrm{C}$, e energia de ativação em torno de $35 \mathrm{KJmol}^{-1}$, e transmitância de $75 \%$ no intervalo do visível. Os resultados obtidos indicaram que os eletrólitos a base de pectina são promissores para aplicações em dispositivos opto-eletroquimicos. 


\begin{abstract}
This work presents the preparation and characterization of pectin GENU ${ }^{\circledR}$ based gel polymeric electrolytes (GPEs), plasticized with glycerol and doped with lithium perchlorate. The use of a new raw material for the production of polymeric electrolytes, as substitutes of synthetic polymers is the proposal of this work. Pectin is a natural polymer found in plants. This polymer is chemically heterogeneous and

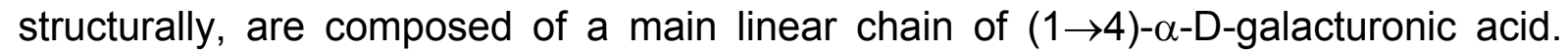
The electrolytes were prepared using salt as $\mathrm{LiClO}_{4}(0.24 \mathrm{~g}$ or $30[\mathrm{O}] /[\mathrm{Li}])$ to $0.6 \mathrm{~g}$ of pectin and with different amounts of glycerol (0-2.0g, 0-70\%) as plasticizer. The films were characterized by impedance spectroscopy, X-ray diffraction, UV-Vis, FT-IR, thermal analysis (DSC and TG). The best results were obtained with films containing $70 \%$ of glycerol and $30[\mathrm{O}] /[\mathrm{Li}]$ and $68 \%$ of glycerol and $0.24 \mathrm{~g} \mathrm{LiClO}_{4}$. The films with $68 \%$ of glycerol exhibit ionic conductivity values of $1.61 \times 10^{-4}{\mathrm{~S} . \mathrm{cm}^{-1}}^{\text {at }}$ room temperature with increase to $1.72 \times 10^{-3} \mathrm{~S} \mathrm{~cm}^{-1}$ at $80^{\circ} \mathrm{C}$, and showed a transmittance of $80 \%$ in the visible range. The values of activation energy for this sample is around $37 \mathrm{kJmol}^{-1}$. It was also observed the electrochemical stability in the potential range of -1.5 to $+1.5 \mathrm{~V}$. The films with $70 \%$ of glycerol showed best ionic conductivity values

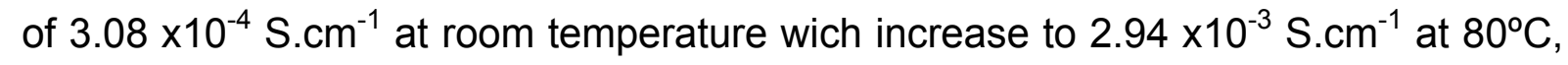
and activation energy around $35 \mathrm{kJmol}^{-1}$, and a transmittance of $75 \%$ in the visible range. All the obtained results show pectin-based polymer electrolytes over promising materials to be used in opto-electrochemical devices.
\end{abstract}




\section{CAPITULO 1 - INTRODUÇÃO}

\subsection{Polímeros e Polímeros Condutores lônicos}

$\mathrm{O}$ desenvolvimento na segunda metade do século $\mathrm{XX}$ foi profundamente caracterizado pelo surgimento dos materiais poliméricos, os quais constituem atualmente boa parte dos materiais utilizados pelo homem. Pode-se dizer seguramente que os polímeros representam um dos alicerces para o atual nível de desenvolvimento, nos critérios de saúde e sobrevivência das pessoas ao redor do mundo. Espera-se que esse extraordinário sucesso continue no século XXI, quando a demanda por estes materiais deverá sofrer um aumento de duas a três vezes. A maior parte deste crescimento será resultado do aumento no consumo de polímeros nos países em desenvolvimento, onde o consumo per capita anual varia entre 1 e 15 $\mathrm{kg}$, comparados a aproximadamente $100 \mathrm{~kg}$ em países industrializados.

O crescimento explosivo do consumo de polímeros sintéticos tem tornado necessária à produção de substitutos ambientalmente sustentáveis, importantes no gerenciamento de resíduos. Inúmeras disposições, tecnológicas de reciclagem e reutilização foram desenvolvidas para conter o problema do "lixo plástico", mas todos possuem pontos fracos.

A troca continuada da produção de polímeros sintéticos, de recursos nãorenováveis (ex. petróleo) por recursos renováveis (ex. polímeros naturais), irá contribuir mais adiante com o desenvolvimento sustentável ${ }^{1}$.

Polímeros são substâncias constituídas de moléculas caracterizadas pela repetição de uma ou mais espécies de átomos ou grupos de átomos (unidades 
constitucionais) ligados uns aos outros em quantidade suficiente para fornecer um conjunto de propriedades que não variam acentuadamente com a adição ou a remoção de uma ou algumas unidades constitucionais de suas moléculas.

Os polímeros foram utilizados e caracterizados por muito tempo como isolantes elétricos (na prática, não existem isolantes perfeitos, e sim malcondutores). Qualquer tipo de condução elétrica era tido como uma anomalia, e durante muito tempo essa característica foi negligenciada ${ }^{2}$.

Em 1975, P. Wright publicou um trabalho pioneiro sobre a condutividade iônica em sistemas complexos de poli (óxido de etileno) (PEO), assinalando o início das pesquisas no campo dos eletrólitos sólidos poliméricos $(E S P)^{3,4}$, alterando assim a antiga concepção sobre os polímeros. Ainda, em 1977, Shirakawa e cols. verificaram que uma matriz de poli(acetileno) tratado com ácidos e/ou bases de Lewis alteravam a condutividade eletrônica desse polímero em até dez ordens de grandeza. Alcançaram-se até mesmo valores de condutividade próximos do cobre metálico (cerca de $\left.10^{6} \mathrm{~S} . \mathrm{cm}^{-1}\right)^{5}$. Dessa maneira o conceito de polímero ser isolante começou ser modificado.

Com essas descobertas, diversas pesquisas têm sido realizadas tanto para compreender quanto para desenvolver novos sistemas poliméricos com propriedades de condução tanto elétrica quanto iônica. No caso deste último ao longo dos últimos anos tenta se encontrar um substituto adequado para o PEO, o qual possua boa condutividade e que seja biodegradável, sem perder as características de polímeros, uma vez que o PEO apresenta problemas ligados a sua cristalinidade intrínseca. 
Os ESPs são condutores iônicos sólidos que consistem de um sal disperso numa matriz polimérica ${ }^{6}$. Polímeros condutores são geralmente polímeros conjugados ou dopados, que apresentam condutividade elétrica ${ }^{7}$.

Em 1977, M. Armand ${ }^{8}$ propôs a aplicação dos ESPs em baterias de lítio mostrando a viabilidade vantagens de uma célula eletrolítica do estado sólido com facilidade de processamento inerente aos polímeros. Este trabalho consolidou o estudo desses eletrólitos nos EUA, Japão e Europa ${ }^{9}$ e a partir disso, todo empenho foi a favor de melhorar a condutividade iônica dos ESPs.

Uma das maiores preocupações da indústria e da sociedade moderna está em produzir, armazenar e distribuir energia a baixo custo, bem como o desenvolvimento de novos materiais para substituir os polímeros sintéticos visando à preservação do meio ambiente.

Pesquisadores têm se dedicado na investigação de novos dispositivos, recarregáveis, de longa duração, menores, mais leves, mais seguros e mais baratos. A demanda do mercado é intensa: o número de telefones celulares, computadores portáteis, reprodutores de áudio e mídia portáteis tem aumentado vigorosamente. A busca por baterias de alta duração e biodegradáveis para a utilização nesses eletrônicos é intensa.

Geralmente as moléculas poliméricas possuem baixos valores de condutividade $\left(10^{-12}\right.$ a $\left.10^{-10} \mathrm{~S} . \mathrm{cm}^{-1}\right)$ devido à sua natureza. Porém, a adição de cátions alcalinos dos sais inorgânicos $\left(\mathrm{LiClO}_{4}, \mathrm{NaClO}_{4}, \mathrm{LiCF}_{3} \mathrm{SO}_{3}, \mathrm{LiBF}_{4}\right.$, por exemplo) originam polímeros condutores iônicos eficientes. Contudo, essa propriedade condutora e/ou de dissolução de sais inorgânicos é característica de polímeros que possuem grupos funcionais com heteroátomos carregadores de pares de elétrons os quais são capazes de interagir com os íons solvatando-os, um 
exemplo é PEO. Outra classe de polímeros que podem vir a ser bons condutores iônicos são aqueles que possuem ligações duplas conjugadas em sua estrutura as quais se associam aos íons permitindo a condução iônica ${ }^{10}$.

Um polímero para ser útil como um ESPs deve possuir algumas propriedades como: caráter amorfo, capacidade de solvatar íons, baixa temperatura de transição vítrea, estabilidade eletroquímica e dimensional, resistência mecânica e possibilidade de formar membranas finas ou pastilhas ${ }^{11}$. Os biopolímeros mais usados na preparação de eletrólitos sólidos são os polissacarídeos de origem animal e vegetal (ex. amido, agar-agar, celulose, e quitosana) ou as proteínas (ex. gelatina) já que possuem boas propriedades mecânicas e ópticas, como podemos ver em vários trabalhos já publicados ${ }^{4,12}$.

Algumas vantagens dos ESPs com polímeros naturais, em comparação com outros sistemas poliméricos condutores são: a facilidade em seu preparo na forma de filmes finos, alta estabilidade térmica e eletrocrômica e possibilidade de obter

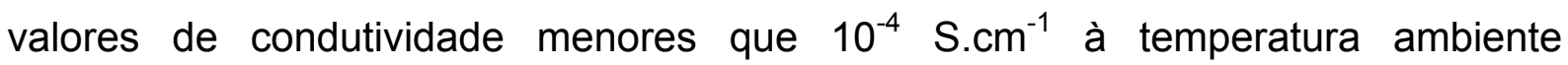
suficientes para as aplicações desejadas.

O aumento da condutividade iônica de um eletrólito sólido pode ser devido a supressão da cristalinidade das cadeias do polímero, a qual é feita por meio da adição de plastificantes, polióis. Como exemplos têm-se o glicerol, o sorbitol, o etilenoglicol, o propilenoglicol, o dietilenoglicol e o tetraetilenoglicol ${ }^{13}$. O plastificante aumenta a mobilidade dos portadores de carga ao afastar as cadeias poliméricas uma das outras, diminuindo a temperatura de transição vítrea $\left(T_{g}\right)$ e aumentando o caráter amorfo ${ }^{14}$. 
O processo utilizado para obtenção de ESPs em forma de membrana é a evaporação do solvente "solvent casting", o qual é baseado na dispersão do polímero em um solvente, formando um sistema viscoso.

\subsection{Eletrólitos Poliméricos}

Como apresentado anteriormente os eletrólitos poliméricos são soluções sólidas formadas pela dissolução de sais de metais alcalinos em uma matriz polimérica $^{15}$.

Nos últimos anos, as pesquisas têm enfatizado o desenvolvimento de eletrólitos sólidos poliméricos, pois eles oferecem algumas vantagens sob os eletrólitos líquidos como, por exemplo, eliminação de problemas de vazamento, por ser sólido e baixo custo, entre outras.

A aplicação desses eletrólitos está em diversas áreas como, por exemplo, janelas eletrocrômicas, células fotovoltáicas, músculos artificiais, baterias e capacitores.

Geralmente, a condutividade iônica é associada a líquidos, mas podem ocorrer também em géis, cerâmicas ou polímeros. Nos polímeros eles podem ocorrer com a adição de sais inorgânicos $\left(\mathrm{LiClO}_{4}, \mathrm{NaClO}_{4}, \mathrm{LiCF}_{3} \mathrm{SO}_{3}, \mathrm{BF}_{4}\right.$, por exemplo) ou a adição de ácidos, fornecedores de prótons $\left(\mathrm{H}^{+}\right)^{10,16}$. Os primeiros materiais utilizados para substituição dos eletrólitos líquidos foram os géis poliméricos, ou seja, materiais poliméricos com grande quantidade de plastificante adicionada à sua composição. Estes sistemas mostraram bom desempenho relacionado à alta mobilidade iônica e alta concentração de transportadores de 
carga. Entretanto, suas estabilidades químicas e eletroquímicas eram relativamente baixas.

Antigamente acreditava-se que estruturas cristalinas eram as responsáveis pela condutividade iônica, permitindo a locomoção dos íons pelos canais formados pelas hélices das moléculas de PEO. Entretanto ficou claramente estabelecido que a presença de fase amorfa favorece o transporte iônico ${ }^{17}$. Contudo os trabalhos recentes estão novamente voltados para demonstrar a condutividade iônica em sistemas cristalinos ${ }^{18}$.

A dissolução de sais inorgânicos em matrizes poliméricas é facilitada quando a energia de rede do sal é baixa e a constante dielétrica $(\varepsilon)$ do polímero é alta. Conseqüentemente, a condutividade iônica de misturas de sais de lítio com poli(propileno óxido) (PPO) amorfo é consideravelmente menor quando essa mesma solução é preparada com $\mathrm{PEO}^{19}$, devido ao menor valor da constante dielétrica, resultante da presença do agrupamento metila que induz um efeito estérico sobre a complexação do $\mathrm{Li}^{+}$. Por outro lado, matrizes poliméricas de alta constante dielétrica podem induzir a imobilização dos íons devido a maior tendência à formação dos complexos.

A condutividade iônica é geralmente expressa pela (Equação 1.1):

$$
\sigma=\text { Z.n.e. } \mu
$$

onde $Z$, $\eta$, e e $\mu$ são a carga efetiva do íon, o número de íons móveis, a carga elétrica elementar e a mobilidade do íon, respectivamente. A fração de íons livres que podem ser transportados é um parâmetro importante, deste modo, o uso de sais com um alto grau de dissociação no polímero é um pré-requisito para preparar materiais com alta condutividade. O grau de dissociação de um sal em uma matriz 
polimérica depende da natureza da matriz, do sal e da sua concentração. Geralmente, o grau de dissociação do sal diminui com o aumento da concentração.

Devido à natureza amorfa dos melhores condutores iônicos poliméricos não se conhece com detalhes os aspectos estruturais relacionados à coordenação dos cátions dopantes com as matrizes poliméricas. Simulações de dinâmica molecular sugerem que os íons lítio estão complexados com o PEO com aproximadamente 5 oxigênios do tipo éter da cadeia polimérica e que a mobilidade do cátion diminui consideravelmente devido a essa complexação. Conseqüentemente, assume-se que a mobilidade dos íons lítio está relacionada com os movimentos dos segmentos complexados da cadeia de PEO. Neste caso o movimento das espécies catiônicas, entre os sítios de complexação é assistido pelos movimentos dos segmentos da matriz amorfa de PEO conforme ilustrado na Figura $1-1^{20}$.

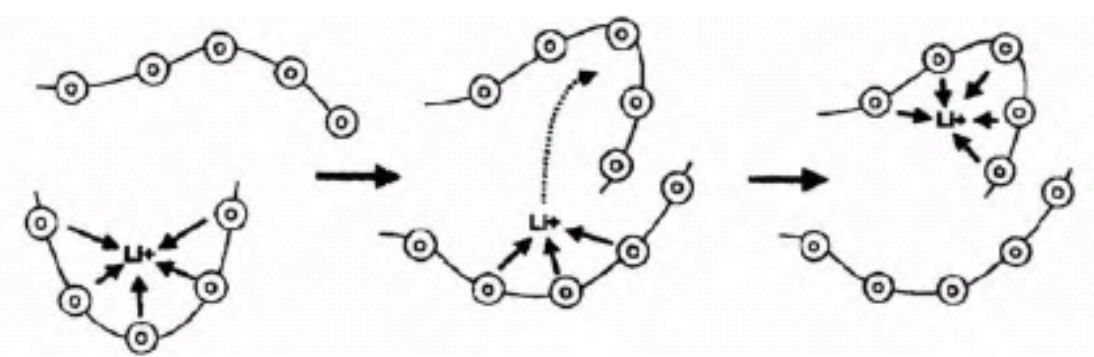

Figura 1-1: Representação do movimento dos segmentos do polímero que auxilia na difusão do íon $\mathrm{Li}^{+}$na matriz polimérica. Os círculos representam os oxigênios do tipo éter.

Outro mecanismo de mobilidade iônica, ilustrado na Figura 1-2, supõe que o movimento do cátion ocorre através do salto entre um par de íons e os oxigênios do tipo éter da cadeia polimérica em (a) e entre dois pares de íons coordenados ao oxigênio éter, em (b). 

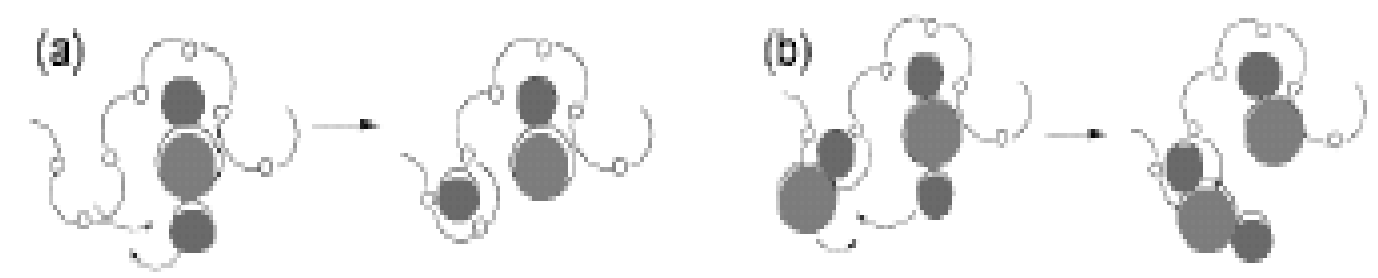

Figura 1-2: Representação esquemática do modelo de saltos para transporte iônico. O movimento do cátion ocorre através do salto entre um par de íons e os oxigênios do tipo éter da cadeia polimérica (a) e entre dois pares de íons coordenados ao oxigênio éter (b).

Umas das propriedades mais citadas para eletrólitos sólidos poliméricos é o comportamento da condutividade iônica das amostras em função da temperatura. Isso fornece as informações sobre os mecanismos que governam a condutividade iônica. Quando a movimentação dos íons não resulta do compartilhamento da movimentação do polímero (matriz), ou seja, os íons "saltam" de um sítio de solvatação para outro (Figura 1-2), temos um comportamento da condutividade em função da temperatura do tipo Arrehenius. Entretanto, quando o transporte dos íons é feito com o auxílio dos movimentos da cadeia polimérica da matriz onde o sal é dissolvido (Figura 1-1), temos um comportamento com relação ao modelo VTF (Vogel-Tammam-Fulcher) ou WLF (Willians-landel-Ferry) ${ }^{21}$.

Os pesquisadores da área de eletrólitos buscam eletrólito polimérico, que combine uma ótima condutividade com boa estabilidade eletroquímica.

\subsection{Eletrólitos a base de biopolímeros}

O crescente desenvolvimento de polímeros condutores iônicos a partir do século XX foi incentivado pela necessidade industrial de sistemas de produção e estocagem de energia, porém muito mais que isso, esse desenvolvimento se deu 
preocupando-se com a substituição de polímeros sintéticos, para produção dos plásticos, por produtos biodegradáveis visando à preservação do meio ambiente ${ }^{22}$.

Os biopolímeros estão ganhando mercado do ponto de vista industrial para a substituição dos polímeros sintéticos, além de baixo custo, são encontrados na natureza em abundância, e são de fácil obtenção.

Polissacarídeos, por exemplo, como o amido, a pectina e celulose (principalmente seus derivados como, por exemplo, a carboximetilcelulose, CMC) assim como proteínas, i.e., a gelatina tradicionalmente utilizados na indústria alimentícia, hoje estão ganhando cada vez mais atenção para o desenvolvimento de novos materiais. Estes polímeros também foram propostos para aplicação como eletrólitos sólidos e/ou géis uma vez que possuem propriedades de dissolução e também alguns deles formam polieletrólitos, como é o caso de quitosana ${ }^{23}$. Desta maneira polissacarídeos de origem vegetal (ex. amido, agar-agar, celulose, quitosana e pectina) $)^{24,25,26}$ e as proteínas (ex. gelatina), de origem animal já estão sendo estudadas como potenciais substitutos ao tradicional poli(óxido de etileno) para aplicação como eletrólitos polimérico ${ }^{27}$. A grande vantagem dessas macromoléculas além de sua biodegrabilidade também está ligada a propriedades de formação de membranas transparentes com boas propriedades mecânicas e ópticas, como podemos ver em vários trabalhos já publicados ${ }^{12,28}$.

\subsection{Polissacarídeos}

Os polissacarídeos são uma família de polímeros naturais sintetizada preferencialmente pelas plantas, embora haja polissacarídeos também sintetizados pelos animais, como é o caso de crustáceos. Entre os polissacarídeos mais 
conhecidos destaca-se a celulose, que exerce a função de sustentação das plantas (encontrada principalmente nos caules das plantas), o amido, que é a reserva energética das plantas (encontrado em bulbos, raízes e sementes), a pectina, presente nos frutos, o agar e alginato presentes em algas marinhas e quitosana componente principal de esqueleto dos crustáceos. As cadeias poliméricas de polissacarídeos são constituídas pelos anéis de anidroglicose ligados entre si

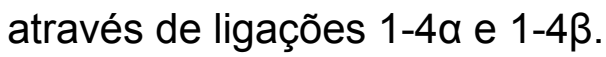

\subsubsection{Pectina}

A pectina é um polissacarídeo, composto de diferentes entidades, subestrutural, que varia com a metodologia de extração, matéria prima, localização, e outros fatores ambientais. Ocorre em plantas terrestres e é abundante em vegetais e frutas. Quando extraída das plantas é utilizada como aditivo para os produtos alimentícios, tendo efeitos benéficos para saúde, contribuindo para melhorar a digestão e diminuição da quantidade de colesterol no sangue.

A matéria prima mais utilizada na fabricação da pectina é a casca de frutas cítricas (limão, laranja, lima, e ocasionalmente grapefruit). O produto comercial é um pó branco ou creme que pode ser dissolvido em água formando uma solução viscosa. A pectina forma géis facilmente na presença de açúcar dissolvido e pH baixo, i.e., em torno de 3.

Antes de fabricarem a pectina comercial, as geléias caseiras eram gelificadas pela pectina "natural" da fruta. Frutas ricas em pectina era parte necessária das receitas. A aplicação de pectina é tradicional nas geléias, mas hoje está longe de ser só nesta. Um exemplo da ótima propriedade de formação de geléias pode ser a geléia de jabuticaba que tem uma quantidade expressiva de pectina. 
A pectina é importante para estabilização da proteína do leite em yogurt, bebidas de leite e frutas, e cosméticos, como shampoos, condicionadores e bronzeadores.

O termo geral pectina designa ácidos pectínicos solúveis em água, com grau variável de grupos metil éster e um grau de neutralização capaz de formar gel com açúcares e ácidos em condições adequadas.

Quimicamente, a pectina é um polímero heterogêneo. Estruturalmente, as moléculas de pectina são constituídas de uma cadeia principal linear de unidades repetidas de $(1 \rightarrow 4)$ - $\alpha$-D-ácido galacturônico (Figura 1-3), sendo que parte destas unidades apresenta-se esterificada, com grupos metílicos, formando o ácido poligalacturônico, ou grupos livres de ácidos.

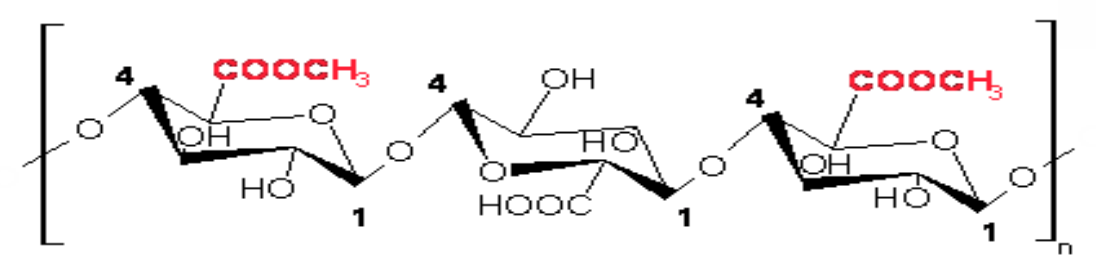

Figura 1-3: Cadeia linear de $(1 \rightarrow 4)-\alpha-D$-ácido galacturônico.

As composições das pectinas podem variar em todos os níveis, i.e., tem a possibilidade de diferentes regiões de uma molécula ter composições diferentes, e diferentes composições entre lotes das amostras. Nas amostras comerciais típicas, a distribuição de massa molecular pode ser controlada durante o processo, mas é bastante ampla de 80 a 400 kDa, e a polidispersividade é de 4-8.

A seleção apropriada da matéria prima e as condições de processamento permitem controlar parâmetros da estrutura média. A pectina para aplicação alimentícia é geralmente padronizada por misturas de lotes e diluição com sacarose 
ou dextrose. Desta maneira estas propriedades são mantidas constantes de lote para lote apesar das variações naturais ${ }^{29}$.

A razão entre os grupos ésteres e os grupos ácidos galacturônicos totais, é chamado de grau de esterificação (DE), que tem uma influência importante nas propriedades da pectina. As pectinas comerciais geralmente apresentam um DE de $50 \%$, e podem ser divididas em duas classificações: alto grau de metoxilação (HM) e baixo grau de metoxilação (LM).

Pectina do tipo HM forma géis em pH baixos em torno de 3,0 ou menor, já a pectina do tipo LM requer a presença de uma quantidade controlada de cálcio, ou outros cátions divalentes, para formar gel entre cadeias adjacentes.

Aproveitando as ótimas propriedades de formação de géis transparentes a partir das soluções de pectina o presente projeto propõe a utilização da mesma para obtenção de eletrólitos poliméricos com a finalidade de se conseguir uma melhor condutividade iônica, comparado aos trabalhos previamente desenvolvidos no grupo utilizando outros polissacarídeos ${ }^{10,16}$.

\subsection{Características dos plastificantes}

Os plastificantes são usados como aditivos para polímeros porque melhoram a processabilidade e a flexibilidade dos artefatos comerciais. Além disso, o uso de plastificantes promove a redução da viscosidade do sistema aumentando a mobilidade das macromoléculas e provocando um deslocamento da Tg para temperaturas mais baixas ${ }^{30}$.

A plastificação altera a viscosidade do sistema polimérico usado, ou seja, aumenta a mobilidade das macromoléculas melhorando a sua processabilidade e 
dando um produto mais flexível. Em muitas circunstâncias, eles são adicionados para obtenção de ampla escala de propriedades físicas em um único polímero ${ }^{29,}$.

Em termos práticos, a plastificação (ou plasticização) consiste em adicionar o plastificante através de mistura física com o polímero para alterar a viscosidade do sistema, aumentando a mobilidade das macromoléculas. Os plastificantes podem ser sólidos ou, líquidos de baixa volatilidade (alto ponto de ebulição) ${ }^{33,34}$.

Na Tabela 1-1 estão apresentados alguns tipos de plastificantes e as propriedades alteradas.

Tabela 1-1: Tipos de plastificantes e propriedade alterada ${ }^{35}$.

\begin{tabular}{|c|c|}
\hline $\begin{array}{c}\text { Propriedade desejada } \\
\text { Baixa temp. gelificação }\end{array}$ & $\begin{array}{c}\text { Plastificante recomendado } \\
\text { Butil benzil ftlato, butil octil ftalato } \\
\text { Baixa viscosidade }\end{array}$ \\
\hline Alta viscostil e n-decil ftalatos \\
\hline Retardamento de chama & $\begin{array}{c}\text { Butil benzil ftalato, tricresil ftalato, poli } \\
\text { ésteres }\end{array}$ \\
\hline Estabilidade, luz e calor & Fosfatos, parafinas cloradas \\
\hline Baixa volatilidade & Epoxídicos \\
\hline Baixa migração & Ftalatos de cadeia longa \\
\hline Baixa Tg & Trimelitatos e poliméricos \\
\hline
\end{tabular}

Os efeitos plastificantes de óleos, bálsamos e graxas são conhecidos desde a antiguidade. O primeiro registro de utilização de plastificante em polímero data de 1865, quando adicionou-se, em grande excesso, óleo de caroço de algodão e de mamona ao nitrato de celulose. O celulóide (nitrocelulose plastificada com cânfora) foi o primeiro plástico com importância comercial, usado inicialmente para produção 
de películas fotográficas e de cinema, além de ter sido o substituto do caríssimo marfim, que era usado para fabricação de bolas de bilhar.

Em 1930 surgiu o DOP (dioctil-ftalato), um dos plastificantes de mais largo uso na atualidade. O DOP é compatível com a maioria das resinas naturais e sintéticas, polímeros vinílicos e ésteres celulósicos; sendo largamente utilizado na plastificação do PVC poli(cloreto de vinila) (polímero que aceita maior concentração de plastificante).

O DOP apresenta boa compatibilidade com diversos polímeros, facilidade de processamento das misturas com polímeros, baixa volatilidade e flexibilidade à baixas temperaturas. Dentre suas principais aplicações destacam-se plásticos para mangueiras, tintas, vernizes, pisos vinílicos, adesivos, solado de calçados, estofamento de carros e móveis, revestimentos de fios e cabos elétricos e embalagens alimentícias.

Em 1934 existiam 56 plastificantes, em 1943 eram 150 e na década de 60 já eram 300. No final dos anos 70 existiam mais de 600 tipos.

Para que os plastificantes possam ser usados para fabricação de artefatos algumas características devem ser observadas:

- $\quad$ Pureza.

- $\quad$ Comportamento no processamento.

- $\quad$ Alta permanência, ou baixa migração.

- $\quad$ Baixa toxicidade.

- Propriedades conferidas ao polímero em função do teor.

- $\quad$ Não alterar a cor do polímero, ausência de cor.

- $\quad$ Estabilidade térmica e à luz.

- $\quad$ Não ser extraível por água. 
- Insípidos e inodoros.

- $\quad$ Permanência, ou baixa migração. Depende da volatilidade do aditivo, da sua susceptibilidade à migração na massa polimérica durante o processamento e durante o uso da peça (exsudação) e da possibilidade de extração por solventes (lixiviação).

Um plastificante deve ser capaz de misturar-se uniforme, homogeneamente e permanecer dissolvido quando resfriado à temperatura ambiente. Para isso, é preciso que o plastificante tenha baixa pressão de vapor e baixa taxa de difusão no polímero. Desta forma, a estabilidade do plastificante, quando misturado ao material polimérico, deve ser mantida durante o tempo de vida útil do produto plastificado.

Um plastificante pode migrar do material devido à volatilidade, exsudação (migração para a superfície), extração ou outras influências do meio. Pode, também, ser degradado por ação química do ambiente, radiação ou outras condições. Um plastificante pode mudar outras propriedades físicas do polímero como adesão, flamabilidade e toxicidade ${ }^{36}$. Portanto é importante a escolha adequada de um plastificante. De modo geral para isso devem ser observados os seguintes pontos:

1. Tipo de polímero a ser plastificado e seu desempenho.

2. Tipo de produto a ser produzido e propriedades mecânicas almejadas.

3. Tipo de processamento.

4. Propriedade, cor, odor, volatilidade, solubilidade, viscosidade, toxicidade, temperatura de ebulição, temperatura de decomposição, estabilidade, resistência a ataque de microorganismos.

5. Permanência.

6. Custo. 
$\mathrm{Na}$ escolha do plastificante é preciso considerar sua eficiência em modificar as propriedades desejadas, tanto quanto a otimização de seus efeitos sobre outras propriedades. Desta forma, as transições que podem ocorrer nos materiais poliméricos são fatores importantes a serem conhecidos quando se trabalha com plastificantes, pois seu desempenho está intimamente ligado a essa variável, como será mostrado em seguida.

\subsubsection{Transições em polímeros}

Os polímeros podem sofrer mudanças de estado que alteram drasticamente suas propriedades físicas e mecânicas. Os principais fatores que influem nessas transições são temperatura da amostra, presença de tensões externas e taxa de realização do experimento (escala de tempo) utilizada para medir a transição em consideração. As temperaturas em que ocorrem tais transições são parâmetros muito importantes na engenharia de materiais poliméricos. As temperaturas de transição mais importantes no estudo do comportamento de materiais poliméricos são temperatura de fusão cristalina $\left(T_{m}\right)$ e temperatura de transição vítrea $\left(T_{g}\right)^{37}$.

Com a variação da temperatura, geralmente os polímeros amorfos podem passar pelas fases e transições descritas a seguir:
A) Estado vítreo
B) Transição vítrea
C) Rubbery state (ou estado borrachoso)
D) Estado viscofluído 
Na Figura 1-4 está representado um esquema geral dessas transições em macromoléculas.

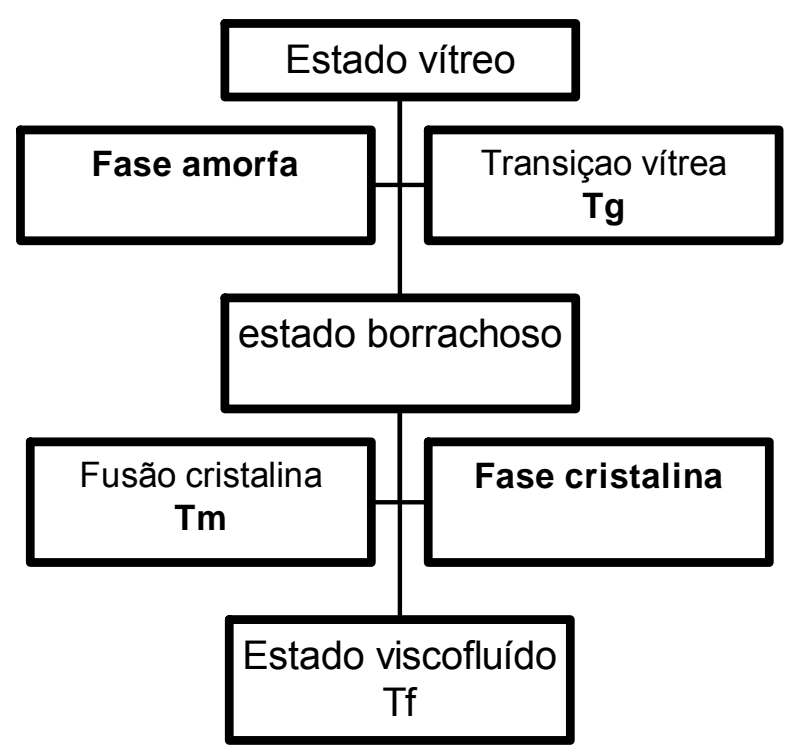

Figura 1-4: Mudanças de estado físico de macromoléculas.

Às baixas temperaturas, a interação entre as moléculas é forte; a movimentação de segmentos das cadeias (mesmo de grupos laterais) é dificultada, ocorrendo apenas vibração dos átomos em torno de sua posição de equilíbrio. Essa temperatura muito baixa depende do tipo de polímero e pode ser menor que zero grau Celsius ou, ainda, a temperatura ambiente. Se a macromolécula for submetida a resfriamento lento, dependendo da estrutura do mero, segmentos das cadeias podem se organizar e formar regiões cristalinas. A presença de cristalinidade está ligada à estrutura da macromolécula; e a simetria é fator importante na ocorrência de cristalização. Esse estado de baixa movimentação é denominado estado vítreo, o qual é caracterizado pela inexistência de rotações (dos átomos em torno das ligações simples) e flexibilidade, grande rigidez e comportamento que lembra a de um vidro ${ }^{38}$. 
Com aumento da temperatura, ocorre uma maior movimentação dos segmentos presentes na fase amorfa (devido à rotação de átomos em torno das ligações simples presentes nos segmentos das cadeias) e o polímero começa a apresentar comportamento flexível. Desta forma, o polímero passa de um estado rígido para um estado de flexibilidade. Esta transição recebe o nome de transição vítrea, $\mathrm{T}_{\mathrm{g}}$.

Aumentando ainda mais a temperatura, o polímero, em particular o elastômero, começa a se comportar como borracha. Este estado recebe o nome de rubbery state. A macromolécula apresenta alto grau de flexibilidade, e sob ação de força elástica se deforma e volta ao seu estado original. Contudo, precisa ressaltar que o estado de rubbery state é exclusivo de elastômeros.

No caso de polímeros semi-cristalinos, com o aumento de temperatura, é observada outra transição: a fusão dos cristalitos ou da fase cristalina $\left(T_{m}\right)$, o que caracteriza a transição de fusão dos materiais poliméricos. A interação entre as moléculas é enfraquecida e se uma força for aplicada, as cadeias deslizam umas em relação às outras.

Se a temperatura for ainda mais elevada, aumenta a extensão dos segmentos que podem se movimentar, até que as cadeias passem a fluir como um todo; o material passa a ter capacidade de fluir quando submetido à tensão, sem resistência elástica. A temperatura em que ocorre o fluxo é denominada $T_{f}$, temperatura de fusão, e esta transição caracteriza o estado viscofluído (estado viscoelástico). A resistência e o módulo de elasticidade (quantidade pela qual um material estende-se ou deforma-se quando é aplicada uma força ou tensão) são aproximadamente zero. Este estado é de grande importância tecnológica, por permitir o processamento do polímero $^{39}$. 
Em moléculas pequenas, ocorre a transição líquido-vapor. Esta mudança de fase não é observada em materiais poliméricos, uma vez que a energia necessária para afastar duas macromoléculas é maior que a energia de ligação. Desta forma, ocorre degradação, mas não há volatilização.

Como será exposto a seguir, a teoria da plastificação explica de que forma a atuação do plastificante afeta as transições físicas dos polímeros.

\subsubsection{Teoria da plastificação}

Uma possível forma de atuação dos plastificantes envolve a neutralização, ou redução, das forças intermoleculares do polímero pelas moléculas do plastificante. A miscibilidade com o polímero, a compatibilidade e sua permanência no sistema implicam em similaridade de forças intermoleculares de ambos os componentes.

Desta forma, os plastificantes adicionados aos polímeros atuam como solventes, provocando a separação entre as macromoléculas e, desse modo, levam à dissolução. O efeito final é a diminuição da energia necessária para os movimentos moleculares, o que caracteriza a flexibilidade. Assim, o plastificante precisa ter afinidade química, isto é, ser compatível com o polímero. A compatibilidade é função da atração relativa entre o polímero e o plastificante. Quando se adiciona um plastificante líquido a um polímero pode ocorrer uma dispersão coloidal ou molecular. Se entre ambos existir afinidade, haverá dispersão molecular, isto é, o polímero incha no plastificante e em seguida como em qualquer processo de solubilização de polímeros, forma-se a solução. Se não existir afinidade não ocorrerá inchamento, caracterizando a incompatibilidade entre ambos e a mistura permanece na forma de dispersão. 
Três teorias foram propostas para explicar o mecanismo de plastificação - a teoria da lubrificação, a teoria do gel e a teoria do volume livre ${ }^{40}$.

\subsubsection{Teoria da lubrificação}

A teoria da lubrificação trata a resistência à deformação como resultado da fricção molecular. O plastificante atuaria como lubrificante interno, facilitando o movimento de uma cadeia em relação à outra, e tornando o processamento (fluxo) mais fácil.

\subsubsection{Teoria do gel}

A teoria do gel propõe que os plastificantes atuam sobre as ligações dipolodipolo e forças de van der Waals, atenuando-as, e, conseqüentemente, reduzindo a rigidez do polímero. A atenuação destas interações ocorre uma vez que as moléculas de plastificante, ao se posicionarem entre as cadeias do polimero, aumentam a distância entre as mesmas. A força de atração eletrostática é inversamente proporcional à distância entre as cargas elétricas; portanto, o aumento da distância intermolecular atenua a força de atração entre as cadeias, flexibilizando o polímero. Em outras palavras, a presença das moléculas do plastificante, em meio às cadeias poliméricas, promove a "quebra" das ligações dipolo-dipolo entre as últimas, criando novos dipolos entre o polímero e o plastificante. 


\subsubsection{Teoria do volume livre}

Esta teoria tem origem no conhecimento da temperatura de transição vítrea em polímeros amorfos. Neste caso, as moléculas do plastificante são descritas como moléculas pequenas e, assim, possuem maior volume livre. A adição do plastificante tem o efeito de aumentar o volume livre do polímero plastificado o que leva a uma maior facilidade de movimento das cadeias poliméricas.

A compatibilidade entre um plastificante e um polímero, como função da constituição química destes componentes, pode ser estimada por dois parâmetros:

$$
\begin{aligned}
& \Rightarrow \text { Parâmetro de solubilidade }(\delta) \text { e } \\
& \Rightarrow \text { Constante dielétrica }(\varepsilon) .
\end{aligned}
$$

A inclusão da constante dielétrica como fator de controle da compatibilidade é devido a um fato prático. Alguns plastificantes com parâmetros de solubilidade e pesos moleculares semelhantes podem conferir propriedades diferentes quando adicionados a um mesmo polímero ${ }^{37}$.

O plastificante pode atuar não somente como espaçador molecular; mas também, formar ligações, embora momentâneas, com moléculas do polímero, por interações dipolo entre um grupo polar do polímero e um do plastificante. Quanto mais forte for essa interação (polímero-plastificante), menor o efeito do espaçamento, o que torna o produto mais duro e rígido com conseqüente aumento da temperatura de transição. Porém, quando cada grupo polar do polímero fica ligado a uma ou duas moléculas de plastificante, os grupos polares das cadeias vizinhas ficam protegidos por moléculas de plastificantes sem possibilidade de interagirem entre si e, portanto, pode ocorrer diminuição na temperatura vítrea. 
Desta forma, a compatibilidade não ocorre com muitos tipos de plastificantes, apesar de terem parâmetros de solubilidade semelhantes, necessitando-se, também, do conhecimento da constante dielétrica para prever a compatibilidade.

\subsubsection{Constante dielétrica do plastificante}

Plastificantes que têm alta constante dielétrica $(\varepsilon)$ também podem aumentar à dissociação dos pares iônicos do sal. A baixa viscosidade e a alta constante dielétrica do plastificante, efetivamente baixa a barreira do potencial do transporte iônico e tende a dissociar pares iônicos em anions e cátions, resultando em condutividade mais alta $^{41,42}$.

A constante dielétrica, grosseira indicação da polaridade do plastificante, é uma medida da habilidade do mesmo em separar cargas opostas. Assim, as atrações e repulsões eletrostáticas entre íons são menores em solventes com alta constante dielétrica. Valores de $\varepsilon$ de alguns plastificantes estão mostrados na Tabela $1-2$.

Tabela 1-2: Valores de constante dielétrica $(\varepsilon)$ de plastificantes comuns

\begin{tabular}{|c|c|}
\hline Plastificante & $\varepsilon$ \\
\hline Poliéteres & $4-7$ \\
\hline Dimetilsulfóxido & 46 \\
\hline Glicerol & 47 \\
\hline Carbonato de propileno & 64 \\
\hline Carbonato de etileno & 95 \\
\hline
\end{tabular}


Plastificantes polares têm alta constante dielétrica e, assim, são muito bons no isolamento de cargas. A força entre duas partículas carregadas é reduzida, tornando os íons estáveis no meio, se entre elas houver um meio de alta constante dielétrica.

\subsection{Dispositivos eletrocrômicos}

Dispositivos eletrocrômicos são aplicações práticas do fenômeno de eletrocrômismo. O termo eletrocrômico foi inventado por Platt ${ }^{43}$ e provêm de "eletro" (eletricidade) e "crômico" (relativo à cor). Este fenômeno é definido como mudança reversível de coloração de material, no caso do óxido de tungstênio de transparente para o azul escuro, causada pela aplicação de corrente ou potencial elétrico ${ }^{44}$.

Os dispositivos eletrocrômicos vêm sendo muito estudados por apresentarem várias vantagens em relação às janelas ou visores de cristais líquidos. Estas vantagens seriam: alto contraste óptico com contínua variação de transmitância e independência em relação ao ângulo de visão, memória óptica, estabilidade aos raios ultravioleta, além de ampla operação nas mais variadas faixas de temperatura.

Algumas aplicações de dispositivos eletrocrômicos conhecidos comercialmente são as janelas eletrocrômicas para controle da transmissão, aos ambientes internos, de comprimentos de ondas que variam desde o ultravioleta ao infravermelho próximo, exemplos:

- teto solar da Ferrari 575M, com 5 níveis de luminosidade no interior do carro.

- displays,

- retrovisores com reflexão variável para aplicação em veículos como exemplo do modelo 2004 Chrysler Pacifica ${ }^{45}$ e 
- superfícies com emissão térmica variável para refletir no infravermelho.

Os dispositivos eletrocrômicos podem ser montados na forma de sanduíche, composta por filmes finos, como o eletrocrômico $\mathrm{WO}_{3}$ e o transparente $\mathrm{CeO}_{2}-\mathrm{TiO}_{2}$. A construção desse tipo de dispositivo está representada na Figura 1-5 contemplando cinco filmes finos prensados entre dois substratos de vidro. Nesta figura observa-se dois condutores iônicos, usualmente feitos de óxido de estanho dopado com índio (ITO); um filme fino eletrocrômico (eletrodo de trabalho); eletrólito (condutor iônico); e um reservatório de íons de lítio ou hidrogênio. O fenômeno de mudança de coloração está ligado à inserção de íons de lítio $\left(\mathrm{Li}^{+}\right)$ou hidrogênio $\left(\mathrm{H}^{+}\right)$ que vêm da camada de eletrólito para a camada de filme eletrocrômico, geralmente formado por óxidos de tungstênio, nióbio ou vanádio e elétrons do eletrodo. No caso, por exemplo, de óxidos de tungstênio e nióbio ocorre brusca mudança de coloração, passando de quase transparentes (transmissão de 80\%) para azul-escuro (transmissão de 10\%).

Devido à aplicação de potencial ou corrente elétrica, os dispositivos eletrocrômicos mudam a sua coloração, pois quando estão desativados encontramse no estado incolor, e quando ativados passam a apresentar determinada coloração. As colorações obtidas com os vidros eletrocrômicos, quando ativados, são azul, verde, amarelo, vermelho e cinza ${ }^{46}$. 


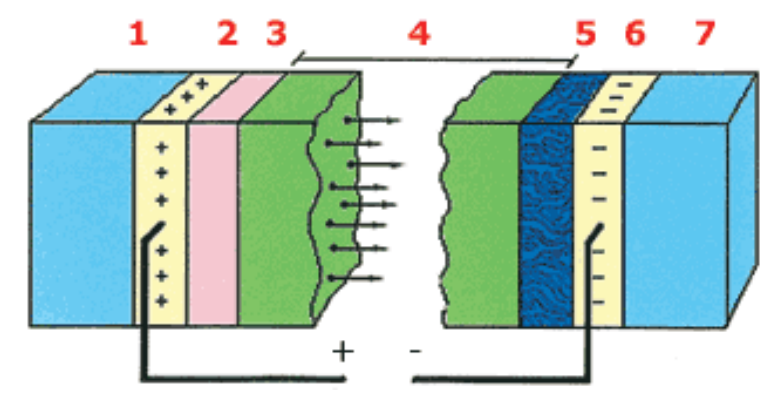

1 e 7 - Vidro

4 - Eletrólito

2 e 6 - Condutor Transparente 5 - Filme Eletrocrômico

3 - Reservatórios de íons

Figura 1-5: Esquema de janela eletrocrômica.

Os dispositivos eletrocrômicos podem trabalhar no modo de reflexão, dependendo de que material ele é formado como, por exemplo, no caso de displays ou espelhos retrovisores ou no modo de transmissão como as janelas o que é assunto de pesquisa de vários laboratórios tanto industriais como científicos. No trabalho de Munro e colaboradores ${ }^{47}$ podemos observar que eles desenvolveram uma janela eletrocrômica constituída por ITO/ $\mathrm{WO}_{3} / \mathrm{Li}^{+}$-eletrólito/CeO $\mathrm{Ce}_{2}-\mathrm{TiO}_{2} / \mathrm{ITO}$. Esta janela apresentou uma ótima variação na transmitância, de $60 \%$, entre o estado colorido e transparente.

A Figura 1-6 apresenta um esquema do funcionamento das janelas eletrocrômicas, a qual com a aplicação do potencial altera a cor na camada eletrocrômica. 

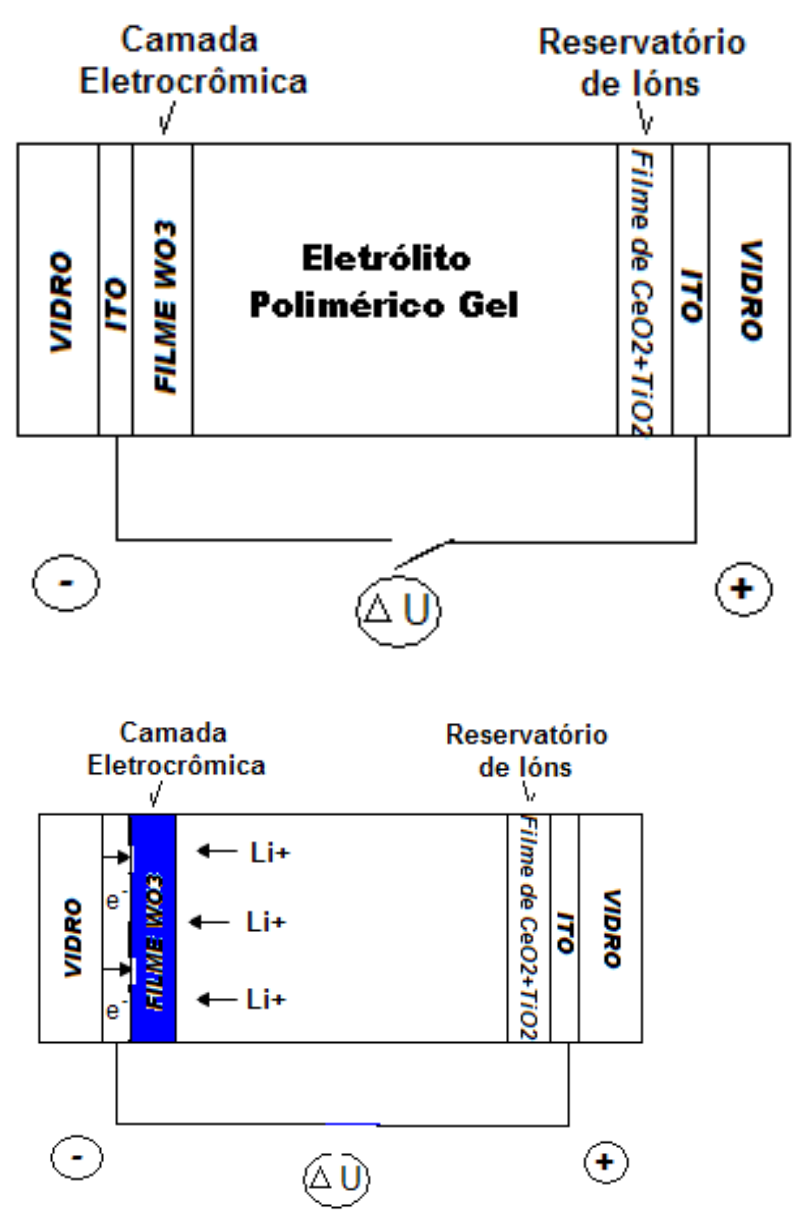

Figura 1-6 - Visualização e esquema de funcionamento de uma janela eletrocrômica.

Este trabalho propõe a produção de eletrólitos poliméricos (EPs) à base de pectina, que é um bom candidato para substituir o PEO para aplicação em dispositivos eletrocrômicos. 


\section{REFERÊNCIAS BIBLIOGRÁFICAS}

\footnotetext{
${ }^{1}$ MARIANI, P. D. S. C.; INNOCENTINI-MEI, L. H. Visão geral sobre polímeros ou plásticos ambientalmente degradáveis (PADs). Campinas: Unicamp, 2005. p. 9
}

${ }^{2}$ INZELT, G. Conducting polymers: a new era in eletrochemistry. Berlin: Fritz Scholz, 2008. 282 p.

${ }^{3}$ WRIGHT, P. V. Electrical conductivity in ionic complexes of poly (ethylene oxide). British Polymer Journal, v. 7, p. 319 - 327, 1975

${ }^{4}$ VIEIRA, D. F.; AVELLANEDA, C. O.; PAWLICKA, A. Conductivity study of a gelatin-based polymer electrolyte. Electrochimica Acta, v. 53, n. 4, p. 1404-1408, 2007.

${ }^{5}$ CHIANG, C. K., FINCHER, C. R.; PARK Y. W.; HEEGER, A. J.; SHIRAKAWA, H.; LOUIS, E. J.; GAU, S. C.; MACDIARMID, ALAN G. Electrical-conductivity in doped polyacetylene. Physical Review Letters, v. 39, n.17, p. 1098-1101, 1977.

${ }^{6}$ BRUCE, P. G.; VINCENT, C. A. Polymer electrolytes. Journal of the Chemical Society, Faraday Transactions, v. 89, n. 17, p. 3187-3203, 1993.

${ }^{7}$ ANDRADE, C. T.; COUTINHO, F.; DIAS, M. L.; LUCAS, E. F. Dicionário de polímeros. São Paulo: São Paulo, 2001. 256p.

${ }^{8}$ ARMAND, M. B.; CHABAGNO, J. M.; DUCLOT, M. Polymer solid electrolytes. In: INTERNATIONAL MEETING ON SOLID ELECTROLYTES, 2., 1978, St. Andrews. Anais... [s.l.:s.n.], 1978. p. 20-22.

9 MURATA, K.; IZUCHI, S.; YOSHIHISA, Y. An overview of the research and development of solid polymer electrolyte batteries. Electrochimica Acta, v. 45, p. 1501-1508, 2000.

${ }^{10}$ MACHADO, G. O. Preparação e caracterização de eletrólitos sólidos poliméricos a partir dos derivados de celulose - hidroxietilcelulose e hidroxipropilcelulose. 2004. 127 f. Tese (Doutorado em Ciências e Engenharia de Materiais) - Área Interunidades em Ciências e Engenharia de Materiais, Universidade de São Paulo, São Carlos, 2004.

${ }^{11}$ NEYERTZ, S.; BROWN, D. Local structure and mobility of íons in polymer electrolytes, Journal of Chemical Physics, v.104, n.10, p. 3797-3809, 1996. 
12 KHIAR, A. S. A.; PUTEH R.; AROF, A. K. Conductivity studies of a chitosan-based polymer electrolyte. Physica B: Condensed Matter, v. 373, p. 23-27, 2006.

${ }^{13}$ REDESCHI, M.C.M.R. Preparação e caracterização de filmes a base de xiloglucana extraída de sementes de Hymenaea Courbaril (Jatobá). 2006. 113 f. Dissertação de (Mestrado) Faculdade de Ciências Farmacêuticas, Universidade Estadual Paulista, Araraquara, 2006.

${ }^{14}$ PRZYLUSKI, J.; WIECZOREK W. Increasing the conductivity of polymer solid electrolytes: a review. Solid State Ionics, v. 36, p. 165-169, 1989.

15 JEON, J.D.; KWAK, S.Y. Variable-temperature Li-7 solid-state NMR investigation of Li-ion mobility and its correlation with conductivity in pore-filling polymer electrolytes for secondary batteries. Macromolecules, v. 39, n. 23, p. 8027-8034, 2006.

${ }^{16}$ DRAGUNSKI, D. C. Preparação de eletrólitos sólidos poliméricos a partir do amido. 2003. 163 f. Tese (Doutorado em Fisico-Química) - Instituto de Química de São Carlos, Universidade de São Paulo, São Carlos, 2003.

${ }^{17}$ ZHANG, H.; KULKARNI, S.; WUNDER, S.L. Blends of POSS-PEO $(n=4)(8)$ and high molecular weight poly(ethylene oxide) as solid polymer electrolytes for lithium batteries. Journal of Physical Chemistry B, v. 111, n. 14, p. 3583-3590, 2007.

${ }^{18}$ HASSOUN, J.; REALE, P.; PANERO, S.; SCROSATI, B.; WACHTLER, M.;

FLEISCHHAMMER, M.; KASPER, M.; WOHLFAHRT-MEHRENS, M. Determination of the safety level of an advanced lithium ion battery having a nanostructured $\mathrm{Sn}-\mathrm{C}$ anode, a high voltage $\mathrm{LiNi}_{0.5} \mathrm{Mn}_{1.5} \mathrm{O}_{4}$ cathode, and a polyvinylidene fluoride-based gel electrolyte.

Electrochimica Acta, v. 55, p. 4194-4200, 2010.

${ }^{19}$ NICHOLAS, C.V.; WILSON, D.J.; BOOTH, C.; GILES, J.R.M. Improved synthesis of oxymethylene-linked poly(oxyethylene). British Polymer Journal, n. 20, p. 289-292, 1988.

${ }^{20}$ CHAKER, Juliano Alexandre. Correlações entre estrutura e propriedades de condução iônica em materiais híbridos siloxanopoli(propileno óxido), dopados com sais de sódio e potássio. 2004. 164 f. Tese (Doutorado em Química) - Instituto da Química, Universidade Estadual Paulista, Araraquara, 2004.

${ }^{21}$ GRAY, F. M. Solid polymer electrolytes: fundamentals and technological applications. Cambridge: $\mathrm{VCH}, 1991.245$ p.

${ }^{22}$ GREGG, B.A. Photoelectrochromic cells and their applications. Endeavour, v. 21, n. 2, p. 52-55, 1997. 
${ }^{23}$ SIGNINI, R.; CAMPANA FILHO, S. P. Características e propriedades de quitosanas purificadas nas formas neutra, acetato e cloridrato, Polímeros. v. 11, n. 2, p. 58-64, 2001.

${ }^{24}$ DRAGUNSKI, D. C.; PAWLICKA, A. Starch based solid polymeric electrolytes. Molecular Crystals and Liquid Crystals, v. 374, p. 561-568, 2002.

${ }^{25}$ MACHADO, G. O.; PRUD'HOMME, R. E.; PAWLICKA A. Conductivity and thermal analysis studies of solid polymeric electrolytes based on plasticized hydroxyethyl cellulose. E-Polymers, v. 115, p. 1-9, 2007.

${ }^{26}$ KHIAR,A. S. A.; PUTEH R.; AROF, A. K. Conductivity studies of a chitosan-based polymer electrolyte. Physica B: Condensed Matter, v. 373, p. 23-27, 2006.

${ }^{27}$ VIEIRA, D. F.; AVELLANEDA, C. O.; PAWLICKA, A. Conductivity study of a gelatin-based polymer electrolyte. Electrochimica Acta, v. 53, n. 4, p. 1404-1408, 2007.

${ }^{28}$ VIEIRA, D. F.; AVELLANEDA, C. O.; PAWLICKA, A. Conductivity study of a gelatin-based polymer electrolyte. Electrochimica Acta, v. 53, n. 4, p. 1404-1408, 2007.

${ }^{29}$ GENU Pectin Book. Disponível em: <www.cpkelco.com>. Acesso em: 10 jan. 2010.

${ }^{30}$ DE PAOLI, M. A. Degradação e estabilização de polímeros. São Paulo: Artliber, 2009. v. 01.

${ }^{31}$ KUMAR, G. G.; MUNICHANDRAIAH, N. Effect of plasticizers on magnesiumpoly(ethyleneoxide) polymer electrolyte. Journal of Electroanalytical Chemistry, v. 495, n. 1, p. 42-50, 2000.

${ }^{32} \mathrm{XU}$, W.; SIOW, S. K.; GAO, Z.; LEE, S. Y. Electrochemical characterization of plasticized polyelectrolyte based on lithium-N-(4-sulfophenil) maleimide. Electrochimica Acta, v. 44, n. 13, p. 2287-2296, 1999.

${ }^{33}$ RABELO, M. Aditivação de polímeros. São Carlos, Artliber, 2000. 242p.

${ }^{34}$ AVEROUS, L.; FRINGANT, C.; MORO, L. Plasticized starch-cellulose interactions in polysaccharide composites. Polymer, v. 42, n. 15, p. 6565-6572, 2001.

${ }^{35}$ DE PAOLI, M. A. Disponível em :

$<$ http://lpcr.iqm.unicamp.br/arquivos/dplastificanteslubrificantes.pdf $>$ Acesso em: 12 maio 2010. 
${ }^{36}$ NICOTERA, I.; RAMIERI, G. A.; TERENZI, M.; CHADWICK, A. V.; WEBSTER, M. I. A study of stability of plasticized PEO electrolytes. Solid State Ionics, v. 146, n. 1-2, p. 143150, 2002.

${ }^{37}$ SIMAL, A. L. Estrutura e propriedades dos polímeros. São Carlos: Edufscar, 2002. 168p.

${ }^{38}$ PEREPECHKO, I. I. An introduction to polymer physics. Moscow: Mir Publishers, 1981. 266p.

${ }^{39}$ MARK, J. E.; EISENBERG, A.; GRAESSLEY, W. W.; MANDELKERN, L.; KOENIG, J. L. Physical properties of polymers. Washington: American Chemical Society, 1984. 246p.

${ }^{40}$ WANG, F. C. Y. Polymer additive analysis by pyrolysis-gas chromatography. I-

Plasticizers. Journal of Chromatography A, v. 883, p. 199-210, 2000.

${ }^{41}$ CHUNG, S. H.; HEITJANS, P.; WINTER, R.; BZAUCHA, W.; FLORJANCZYK, Z.; ONODA, $\mathrm{Y}$. Enhancement of ionic conductivity by the addition of plasticizers in cationic monoconducting polymer electrolytes. Solid State Ionics, v. 112, p. 153-159, 1998.

${ }^{42}$ CHEN, H. W.; LIN, T. P.; CHANG, F. C. Ionic conductivity enhancement of the plasticized $\mathrm{PMMA} / \mathrm{LiClO} 4$ polymer nanocomposite electrolyte containing clay. Polymer, v. 43, p. 52815288, 2002.

${ }^{43}$ PLATT, J. R. Electrochromism, a possible change of color producible in dyes by an electric field. Journal of Chemical Physics, v. 34, n. 3, p. 862, 1961.

${ }^{44}$ AL-KAHLOUT, A.; VIEIRA, D.; AVELLANEDA, C.O.; LEITE, E.R.; AEGERTER, M.A. ; PAWLICKA, A. Gelatin-based protonic electrolyte for electrochromic windows. Ionics, v. 16, p. 13-19, 2010.

${ }^{45}$ KEVIN, B. HowStuffWorks: Como funcionam as janelas inteligentes. Disponível em: http://casa.hsw.com.br/janelas-inteligentes.htm . Acesso em: 15 set. 2007.

${ }^{46}$ CARAM, R.; SICHIERI, E.; PAWLICKA, A. Vidros que mudam de cor. FINESTRA, v. 35, p. 20, 2003.

${ }^{47}$ MUNRO, B.; CONRAD, P.; KRAMER, S.; SCHMIDT, H.; ZAPP, P. Development of electrochromic cells by the sol-gel process. Solar Energy Material and Solar Cells, v. 54, n. 1-4, p. 131-137, 1998. 


\section{CAPITULO 2 - OBJETIVOS}

Os principais objetivos deste projeto são a preparação e caracterização de eletrólitos poliméricos géis a partir de Pectina Comercial, visto que trabalhos anteriores desenvolvendo eletrólitos a base de amido rico em amilopectina, quitosana, gelatina e agar-agar são muito promissores devido aos seus ótimos valores das condutividades iônicas, baixo custo, boa estabilidade eletroquímica, boa transparência na região do UV-Vis e fácil preparação. Por estas razões propõe-se estudar pectinas comerciais devido à presença de grupos ácidos carboxílicos que podem promover melhores resultados nos valores de condutividades iônicas. 


\section{CAPITULO 3 - MATERIAIS E MÉTODOS}

\subsection{Materiais}

As pectinas utilizadas para o desenvolvimento do trabalho foram GENU ${ }^{\circledR}$ tipo "B rapid set - Z" (BRS-Z) e tipo USP-200, as quais foram cedidas gentilmente pela CP Kelco Brasil S/A.

As pectinas $\mathrm{GENU}^{\circledR}$ BRS-Z e GENU ${ }^{\circledR}$ USP-200 tem alto grau de metoxilação (HM) e são extraídas da casca de frutas cítricas (laranja, limão). Enquanto a primeira é utilizada geralmente em indústrias de alimentos como agente gelificante de geléias e doces a segunda é aproveitada pelas indústrias farmacêuticas. Ambas as pectinas estão na forma de pó com uma coloração creme, e o grau de esterificação tipicamente apresentado é de $72 \%$.

Na preparação de membranas condutoras iônicas foi utilizado perclorato de lítio $\left(\mathrm{LiClO}_{4}\right)$ da Aldrich (Figura 3-1), peso molecular 106,39 g/mol, aparência de cristais brancos, ponto de fusão $236^{\circ} \mathrm{C}$ e solubilidade em água de $60 \mathrm{~g} / 100 \mathrm{~mL}$.

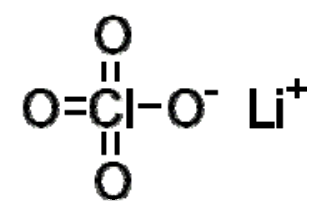

Figura 3-1: Fórmula molecular do perclorato de lítio.

O plastificante utilizado foi glicerol $\left(\mathrm{C}_{3} \mathrm{H}_{5}(\mathrm{OH})_{3}\right)$ P.A. da Synth (Figura 32), que é um álcool com peso molecular de $92,09 \mathrm{~g} / \mathrm{mol}$, em estado liquido 
incolor e inodoro em temperatura ambiente, com ponto de fusão $18,1^{\circ} \mathrm{C}$, ponto de ebulição $290^{\circ} \mathrm{C}$ e é miscível em água.<smiles>OCC(O)CO</smiles>

Figura 3-2: Fórmula molecular do glicerol.

$\mathrm{O}$ outro plastificante testado foi o etileno glicol $\left(\mathrm{C}_{2} \mathrm{H}_{4}(\mathrm{OH})_{2}\right)$ P.A. da Synth (Figura 3-3), que é um álcool com peso molecular 62,07 g/mol, aparência liquida incolor e inodoro, ponto de fusão $-12,9^{\circ} \mathrm{C}$, ponto de ebulição $197,3^{\circ} \mathrm{C}$, miscível em água.

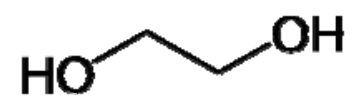

Figura 3-3: Fórmula molecular do etileno glicol.

\subsection{Obtenção dos eletrólitos a base de pectina}

Os eletrólitos foram preparados a partir da dissolução de $0,6 \mathrm{~g}$ de pectina $\left(\mathrm{GENU}^{\circledR}\right)$ em $20 \mathrm{~mL}$ de água Millipore Milli-Q com resistividade controlada de $18,2 \mathrm{~m}^{-1} \mathrm{~cm}^{-1}$ à $25^{\circ} \mathrm{C}$. A dissolução foi feita sob agitação magnética e aquecimento a aproximadamente $60^{\circ} \mathrm{C}$. Após completa solubilização da pectina, preparou-se amostras com diferentes teores de glicerol $(0 \%, 37 \%, 54 \%, 60 \%, 64 \%, 68 \%$ e $70 \%)(\mathrm{m} / \mathrm{m})$ e com duas quantidades diferentes de perclorato de lítio $(0,24 \mathrm{~g}$ e $30[\mathrm{O}] /[\mathrm{Li}])$. As composições das amostras estão apresentadas na Tabela 3-1, as amostras 
foram identificadas como PA e PB, sendo PA amostras com quantidade fixa de $30[\mathrm{O}] /[\mathrm{Li}]$ e PB amostras com quantidade fixa de $0,24 \mathrm{~g}$ de perclorato de lítio..

Tabela 3-1: Concentrações de $\mathrm{LiClO}_{4}$

\begin{tabular}{|c|c|c|c|c|}
\hline $\begin{array}{c}\text { Glicerol } \\
\text { (g) }\end{array}$ & $\begin{array}{c}\text { PA } \\
\text { ([O]/[Li]) }\end{array}$ & $\begin{array}{c}\text { PB } \\
\text { ([O]/[Li]) }\end{array}$ & $\begin{array}{l}\text { PA } \\
\text { (g) }\end{array}$ & $\begin{array}{l}\text { PB } \\
(g)\end{array}$ \\
\hline 0,00 & \multirow{8}{*}{30} & 8 & 0,0672 & \multirow{8}{*}{0,24} \\
\hline 0,29 & & 12 & 0,1007 & \\
\hline 0,50 & & 15 & 0,1250 & \\
\hline 1,00 & & 20 & 0,1829 & \\
\hline 1,25 & & 24 & 0,2118 & \\
\hline 1,50 & & 30 & 0,2400 & \\
\hline 1,75 & & 33 & 0,2696 & \\
\hline 2,00 & & 37 & 0,2985 & \\
\hline
\end{tabular}

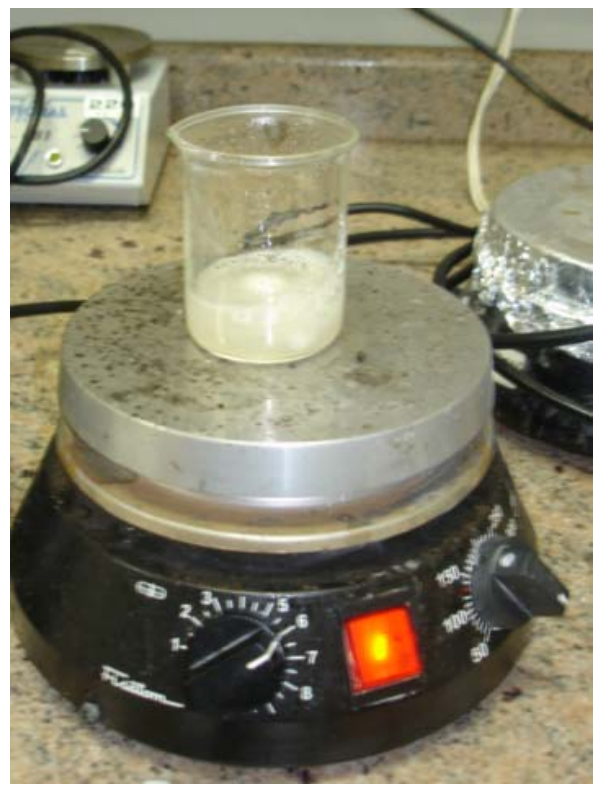

Figura 3-4: Fotografia da obtenção da solução viscosa dos eletrólitos. 
A solução viscosa foi vertida em placas de Petri e seca à temperatura ambiente por 48 horas, após isso, foi colocada em estufa à $50^{\circ} \mathrm{C}$ por mais 48 horas.

As membranas secas foram armazenadas em dessecador para evitar a absorção de água da atmosfera, e caracterizadas por difração de raios-X, microscopia eletrônica de varredura (MEV), espectroscopia no ultravioletavisivel (UV-vis), espectroscopia de impedância eletroquímica (EIE) e análises térmicas (DSC e TG).

\subsection{Técnicas utilizadas para a caracterização das}

\section{pectinas e dos eletrólitos}

\subsection{1 - Espectroscopia na região do Infra-vermelho por transformada de Fourier (FT-IR)}

Absorção na região do Infravermelho (FT-IR) é devida a movimentos vibracionais e rotacionais dos grupos moleculares e ligações químicas de uma molécula. Essencialmente, existem duas vibrações fundamentais: estiramento das ligações, quando os átomos permanecem no mesmo eixo da ligação, porém a distância entre os átomos aumenta ou diminui, e deformação angular, quando as posições dos átomos mudam em relação ao eixo de ligação original. Se luz infravermelho de mesma freqüência de vibração, de estiramento ou de deformação angular, incide na amostra, a energia é absorvida e a amplitude de vibração é aumentada. Devido à energia de absorção na freqüência de ressonância, o detector do espectrômetro de infravermelho grava um pico de absorção naquele número de onda. Vibrações de deformação angular 
geralmente requerem energias menores e são encontradas em freqüências menores do que as vibrações de estiramento ${ }^{1,2,3}$.

Os espectros de FT-IR foram obtidos com um espectrofotômetro Nexus 4700 FTIR da Thermo Nicolet, utilizando a técnica de refletância total atenuada horizontal (ATR de contato) modelo Thunder Dome da Thermo Nicolet, através de um método de reflexão, com 32 repetições, leitura de 4000 a $750 \mathrm{~cm}^{-1}$ e resolução igual a $4 \mathrm{~cm}^{-1}$.

\subsubsection{Grau de Esterificação (DE)}

As pectinas comerciais geralmente apresentam um grau de esterificação (DE) típico de 50\%, e podem ser divididas em duas classificações: DE acima de $50 \%$ significando alto grau de metoxilação (HM) e DE abaixo de $50 \%$ - baixo grau de metoxilação (LM).

O DE é definido como mostrado na (Equação 3.1):

$$
D E=\frac{\text { número de grupos es terificados }}{\text { número total de grupos carboxilicos }} * 100
$$

Portanto, quanto maior DE maior o número de grupos esterificados.

Há vários métodos para se calcular o grau de esterificação das amostras de pectinas, o método escolhido neste trabalho foi 0 de titulação potenciométrica descrito por Bochek et $a l^{4}$. A escolha desse método se deve ao fato de que não foi possível calcular o DE a partir das técnicas de ressonância magnética nuclear de hidrogênio $\left({ }^{1} \mathrm{H}-\mathrm{NMR}\right)$ e espectroscopia de FT-IR.

Para o método de titulação potenciométrica utilizou-se pectina seca $(0,2$ g) que foi colocada em um copo de Becker e umedecida com etanol $95 \%$. 
Água destilada aquecida a $40^{\circ} \mathrm{C}(20 \mathrm{~mL})$ foi adicionada e o polímero foi dissolvido com agitação por 2 horas. A solução resultante foi titulada com $\mathrm{NaOH}(0,1 \mathrm{~N})$ na presença de fenolftaleína e o resultado foi anotado como titulação inicial $(T i)$. Depois, adicionou-se $10 \mathrm{~mL}$ da solução de $\mathrm{NaOH}(0,1 \mathrm{~N})$ à amostra neutralizada de ácido galacturônico e agitou-se por mais 2 horas para saponificação dos grupos carboxílicos esterificados do polímero. A quantidade de $10 \mathrm{~mL}$ de $\mathrm{HCl}(0,1 \mathrm{~N})$ foi adicionada. $\mathrm{O}$ excesso de $\mathrm{HCl}$ foi titulado com $\mathrm{NaOH}(0,1 \mathrm{~N})$. O número de grupos carboxílicos esterificados foi calculado a partir do volume de $\mathrm{NaOH}(0,1 \mathrm{~N})$ gasto na titulação final $(T f)$. O grau de esterificação foi calculado usando a (Equação 3.2):

$$
D E(\%)=\frac{T_{f}}{T_{t}+T_{f}}=100 \%
$$

Onde, Ti: volume total em $\mathrm{mL}$ de $\mathrm{NaOH}$ usado na titulação inicial; $T f$ : volume total em $\mathrm{mL}$ de $\mathrm{NaOH}$ usado na titulação final.

\subsubsection{Espectroscopia de Impedância Eletroquímica (EIE)}

A propriedade de condução dos eletrólitos sólidos poliméricos pode ser realizada determinando-se a condutividade iônica por meio da espectroscopia de impedância eletroquímica (EIE). Estas medidas podem ser feitas a uma dada temperatura ou em função da temperatura, sendo que neste último caso é possível a identificação da contribuição e da quantidade das diferentes espécies carregadas na condução $0^{5,6}$.

A EIE é uma das técnicas de análise eletroquímica mais poderosa e mais utilizada. Podem ser analisados vários sistemas, como por exemplo, eletrodos cobertos com filmes poliméricos eletroativos (como os eletrólitos 
sólidos poliméricos), soluções contendo líquidos imiscíveis, eletrodos íonseletivos e eletrodos cobertos com filmes finos de óxidos inorgânicos ${ }^{7}$.

O método mais comum para determinação das propriedades elétricas de eletrólitos poliméricos é o da corrente alternada (ca). Um experimento ca descreve a resposta de um circuito a uma corrente ou potencial senoidal em função da freqüência. Ao contrário da teoria de corrente contínua (cc) em que a freqüência é nula e a resistência $(R)$ é definida através da Lei de Ohm (Equação 3.3):

$$
E=\mid R
$$

Na teoria ca, na qual a freqüência é diferente de zero, a (Equação 3.4) análoga é,

$$
E=I Z
$$

onde Z é a impedância medida em ohms $(\Omega)$ e I a corrente em ampéres (A).

O termo impedância e resistência sugerem uma oposição ao fluxo de elétrons. Em circuitos $c c$ somente resistores promovem esse efeito, porém em circuitos ca, capacitores e indutores também podem se opor ao fluxo de elétrons. A impedância pode ser representada por um número complexo no qual a resistência é o componente real e a combinação de reatância e indutância é o componente imaginário.

Assim, a impedância total de um circuito em função do sinal da freqüência $(\omega)$ pode ser definida como (Equação 3.5):

$$
Z(\omega)=Z^{\prime}+i Z^{\prime \prime}
$$


onde Z' é o componente real e Z" o componente imaginário da impedância. Sua representação é dada por meio dos diagramas de impedância no plano complexo (Figura 3-5) . $^{8}$

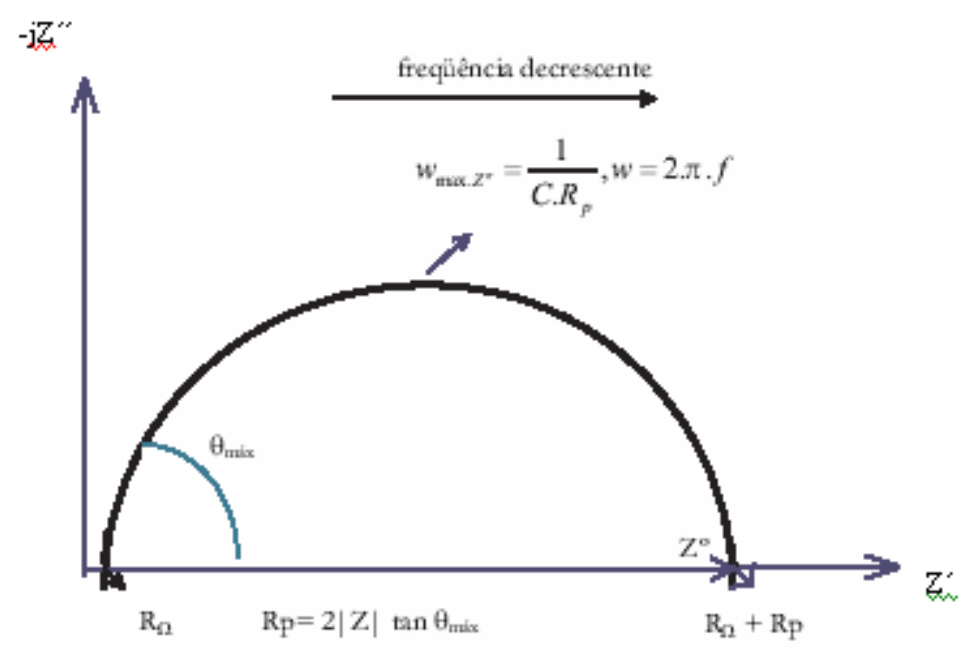

Figura 3-5: Diagrama de Impedância no plano complexo.

Para o cálculo de resistência utiliza-se o modelo mostrado na Figura 3-5, a qual apresenta o plano complexo de Nyquist ${ }^{9}$. Um comportamento comum para eletrólitos poliméricos é o aparecimento de um semicírculo em regiões de altas freqüências (que se refere à parte resistiva) seguido de uma reta referente à parte capacitiva.

No cálculo de resistência de eletrólitos sólidos geralmente se utiliza um circuito RC// (Figura 3-6), o qual possui um resistor e um capacitor em paralelo. A impedância do resistor não possui componente imaginária e a impedância do capacitor não possui componente real. A componente imaginária da impedância do capacitor depende da capacitância e da freqüência e em altas freqüências tende a zero. Sendo assim, é comum utilizar extrapolações na região de altas e baixas freqüências para a determinação da resistência do eletrólito, diminuindo a contribuição da parte capacitiva. 


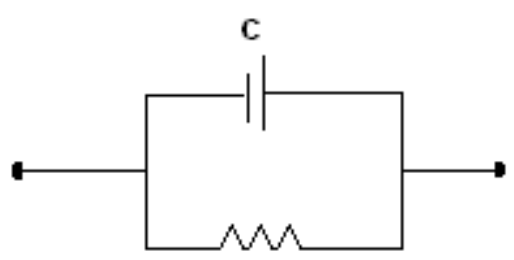

$\mathbf{R}$

Figura 3-6: Circuito $\mathrm{RC} / /^{10,11}$.

Nessa extrapolação, a parte imaginária tende a zero e a resistência da amostra é obtida pelo valor no eixo real. Obtida a resistência foi possível calcular a condutividade $(\sigma)$ da amostra pela (Equação 3.6 ):

$$
\sigma=l /(R \cdot s) \quad\left(\mathrm{S} / \mathrm{cm} \text { ou } \Omega^{-1} \mathrm{~cm}^{-1}\right)
$$

Onde, lé a espessura do filme, $s$ é a área superficial e $R$ a resistência.

Para efetuar o cálculo da resistência do eletrólito foi feita uma extrapolação das duas partes do semicírculo até o eixo x. Nesta extrapolação utilizou-se ajuste efetuado pelo equipamento Solartron modelo 1260, acoplado a um micro-computador. As medidas foram realizadas a vácuo, nas freqüências de $1 \mathrm{~Hz}$ a $32 \mathrm{MHz}$ com amplitude de $5 \mathrm{mV}$ e a diferentes temperaturas (de ambiente até $80^{\circ} \mathrm{C}$ ), o aquecimento da célula foi realizado com o auxílio de um forno EDG \%P, equipado com um termopar alocado ao lado da amostra para permitir a leitura direta da temperatura do sistema.

Com o aumento da temperatura ocorre uma mudança significativa no espectro de impedância, o desaparecimento do semicírculo referente a parte resistiva, pois as amostras apresentam maiores valores de condutividade. Neste caso, o cálculo da resistência foi feito pela extrapolação da parte capacitiva no eixo $\mathrm{x}$. 
Outro tipo de representação de um ensaio de impedância eletroquímica, é através dos diagramas de Bode, pelos quais são examinadas a impedância absoluta (|Z|) a o ângulo de fase (q) da impedância, ambos como função da freqüência.

Os diagramas de Bode apresentam algumas vantagens sobre 0 diagrama de Nyquist. Uma delas é que, devido à freqüência estar presente em um dos eixos, é fácil observar como a impedância depende da freqüência.

Outra vantagem é a de, pelo fato do diagrama de Bode para $|Z|$ representar a magnitude $|\mathrm{Z}|$ em escala logarítmica, poder ser representada uma vasta faixa de limites de impedância em um mesmo eixo. Isto é útil quando a impedância depende fortemente da freqüência, como no caso de sistemas eletroquímicos que atuam de forma capacitiva. A curva obtida no gráfico de $\log |Z| \times \log \omega$ fornece os valores de RP e RW. A Figura 3-7 exemplifica um diagrama de Bode $|Z|$, para o mesmo caso do diagrama de Nyquist da Figura 3-5.

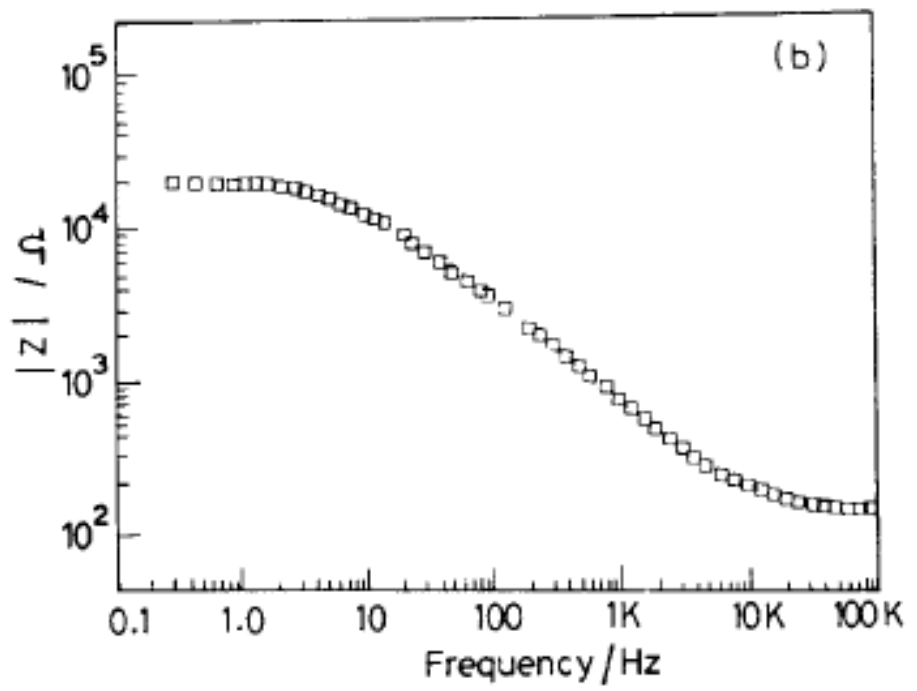

Figura 3-7 : Diagrama de Bode |Z|, para um sistema eletroquímico simples ${ }^{15}$. 
Deste gráfico, mostrado na Figura 3-7, pode-se observar que, a altas freqüências, a resistência ôhmica domina a impedância do sistema, sendo que o log RW pode ser lido, extrapolando-se para o eixo y a plataforma horizontal gerada na curva. As baixas freqüências, são a soma de RW com RP que vai dominar a impedância do sistema, sendo que essa soma pode ser lida, extrapolando-se a plataforma horizontal gerada na curva, para o eixo y, tal como foi feito para a obtenção de RW a altas freqüências. Em freqüências intermediárias, há a formação de uma reta de ligação entre as plataformas horizontais de alta e baixa freqüência, com uma inclinação de -1 , que advém do fato de a impedância capacitiva C, poder estar dominando a impedância do sistema. Extrapolando-se esta reta até o eixo do $\log |Z|$, no ponto onde $\log w=$ $0(w=1, f=0.16 \mathrm{~Hz})$, pode-se obter o valor da capacitância da dupla camada, formada entre o eletrólito e o eletrodo condutivo, da (Equação 3.7):

$$
|Z|=\frac{1}{C_{D L}}
$$

Esta relação é deduzida, partindo-se da expressão para a impedância capacitiva:

$$
Z_{C}=\frac{-j}{w \cdot C}
$$

e da relação:

$$
\log |Z|=\log \frac{1}{w \cdot C}
$$


resolvendo a expressão (3.9), temos:

$$
\begin{aligned}
& \log |Z|=\log (w C) \\
& \log |Z|=-\log (w)-\log (C) \\
& \log |Z|=-\log (2 p f)-\log (C) \\
& \log |Z|=-\log (2 p)-\log (f)-\log (C)
\end{aligned}
$$

No ponto da curva do diagrama de Bode $|\mathrm{Z}|$ onde $\mathrm{f}=0.16 \mathrm{~Hz}, \mathrm{w}=2 \mathrm{pf}=1$ e o $\log (2 \mathrm{pf})=0$. Portanto:

$$
\begin{aligned}
& \log (|Z|)=-\log (C) \\
& \text { ои } \\
& \left|Z_{(f=0,16 \mathrm{~Hz})}\right|=\frac{1}{C}
\end{aligned}
$$

Os eletrólitos, todos na forma de filmes/membranas, foram prensados entre dois eletrodos de aço inoxidável polido e contidos em um porta-amostra de Teflon $^{\circledR}$, que foi colocado no fundo de uma célula de medida. Os contatos elétricos são o fundo metálico da célula e o tubo de aço inoxidável, fechado na extremidade posicionada sobre o eletrodo superior. A célula foi concebida de tal forma a permitir a prensagem da amostra sob vácuo. Um termopar posto ao lado da amostra, no interior do tubo permitiu a leitura direta da temperatura do sistema. O sistema utilizado para a determinação da condutividade está representado na Figura 3-8. 

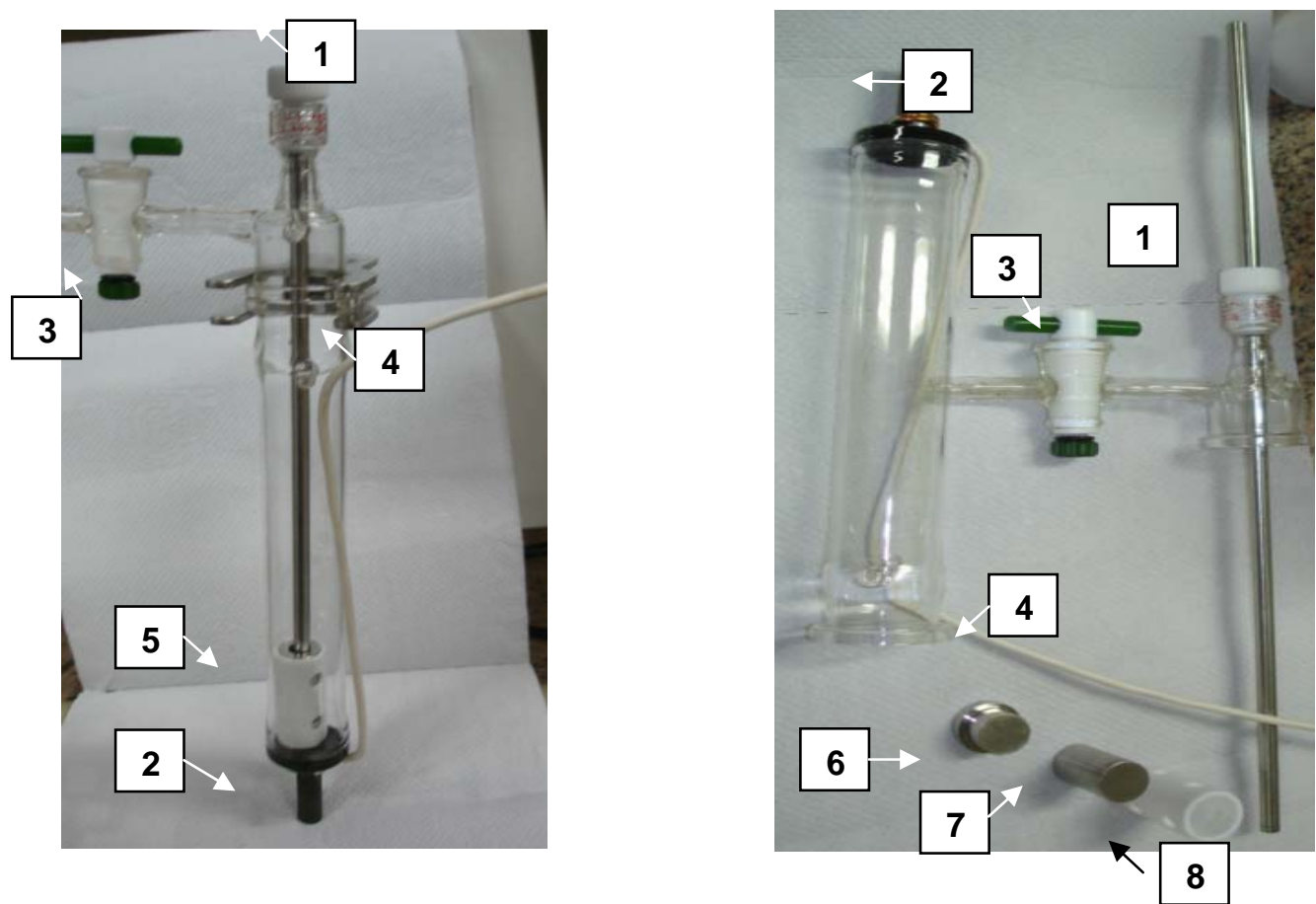

Figura 3-8: Célula de medida utilizada nos experimentos de determinação de condutividade dos filmes: (1) contato do eletrodo superior (tubo de inox fechado na parte inferior); (2) eletrodo inferior feito em Kovar; (3) torneira para conectar a bomba de vácuo; (4) fio de cobre para estabelecer o contato com o metal, Kovar; (5) Porta amostra, (6) eletrodo inferior, (7) eletrodo superior e (8) guia do porta amostra $\left(\right.$ Teflon $\left.^{\circledR}\right)$.

O aquecimento da célula (da temperatura ambiente até $80^{\circ} \mathrm{C}$ ) foi realizado com auxílio de um forno EDG 5P que está ilustrado na Figura 3-9.

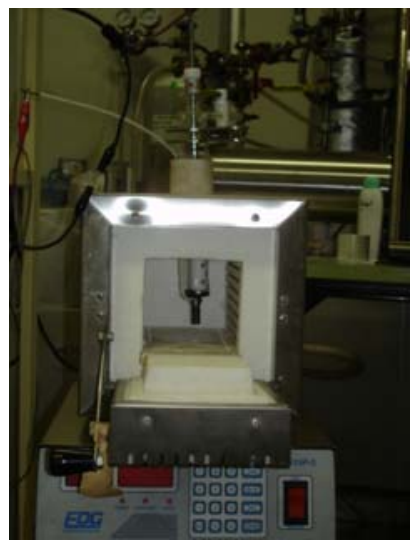

Figura 3-9: Visão do porta-amostra no forno com a porta aberta. 
O diagrama de impedância foi obtido com o impedancímetro Solartron modelo 1260 (Figura 3-10).

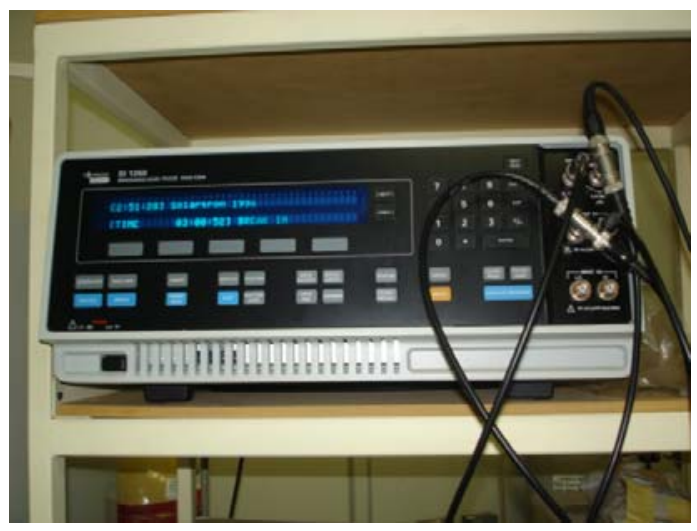

Figura 3-10: Impedancímetro Solartron modelo 1260.

\subsubsection{Voltametria cíclica e Cronoamperometria}

A voltametria cíclica é uma técnica eletroquímica muito usada para estudar os processos de oxidação e redução em vários meios, processos de adsorção em superfícies e mecanismos de transferência de elétrons em superfícies de eletrodos quimicamente modificados ${ }^{16}$. Esta técnica geralmente é efetuada numa célula eletroquímica contendo três eletrodos: eletrodo de trabalho, contra-eletrodo e eletrodo de referência. A técnica de voltametria cíclica consiste na aplicação de um potencial $(E)$ no eletrodo de trabalho, obtendo-se como resposta a corrente em função do potencial (E) aplicado, sendo que o potencial aplicado é repetido ciclicamente entre dois valores determinados previamente.

Através dos voltamogramas cíclicos obtêm-se parâmetros importantes do processo de óxido-redução: potencial de pico catódico $\left(\mathrm{E}_{\mathrm{pc}}\right)$, potencial do pico anódico $\left(E_{p a}\right)$, corrente de pico catódico $\left(i_{p c}\right)$ e corrente de pico anódico 
$\left(\mathrm{i}_{\mathrm{pa}}\right)$. Outra informação que pode ser obtida dos voltamogramas é a razão entre as cargas anódica e catódica $\left(\mathrm{q}_{\mathrm{a}} / \mathrm{q}_{\mathrm{c}}\right)$; para um sistema reversível esta razão deve ser igual a um, independente da velocidade de varredura.

É importante destacar que a altura do pico em um voltamograma cíclico depende de vários fatores, tais como velocidade de varredura, espessura do filme, coeficiente de difusão das espécies iônicas presentes no filme ${ }^{17}$.

A cronoamperometria é uma técnica eletroquímica que consiste na aplicação de potenciais em saltos durante um intervalo de tempo no eletrodo de trabalho, obtendo-se um gráfico de corrente em função do tempo.

As medidas eletroquímicas das janelas eletrocrômicas foram obtidas com um potenciostato/galvanostato Autolab PGSTAT 302N. Os processos de intercalação/deinterclação foram realizados para os potenciais de -2.5 e $+2.0 \mathrm{~V}$ durante 30s respectivamente para as janelas eletrocrômicas.

\subsubsection{Espectroscopia no Ultravioleta-visível (UV-vis)}

A absorção de moléculas na região espectral do UV-vis está relacionada com a estrutura eletrônica molecular. A absorção de energia é quantizada e promove a passagem dos elétrons de orbitais do estado fundamental para orbitais de maior energia originando um estado excitado ${ }^{18}$.

Um espectro de UV-vis corresponde à gráficos da radiação absorvida ou transmitida versus comprimento de onda ou freqüência. As transições são caracterizadas por picos de absorção (geralmente de caráter Gaussiano), pois além da transição eletrônica que aparece nestes espectros, também temos transições vibracionais e rotacionais, causando um alargamento dos picos ${ }^{19,20}$. 
Dois tipos de elétrons contribuem para a absorção eletrônica, os que participam na formação da ligação entre os átomos da molécula, e os elétrons livres, os quais estão localizados ao redor de átomos como: oxigênio, os halogênios, enxofre e nitrogênio.

A técnica de espectroscopia de UV-vis opera em duas faixas de luz no espectro eletromagnético, no ultravioleta de 200 a 400 nm, e no visível de 400 a $800 \mathrm{~nm}$. Também foram realizadas medidas no infravermelho próximo, na região de 800 a $2500 \mathrm{~nm}$.

Para a aplicação de eletrólitos poliméricos, o uso da técnica de UV-vis serve para avaliar a transmitância desses materiais na região do visível (400 a $800 \mathrm{~nm}$ ) visando uma posterior aplicação em janelas eletrocrômicas. Desse modo, quanto maior a transmitância nesta região, maior será a transparência do filme.

Para a técnica de espectroscopia de UV-vis utilizou-se o espectrômetro da marca HITACHI, modelo U-3501.

\subsubsection{Difração de Raios-X}

A técnica de difração de raios-X é utilizada para determinação da estrutura fina do material, não só da sua estrutura cristalina, mas também para análises químicas, medidas de tamanho de partículas e determinação de orientação de cristais.

Raios-X é um tipo de radiação eletromagnética que se encontra na faixa de comprimento de onda entre 0,5 e 2,5 Á. Esses raios são produzidos devido 
à colisão de elétrons com alta velocidade em uma placa de metal liberando radiação em todas as direções.

Um gráfico típico de raios-X é plotado com a intensidade em função do ângulo de difração. Esta intensidade é a soma das intensidades relativas de todos os raios difratados na mesma direção e o ângulo de difração é o ângulo entre a luz difratada e a transmitida ${ }^{21}$.

Difração é um fenômeno de espalhamento de luz proporcionado por um grande número de átomos, porém não há interação entre os raios-X e esses átomos.

Moléculas em um estado de grande desarranjo produzem linhas de difração muito largas e geram regiões chamadas amorfas. Por outro lado, existem algumas regiões organizadas chamadas de "cristalinas" que por sua vez, dão origem a picos mais resolvidos e menos largos.

Quando se fala em raios-X, a maioria das pessoas já associa com radiografia, que é o processo que usa os raios-X para visualizar o interior de objetos (ou ossos/esqueleto de pessoas; Figura 3-11) ao colocá-los entre uma fonte de raios-X e uma chapa fotográfica. De fato, essa é a mais comum das aplicações desse tipo de radiação e a primeira a ser utilizada desde a descoberta desses raios. Porém, devido ao fenômeno da difração de raios-X, é possível estudar materiais em nível atômico, desvendando sua estrutura ${ }^{22}$.

Uma das principais técnicas de caracterização microestrutural de materiais cristalinos é a difratometria de raios- $\mathrm{X}$, aplicada em diversos campos do conhecimento, mais particularmente na engenharia e ciências de materiais, engenharias metalúrgica, química e de minas, além de geociências, dentre outros $^{23}$. 
O físico alemão Wilhelm Conrad Röntgen passou a estudar os chamados raios catódicos (utilizado para designar o fluxo de elétrons gerado no tubo) em 1894, e no ano seguinte começou a observar a radiação que chamaria de "Raios-X", por sua natureza desconhecida.

Percebendo que se tratava de algo novo, a radiação passou a ser estudada exaustivamente por ele, e dessa forma descobriu-se suas principais propriedades, como a propagação em linha reta (daí formar sombras bem delimitadas), alta capacidade de penetração, indiferença à campos magnéticos e capacidade de impressionar chapas fotográficas. Tais propriedades ora aconteciam com a luz, ora com os raios catódicos. Tentativas de verificar reflexão, refração ou difração foram feitas, sem sucesso. Assim, Röntgen supôs que era algo diferente de todas as radiações conhecidas, chegando a sugerir que fossem ondas eletromagnéticas longitudinais.

Laue a partir de 1912 estudou da difração dos raios-X em cristais, quando esteve discutindo aspectos da propagação da luz em cristais com P. P. Ewald, que estava desenvolvendo sua tese de doutorado sobre o assunto. Chamou a atenção de Laue o modelo teórico de Ewald para os cristais, que consistia em pequenos osciladores espaçados periodicamente em três dimensões, com distâncias da ordem de $10^{-8} \mathrm{~cm}$. Dos experimentos de Röntgen, Laue sabia que o comprimento de onda dos raios-X era dessa ordem. Logo, um cristal serviria como uma grade ideal para a difração dos raios-X.

William Henry Bragg e seu filho William Lawrence Bragg demonstraram a relação que passou a ser conhecida como lei de Bragg, fundamental para o estudo de estruturas cristalinas com o uso da difração de raios-X. 


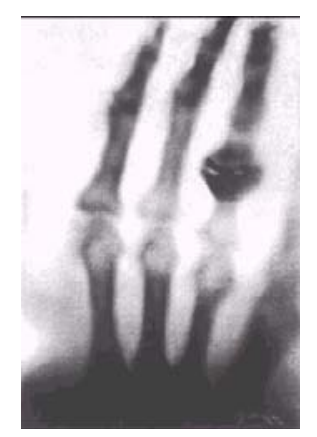

Figura 3-11: A clássica radiografia feita por Röntgen em 1895, mostrando a mão de sua esposa.

\subsubsection{A Técnica}

Uma das mais importantes aplicações da Difratometria de Raios-X é a identificação dos vários componentes puros de uma amostra policristalina. A validade e vantagens do método foram assinadas em 1916 por Debye e Scherrer na Alemanha e em 1917 por Hull em USA os quais chegaram às seguintes conclusões:

- o diagrama de difração é característico de cada substância;

- cada substância em uma mistura produz seu diagrama independentemente dos outro componente;

- $\quad$ o diagrama indica o estado da combinação química dos elementos do material;

- $\quad$ somente uma pequena quantidade de amostra é requerida;

- $\quad$ o método permite, com certas restrições, obter uma análise quantitativa de uma mistura de fases cristalinas ${ }^{24}$.

Este método consiste no registro da difração de raios-X monocromáticos produzida por uma amostra de pó. A amostra é um agregado de um grande 
número de cristais diminutos com orientações ao acaso. As reflexões ocorrem quando as orientações de vários destes cristais são tais que um conjunto particular de planos $(h k l)$ formam um ângulo $\theta$ com o feixe de raios-X, satisfazendo a Lei de Bragg (Equação 3.16) ${ }^{25}$.

$$
n \lambda=2 d \operatorname{sen}(\theta)
$$

onde $\lambda$ corresponde ao comprimento de onda da radiação incidente, $n$ a um número inteiro (ordem de difração), $d$ à distância interplanar para o conjunto de planos $h k l$ (índices de Miller) da estrutura cristalina e $\theta$ ao ângulo de incidência dos raios-X (medido entre o feixe incidente e os planos cristalinos) (Figura 3-12).

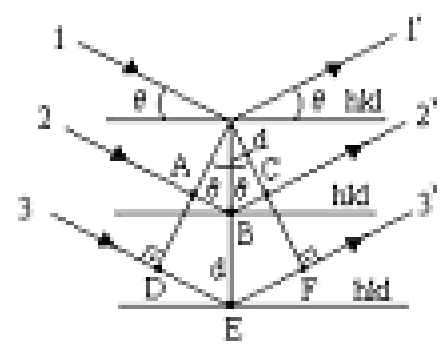

Figura 3-12: Representação da difração de Raios-X.

Cada reflexão presente em um diagrama de pó é medida em função do ângulo $\theta_{\text {hkl }}$ o que permite o cálculo da distância interplanar $d$ aplicada a relação (Equação 3.14). Deste modo, cada reflexão está representada por um valor $d$ específico, fazendo possível a interpretação dos diagramas de pó (com algumas dificuldades nos casos em que as posições de certas reflexões estão tão próximas que estas se superpõem). 
A aplicação deste método foi proposta por Hanawalt, Rinn e Frevel em 1938. Eles fizeram uma compilação de dados testados em mil compostos químicos que constituiriam padrões de referência para identificação de amostras de compostos desconhecidos. Eles sugeriam também um procedimento para preparar um arquivo de fichas destes dados de modo que a ficha que descrevesse um determinado composto pudesse ser facilmente localizada.

\subsubsection{Difratômetro de Raios-X}

Os difratômetros de raios-X disponíveis no mercado são dominados pela geometria parafocal Bragg-Brentano. Seu arranjo geométrico básico pode constituir-se de um goniômetro horizontal $(\theta-2 \theta)$ ou vertical $(\theta-2 \theta$ ou $\theta-\theta)$.

Para a geometria $\theta-2 \theta$ (Figura 3-13), o goniômetro, acoplado aos acessórios de recepção do feixe difratado, move-se $(H)$ com velocidade angular (20/passo) sobre o eixo $\mathrm{P}$ e rotacional a amostra $(\mathrm{P})$ com metade desta velocidade angular ( $\theta /$ passo). O raio do círculo do goniômetro é fixo, apresentando iguais distâncias do tubo gerador de raios-X à amostra e da amostra à fenda de recepção "D" (LP = PD). O plano do círculo focal contém os raios, incidente e difratado, isto é, a fonte, a amostra e a fenda de recepção. 


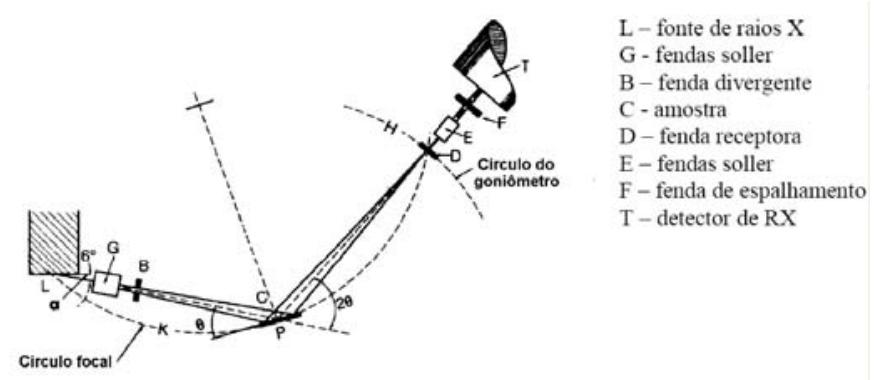

Figura 3-13: Geometria Bragg-Brentano de um difratômetro de raios- $X$, mostrando as diferentes fendas utilizadas.

A partir da fonte, os raios- $X$ atravessam a fenda Soller ou colimadores paralelos (G), a fenda de divergência (B) e irradiam a superfície da amostra (C). Os raios difratados em determinado ângulo $2 \theta$ convergem para a fenda de recepção (D). Antes ou depois da fenda de recepção pode ser colocado um segundo conjunto de colimadores (E) e uma fenda de espalhamento (F). Um monocromador do feixe difratado pode ser colocado após a fenda de recepção, na posição da fenda de espalhamento.

Em relação aos eletrólitos poliméricos, a presença de regiões cristalinas pode influenciar à movimentação do íon. Portanto, a técnica de difração de raios-X foi usada para verificar se os filmes obtidos possuem ou não regiões cristalinas.

As medidas de difração de raios-X foram feitas em um Difratômetro Universal de raios-X URD-6, CARL ZEISS JENA, à potência $\mu=40 \mathrm{KV} / 20 \mathrm{~mA}$ e $\lambda_{(\text {CuKa })}=1540 \AA$. Medidas da intensidade de difração foram feitas em um intervalo de ângulo de $5-40^{\circ}(2 \theta)$ à temperatura ambiente. 


\subsubsection{Análise Elementar}

A análise elementar foi realizada em equipamento analítico e de combustão. Com essa técnica é possível determinar as porcentagens dos átomos de carbono, hidrogênio, nitrogênio e enxofre. O teor de oxigênio, de modo geral, não é obtido diretamente, como regra ele é determinado por diferença. Através das porcentagens atômicas pode-se calcular a fórmula mínima dos compostos.

As análises elementares foram feitas utilizando equipamento da marca CE (Carlo Erba) Instruments, modelo EA 1110 CHNS-O, utilizando-se os padrões de L-cistina $\left(\mathrm{C}_{6} \mathrm{H}_{12} \mathrm{~N}_{2} \mathrm{O}_{4} \mathrm{~S}_{2}\right)$, DL-metionina $\left(\mathrm{C}_{5} \mathrm{H}_{11} \mathrm{NO}_{2} \mathrm{~S}\right)$, sulfanilamida $\left(\mathrm{C}_{6} \mathrm{H}_{8} \mathrm{~N}_{2} \mathrm{O}_{2} \mathrm{~S}\right)$ e BBOT $\left(\mathrm{C}_{26} \mathrm{H}_{26} \mathrm{~N}_{2} \mathrm{O}_{2} \mathrm{~S}\right)$.

\subsubsection{Microscopia Eletrônica de Varredura (MEV ou SEM)}

A microscopia eletrônica de varredura é utilizada em várias áreas de conhecimento, e é muito importante para a caracterização de polímeros.

A imagem eletrônica de varredura é formada pela incidência de um feixe de elétrons em uma amostra sólida e ocorrem alguns processos de interação entre eles, sob condições de vácuo. Os elétrons refletidos e os elétrons absorvidos são utilizados na microscopia eletrônica de varredura. O feixe incidente modula nos eixos $\mathrm{x}$ e y de modo a cobrir uma área da tela e essa área varrida na superfície da amostra, assim, quanto menor a área varrida maior o aumento. Raios-X também são gerados nessa interação entre elétron e a matéria, sendo que os mesmos são utilizados para identificar qualitativamente os elementos químicos presentes na amostra. 
O microscópio eletrônico de varredura é, sem dúvida, o microscópio mais versátil, devido às suas várias características. É geralmente utilizado para o estudo de estruturas superficiais ou sub superficiais de amostras com dimensões relativamente grandes. As imagens têm alta profundidade de foco, o que significa obter diferentes relevos da superfície da amostra simultaneamente em foco. São imagens tridimensionais e, portanto, mais fáceis de interpretar que as imagens de projeção de microscópio de transmissão. O MEV/SEM também produz imagens de alta resolução, o que garante obter alta ampliação de detalhes próximos e sem perda de nitidez. A preparação de amostras e a obtenção de imagens são relativamente simples. A combinação destas características justifica o fato do microscópio eletrônico de varredura ser hoje um dos equipamentos mais utilizados na pesquisa de materiais.

No microscópio eletrônico de varredura, a imagem é formada coletandose um sinal particular em função da posição do feixe sobre a amostra. No caso da detecção de elétrons secundários, que são os formadores mais comuns de imagem, é produzido um sinal elétrico a cada ponto varrido na superfície da amostra. Ao mesmo tempo, este sinal é varrido através da tela do tubo de raios catódicos (CRT), enquanto o brilho deste sinal é modulado por um amplificador de corrente do detector. A varredura do feixe de elétrons sobre a amostra é, portanto, sincronizada com a varredura do sinal intensificado no CRT, preservando assim a correspondência espacial entre a amostra e a imagem.

A determinação da ampliação da imagem é extremamente simples, uma vez que esta não envolve lentes. A ampliação linear é obtida pela razão entre o comprimento da varredura do sinal gerado na CRT e o comprimento da varredura do feixe sobre a amostra. Assim, uma área varrida na amostra de 
$100 \mu \mathrm{m}$ de comprimento e apresentada em uma imagem com $10 \mathrm{~cm}$ de comprimento na tela de um monitor, corresponde a uma ampliação de 1000 vezes.

Na microscopia eletrônica de varredura os sinais de maior interesse para a formação da imagem são os elétrons secundários e os retro-espalhados. A medida que o feixe de elétrons primários vai varrendo a amostra estes sinais vão sofrendo modificações de acordo com as variações da superfície. Os elétrons secundários fornecem imagem de topografia da superfície da amostra e são os responsáveis pela obtenção das imagens de alta resolução, já os retro-espalhados fornecem imagem característica de variação de composição.

O MEVISEM se tornou um instrumento imprescindível nas mais diversas áreas: eletrônica, geologia, ciência e engenharia dos materiais, ciências da vida, etc. Em particular, o desenvolvimento de novos materiais tem exigido um número de informações bastante detalhado das características microestruturais só possível de ser observado no MEV/SEM. Podemos afirmar que onde haja um grupo de desenvolvimento de materiais, há a necessidade de um MEV/SEM para as observações microestruturais.

\subsubsection{Componentes do MEV}

O MEV, conforme pode ser visto na Figura 3-14, consiste basicamente da coluna óptico-eletrônica (canhão de elétrons e sistema de redução do diâmetro do feixe de elétrons), da unidade de varredura, da câmara de amostra, do sistema de detectores e do sistema de visualização da imagem. 


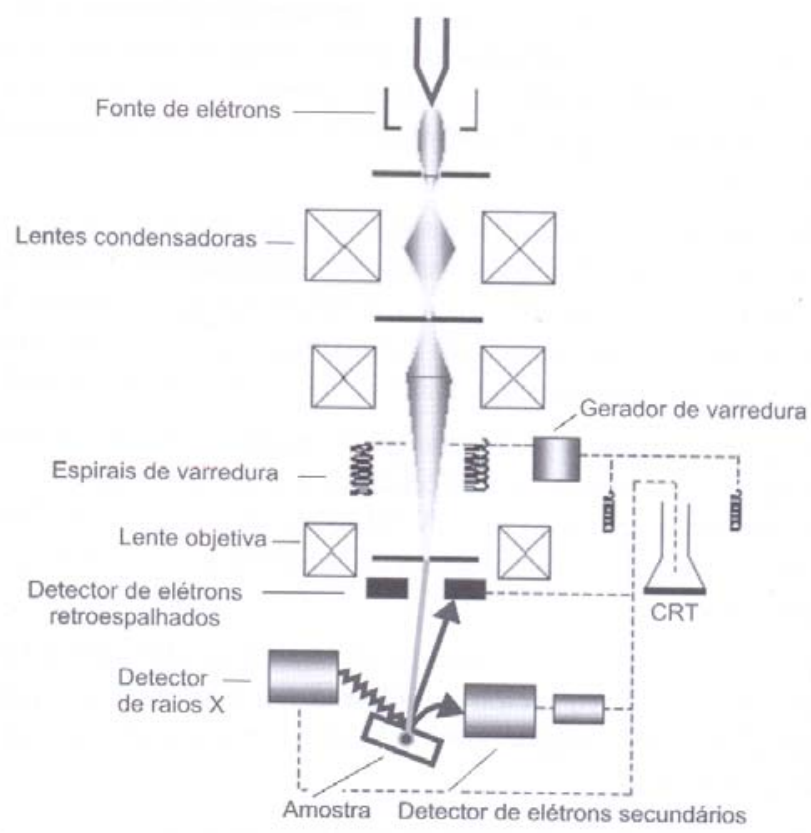

Figura 3-14: Diagrama esquemático mostrando os principais componentes de um microscópio eletrônico de varredura ${ }^{26}$.

O canhão de elétrons é o conjunto de componentes cuja finalidade é a produção dos elétrons e a sua aceleração para o interior da coluna. Este feixe de elétrons deve ser estável e com intensidade suficiente para que ao atingir a amostra possa produzir um bom sinal. O diâmetro do feixe produzido diretamente pelo canhão de elétrons é muito grosseiro para produzir uma boa imagem em grandes aumentos e por isso precisa ser reduzido pelas condensadoras (lentes eletromagnéticas). A maioria dos MEV é capaz de produzir um feixe de elétrons que ao atingir a amostra tenha um diâmetro da ordem de $10 \mathrm{~nm}(100 \AA)$ e que ainda possua corrente suficiente para formar uma imagem com boa resolução.

Para que uma fonte de elétrons (filamento) seja considerada uma boa fonte, alguns parâmetros de desempenho devem ser respeitados: densidade de corrente, brilho, tempo de vida, tamanho e estabilidade da fonte. 
O filamento de tungstênio vem sendo a fonte mais utilizada nos últimos 50 anos pela maioria dos microscópios eletrônicos, apesar da existência de outras fontes emissoras; como o hexaboreto de lantâneo $\left(\mathrm{LaB}_{6}\right)$ e o Field Emission Gun (FEG) (Figura 3-15), que apresentam brilho mais intenso. Isto é conseqüência do seu baixo custo aliado ao seu bom desempenho. Em aplicações onde o alto brilho da fonte não é muito necessário, como para médios aumentos (na faixa de 10000x e que são os aumentos normalmente usados para a análise de materiais), e onde se deseja um feixe bastante estável (caso da microanálise), o filamento de tungstênio pode ser considerado como a melhor opção de fonte.

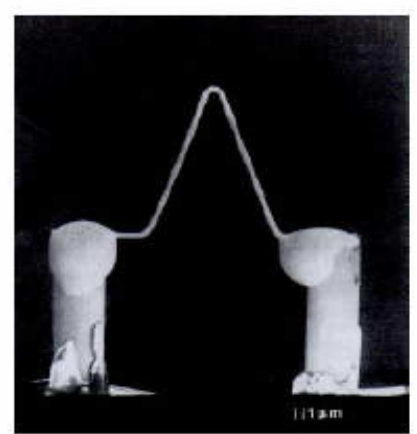

(a)

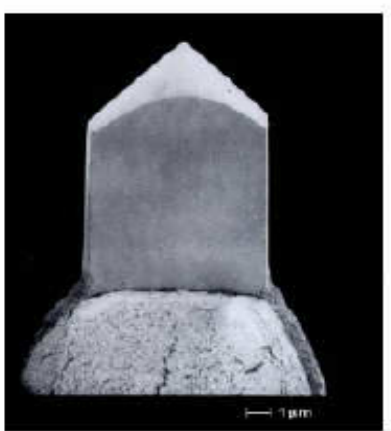

(b)

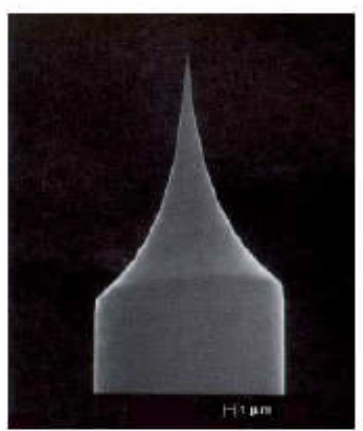

(c)

Figura 3-15: Micrografias eletrônicas de filamentos de (a) W, (b) $\mathrm{LaB}_{6} \mathrm{e}$ (c) $\mathrm{FEG}^{27}$.

Os elétrons podem ser focados pela ação de um campo eletrostático ou de um campo magnético. A primeira focagem dos elétrons dentro do canhão e que resultou no "crossover" é realizada pela ação de um campo eletrostático. As demais lentes dentro da coluna, na grande maioria dos microscópios, são lentes eletromagnéticas. Essas lentes são as mais usadas, pois apresentam menor coeficiente de aberração. Mesmo com a focagem magnética, as lentes 
eletrônicas são bem menos eficientes do que as lentes de vidro para focar a luz. Algumas aberrações que podem ser corrigidas com as lentes de vidro não são possíveis com as lentes eletrônicas.

Fazem parte do sistema de lentes três condensadoras, sendo a última chamada de objetiva. As duas primeiras condensadoras atuam no sentido de colimar o feixe de elétrons primários o máximo possível, demagnificando a imagem do "crossover", enquanto que a objetiva atua no sentido de reduzir aberrações esféricas. Normalmente as lentes condensadoras e a objetiva são controladas automática e simultaneamente. A lente eletromagnética consiste num cilindro de ferro com um furo central através do qual passa o eixo óptico eletrônico do microscópio. No interior do cilindro, e envolvendo o eixo óptico existem muitas bobinas de cobre (Figura 3-16) através da qual circula uma corrente quando a lente está em operação. Esta configuração cria um campo magnético homogêneo no centro do cilindro com o campo magnético na direção norte - sul.

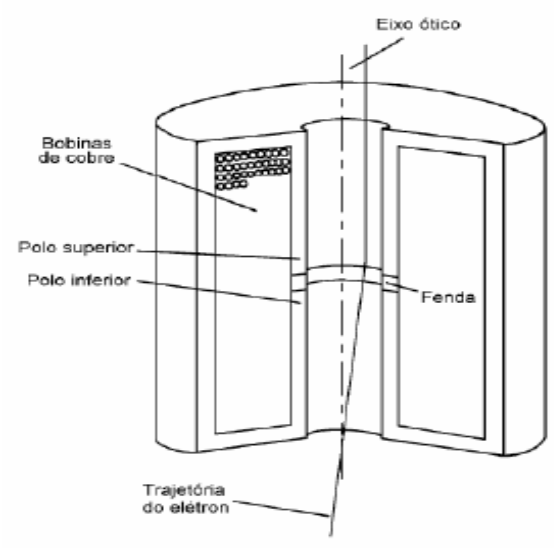

Figura 3-16: Diagrama esquemático de uma lente eletromagnética.

A última lente da coluna é a objetiva, cujo principal papel é focar a imagem variando a distância focal do feixe eletrônico ao longo do eixo óptico 
(eixo Z) da coluna. Como a lente objetiva é a lente mais potente do MEV, com uma intensa corrente fluindo através de suas bobinas, ela normalmente precisa ser refrigerada. Esta lente normalmente contém as bobinas defletoras, as bobinas de correção do astigmatismo e a abertura final.

Como resultado da deflexão não ideal da lente magnética, erros ópticos na formação do feixe são introduzidos. Esses erros são conhecidos como aberrações e causam uma defasagem dos raios eletrônicos no foco. Como resultado a imagem fica desfocada. As três principais aberrações das lentes eletromagnéticas são: astigmatismo, aberração esférica e aberração cromática.

\subsubsection{Varredura do Feixe de Elétrons}

A varredura do feixe de elétrons pelas bobinas defletoras é também acompanhada pela deflexão de sua imagem no vídeo. O aumento da varredura da imagem é simplesmente a relação entre o tamanho da imagem no vídeo pelo tamanho da área varrida na amostra. Como o tamanho da imagem do vídeo não varia, as bobinas de deflexão é que serão as responsáveis pelo aumento da amostra. Quanto maior o aumento, menor a região varrida e menor a deflexão do feixe (Figura 3-17).

É muito importante o fato de se poder variar o aumento da imagem somente variando a área varrida sem ter que modificar outros parâmetros do MEV. Uma conseqüência é a possibilidade de o operador selecionar um aumento maior do que o desejado para a imagem, podendo então focar adequadamente o feixe na amostra e com isso obter um foco correto. 


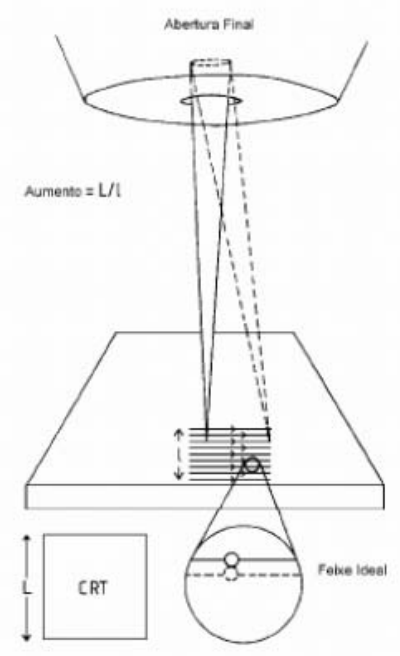

Figura 3-17: Esquema da varredura do feixe de elétrons ${ }^{27}$.

Conforme pode ser observado na Figura 3-17, o tamanho do feixe considerado ideal, para um determinado aumento, é aquele cujas bordas do feixe tocam levemente a linha anteriormente varrida. Se o diâmetro do feixe é muito grande, ocorre uma sobreposição das linhas varridas e o resultado é uma imagem fora de foco.

A outra situação é quando o diâmetro do feixe é muito pequeno. Neste caso ao reduzir o diâmetro do feixe pelo ajuste da corrente nas lentes condensadoras, o número de elétrons no feixe, e, consequentemente, o número de elétrons que irão interagir com a amostra é também reduzido. Isto significa que para obter o mesmo brilho na imagem, como seria com o feixe ideal, o sinal reduzido precisa ser amplificado, resultando em aumento de ruído eletrônico. Outra conseqüência do tamanho do feixe muito pequeno é que algumas áreas da amostra, onde as bordas do feixe não se encontram não serão varridas pelo feixe de elétrons.

Quando a voltagem de aceleração do feixe primário é diminuída, o circuito eletrônico automaticamente compensa a corrente das lentes de tal 
maneira a acomodar esses elétrons menos energéticos e manter as mesmas condições de demagnificação do feixe e de foco como as que se tinha para elevada voltagem. Entretanto, esses elétrons menos energéticos são mais sujeitos a aberrações ópticas (aberrações cromáticas) e mais sensíveis a pequenas variações do campo magnético.

\subsubsection{Interações Elétrons-Amostra}

O elétron do feixe eletrônico ao atingir a superfície da amostra irá interagir com os átomos da amostra. Como conseqüência da presença do potencial atômico e nuclear da amostra este elétron sofrerá modificação na sua velocidade inicial. Esta variação da velocidade pode ser somente na direção ou pode ocorrer tanto na direção quanto no módulo (magnitude). As interações nas quais ocorre a mudança na trajetória do elétron, sem que ocorra variação na sua energia cinética são ditas interações elásticas. Aquelas em que há transferência de energia do elétron primário para os átomos da amostra são chamadas de interações inelásticas.

A profundidade de penetração dos elétrons depende da composição do material a qual influencia tanto o espalhamento elástico quanto o inelástico. Em particular o espalhamento inelástico, que causa a redução da velocidade, é mais intenso para materiais com elevado número atômico $(Z)$ do que para materiais com baixo Z. Isso significa que apesar do espalhamento elástico aumentar para materiais com elevado Z, a profundidade de penetração é menor do que para baixo número atômico. Com base em modelos de probabilidade de ocorrência de espalhamentos elásticos e inelásticos, foi criada 
a simulação de Monte-Carlo, onde são definidos os ângulos de espalhamento e transferência de energia. Através desta simulação as direções aleatórias dos elétrons no interior da amostra são calculadas e estatisticamente os caminhos mais prováveis obtidos, resultando numa boa aproximação do volume de interações. Alguns desses tipos de simulação são mostrados na Figura 3-18 para o C, Fe, Ag e Au.
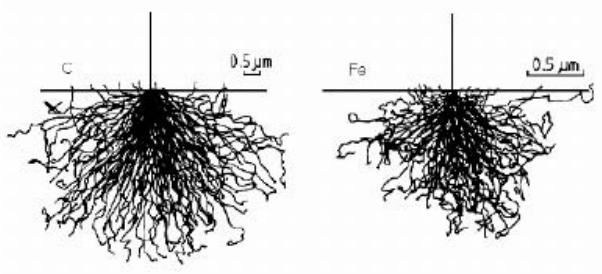

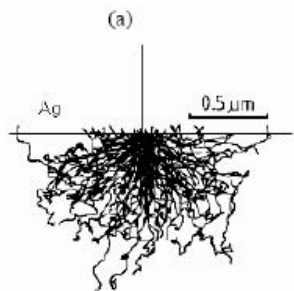

(c)

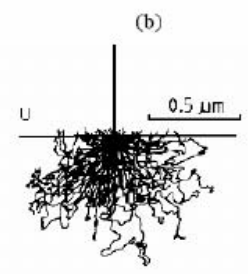

(d)

Figura 3-18: Simulação de Monte-Carlo para o volume de interação de amostra de Carbono (a), Ferro (b), Prata (c) e Ouro (d) com o feixe de elétrons primários de 20 $\mathrm{keV}^{27}$.

Analisando os aumentos destas figuras, observa-se que existe uma grande influência no valor de $Z$ do material com o volume de interação. Neste caso, onde a energia do feixe de elétrons primários é de $20 \mathrm{keV}$, a profundidade de penetração para o caso do carbono é de $3 \mu \mathrm{m}$ e para a prata é de $0,7 \mu \mathrm{m}$.

A forma do volume de interação também é influenciada pela estrutura interna do material. Por exemplo, num material com estrutura cristalina, os 
elétrons penetram por determinados canais preferenciais, sem muita perda de sua energia interna. Se a direção destes canais for à mesma dos elétrons primários, haverá um aumento na profundidade de penetração.

\subsubsection{Resolução espacial}

Na microscopia eletrônica de varredura o sinal que fornece a imagem de maior resolução é a dos elétrons secundários. Isto é resultado da profundidade de onde são originados os sinais, ou seja, do volume de interação. O volume de interação pode ser descrito como tendo a forma de uma pêra (ou de uma gota), conforme pode ser visto na Figura 3-19 28 .

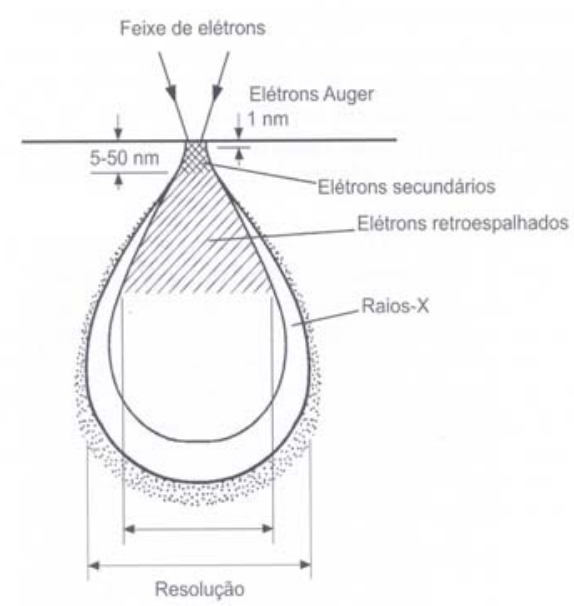

Figura 3-19: Volume de interação e origem de alguns sinais ${ }^{26}$.

Para os sinais provenientes da região mais superficial da amostra a resolução é maior, pois o sinal vem de uma área cuja seção transversal se aproxima do diâmetro do feixe. Portanto, reduzindo o diâmetro do feixe eletrônico, irá resultar num sinal de elétrons secundários com melhor resolução 
(maiores aumentos), considerando que outros fatores como a relação sinal/ruído não sejam problemas.

O detector mais usado na microscopia eletrônica de varredura é o detector do tipo Everhart-Thornley (ET). O detector é formado pelo cintilador, tubo de luz e a fotomultiplicadora. O detector é isolado eletricamente do resto do microscópio e possui na sua frente uma grade com potencial de $+300 \mathrm{eV}$. Os elétrons secundários (ES), que possuem energia inferior a $50 \mathrm{eV}$, são atraídos por esta grade carregada positivamente.

O detector de ES é bastante eficiente sem ser obstrutivo e as imagens de ES são aparentemente fáceis de interpretar. É basicamente por esta razão que a imagem de elétrons secundários é a mais comumente usada na microscopia eletrônica de varredura.

Em adição aos elétrons secundários, elétrons retro-espalhados (essencialmente elétrons primários elasticamente espalhados) podem também ser detectados. Eles podem ser utilizados para detectar ambos os detalhes topológicos e de composição, embora, devido às suas altas energias (aproximadamente a mesma do feixe primário), estes elétrons possam ser espalhados de regiões muito profundas dentro da amostra. Isto resulta num menor contraste topológico do que no caso dos elétrons secundários.

Contudo, a probabilidade de retro-espalhamento é uma função que varia pouco com o número atômico e, portanto, observa-se algum contraste entre áreas com diferentes composições químicas, especialmente quando o número atômico médio de diferentes regiões é bastante diferente.

Adicionalmente, elétrons retro-espalhados não podem ser "coletados" com um detector padrão de elétrons secundários. O uso de um detector 
específico para o retro-espalhamento aumenta significativamente a coleção de elétrons retro-espalhados, por meio de uma melhora na localização do detector e pelo uso de um design de detecção que é sensível somente aos elétrons retro-espalhados altamente energéticos. Há menos elétrons retro-espalhados emitidos de uma amostra do que elétrons secundários. O detector padrão de elétrons secundários possui baixa eficiência geométrica, já que está localizado em um lado da amostra e é altamente direcional em sua coleção. Colocando-se um detector de retro-espalhamento sobre a amostra num arranjo em forma toroidal, com o feixe de elétrons passando pelo seu orifício, aumenta-se significativamente o ângulo sólido de coleção e reduzem-se os efeitos de trajetória associados aos elétrons retro-espalhados.

\subsubsection{Espectroscopia de Energia Dispersiva de Raios-X (EDS)}

A interação do feixe de elétrons do MEV com a amostra causa a liberação de elétrons secundários, raios-X característicos dos elementos químicos presentes na amostra e vários outros tipos de radiação. Na técnica de EDS, o espectro de raios-X emitido pela amostra é analisado.

Quando a amostra é submetida ao feixe eletrônico do MEV, elétrons são ejetados dos átomos que compreendem a amostra, criando-se vacâncias que são ocupadas por elétrons inicialmente em níveis mais energéticos. Em conseqüência, raios-X são emitidos para balancear a diferença de energia entre os dois elétrons como mostrado na Figura 3-20. Um elétron da camada $\mathrm{K}$ é removido mediante energia fornecida pelo feixe de elétrons de análise, em seguida um elétron da camada $\mathrm{L}$ decai para a camada $\mathrm{K}$ com conseqüente 
emissão de fóton com energia correspondente à diferença de energia entre as camadas $\mathrm{K}$ e L, ou seja, um raio- $\mathrm{X}^{29}$.

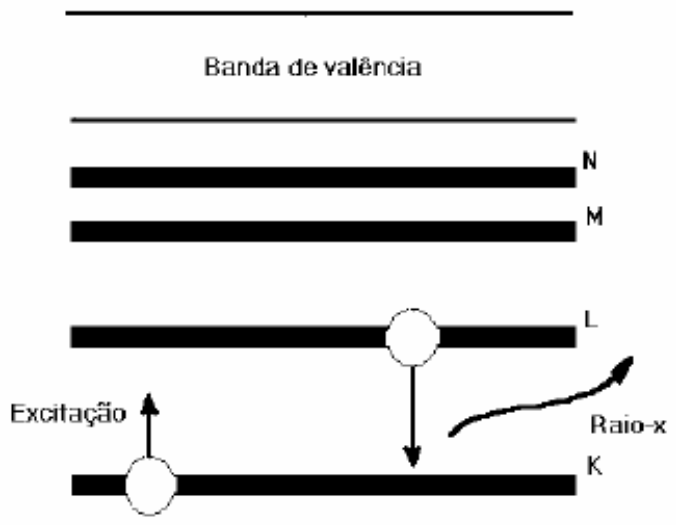

Figura 3-20: llustração do processo associado às medidas de EDS ${ }^{29}$.

O detector de raios-X de um equipamento de EDS mede o número de raios-X emitidos pela correspondente energia. A energia dos raios-X é característica do elemento do qual foi emitido. Um espectro da energia versus contagens relativas dos raios- $\mathrm{X}$ detectados é obtido e pode ser utilizado para estudos qualitativos e quantitativos dos elementos presentes na amostra estudada. Usualmente, a resolução espacial de um equipamento de EDS é de $\sim 1 \mu \mathrm{m}$, com uma sensibilidade da ordem de $10^{-12} \mathrm{~g}$, em um volume de aproximadamente $10 \mu \mathrm{m}^{3}$.

A técnica de microscopia eletrônica de varredura foi utilizada nos filmes produzidos para identificar a morfologia e orientação do polímero, além de homogeneidade, dissolução de substâncias e a aparência microscópica dos filmes.

A morfologia dos eletrólitos foi analisada em um microscópio eletrônico de varredura digital marca LEO modelo 440 . Os filmes foram colocados em porta-amostras de alumínio, colados com uma fita de carbono e recobertos 
com ouro. A corrente do feixe utilizado foi de $1 \mathrm{pA}$ e a potência do feixe de $15 \mathrm{kV}$.

\subsubsection{Análise Térmica}

A definição usualmente aceita para análise térmica foi originalmente proposta pelo Comitê de Nomenclatura da Confederação Internacional de Análises Térmicas (ICTA) sendo, subseqüentemente, adotada tanto pela União Internacional de Química Pura e Aplicada (IUPAC) quanto pela Sociedade Americana de Testes de Materiais (ASTM) ${ }^{30}$.

Segundo Mackenzie (1979), a análise térmica pode ser definida como:

Um grupo de técnicas nas quais uma propriedade física de uma substância e/ou seus produtos de reação é medida, enquanto a amostra é submetida a uma programação de temperatura ${ }^{31}$.

Existem várias técnicas termo analíticas cada qual associada a uma determinada propriedade física. A Tabela 3-2 apresenta as mais utilizadas.

Tabela 3-2: Classificações de algumas técnicas termo analíticas ${ }^{32}$

\begin{tabular}{|c|c|c|}
\hline Propriedade & Técnica & Sigla \\
\hline \multirow{2}{*}{ Massa } & Termogravimetria & TG \\
\cline { 2 - 3 } & $\begin{array}{c}\text { Derivada da } \\
\text { termogravimetria }\end{array}$ & DTG \\
\hline Temperatura & $\begin{array}{c}\text { Análise térmica } \\
\text { diferencial }\end{array}$ & DTA \\
\hline Entalpia & $\begin{array}{c}\text { Calorimetria exploratória } \\
\text { diferencial }\end{array}$ & DSC \\
\hline Dimensões & Termodilatometria & TD \\
\hline $\begin{array}{c}\text { Características } \\
\text { mecânicas }\end{array}$ & $\begin{array}{c}\text { Analise termomecânica } \\
\text { dinâmica }\end{array}$ & DMA \\
\cline { 2 - 3 } & Analise termomecânica & TMA \\
\hline
\end{tabular}


lonashiro e Giolito $^{33}$ apresentaram padrões para nomenclatura e abreviaturas das técnicas termo analíticas em português.

Todos os instrumentos de análise térmica têm características em comum. De maneira geral, o que os diferencia é o tipo de transdutor empregado na sua construção, que tem a função de converter as propriedades físicas avaliadas em sinais elétricos. A Figura 3-21 ilustra um esquema representativo de um analisador térmico. Ele é constituído por um forno (célula de medida) em que a amostra é aquecida (ou resfriada) a uma taxa controlada, sob atmosfera previamente estabelecida. As mudanças das propriedades da amostra são monitoradas por um transdutor seletivo que pode ser constituído por: a) termopares; b) balança; c) sensor calorimétrico; d) medidor de deslocamento; e) detector de gás. O transdutor gera um sinal elétrico que é amplificado e transferido para a unidade controladora mantendo a comunicação permanente com a célula de medida. Esta unidade, além de receber os dados da célula de medidas, transfere as informações necessárias para colocar o equipamento em operação de acordo com os parâmetros (faixa temperatura, razão de aquecimento, tipo de atmosfera) previamente estabelecidos. A unidade controladora é interfaceada a um microcomputador que controla a operação, a aquisição e análise de dados e o registro da curva termo analítica gerada. No exemplo ilustrado, tem-se o registro simultâneo das curvas de termogravimetria/ termogravimetria derivada (TG/DTG) e de análise térmica diferencial (DTA), de onde se pode deduzir que nesse hipotético experimento foram empregados durante 0 processo térmico como transdutores, simultaneamente, a balança (avaliação da variação da massa da amostra) e os 
termopares (avaliação das temperaturas da amostra e do material de referência, permitindo identificar variações entálpicas) ${ }^{34}$.

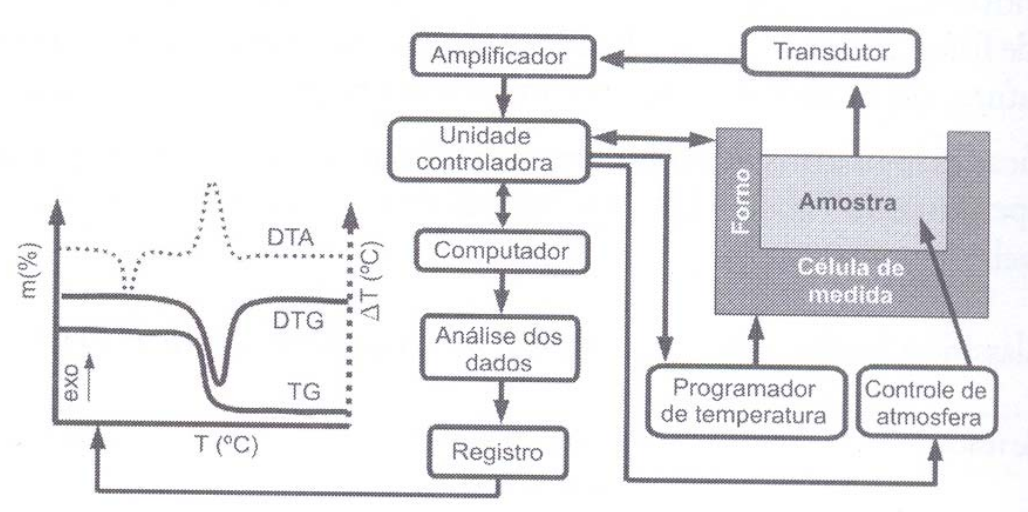

Figura 3-21: Esquema representativo de um analisador térmico.

A análise térmica é aplicada a uma grande variedade de materiais e para o desenvolvimento de uma enorme variabilidade de estudos. É difícil encontrar uma área da ciência e tecnologia em que as técnicas termo analíticas não foram ou não podem ser aplicadas ${ }^{32}$.

As técnicas termo analíticas usadas neste trabalho foram Termogravimetria (TG), Termogravimetria Derivada (DTG) e Calorimetria Exploratória Diferencial (DSC), que serão descritas brevemente a seguir.

\subsubsection{Termogravimetria (TG)}

\subsubsection{Histórico}

Os componentes básicos da TG existem a milhares de anos. Sepulturas e tumbas no antigo Egito (2500 A.C) tem em suas paredes representações esculpidas e pintadas tanto da balança quanto do fogo. Entretanto, centenas de 
anos se passaram antes que estes fossem ligados em um processo, sendo então utilizados no estudo do refinamento do ouro durante o século XIV. O desenvolvimento da TG moderna foi impulsionado pela determinação do raio de estabilidade de vários precipitados utilizados na análise química gravimétrica. Este aspecto alcançou seu apogeu sob Duval (1963), quem estudou mais de mil destes precipitados e desenvolveu um método analítico automatizado baseado na TG.

Honda (1915) levou a posterior fundação da moderna TG quando, utilizando uma "termobalança", conclui suas investigações em $\mathrm{MnSO}_{4} \cdot \mathrm{H}_{2} \mathrm{O}$, $\mathrm{CaCO}_{3}$, e $\mathrm{CrO}_{3}$ com uma declaração modesta, "Todos os resultados dados não são inteiramente originais; a presente investigação com a termobalança tem, entretanto, revelado a exata posição da mudança da estrutura e também da velocidade das mudanças nas respectivas temperaturas".

Outras termobalanças, até mesmo mais antigas, foram construídas por Nernst e Riesenfeld (1903), Brill (1905), Truchot (1907), e Urbain e Boulanger (1912). O primeiro instrumento comercial em 1945 foi baseado no trabalho de Chevenard e outros. (1954). A maioria das termobalanças, exceto a desenvolvida por Chevenard, foi feita por investigadores individuais. $O$ derivatógrafo, criado por Erdey e outros (1956), introduziu a medição simultânea da TG/DTA. Garn (1962) adaptou com sucesso a balança gravadora Ainsworth para a TG até $1600^{\circ} \mathrm{C}$ em várias atmosferas controladas. Similarmente, uma balança Sartorius foi modificada para TG incluindo mudanças automáticas de peso. O advento da balança automática moderna começou com a introdução da eletrobalança por Cahn e Schultz (1963). Esta 
balança tem uma sensibilidade de $0,1 \mu \mathrm{g}$ e a precisão de 1 parte em $10^{5}$ de mudança de massa ${ }^{35}$.

\subsubsection{A Técnica}

A termogravimetria (TG) é definida como uma técnica termoanalítica na qual a variação da massa da amostra (perda ou ganho) é determinada em função da temperatura e/ou tempo, enquanto a amostra é submetida a uma programação controlada de temperatura. Uma pequena quantidade de amostra é colocada em um suporte de alumina (cadinho), onde sua massa é constantemente monitorada por uma termobalança. Esta técnica é utilizada para conhecer as alterações que o aquecimento pode provocar na massa das substâncias, permitindo estabelecer a faixa de temperatura em que elas adquirem composição química fixa, definida e constante, a temperatura em que começam a se decompor, acompanhar 0 andamento de reações de desidratação, oxidação, combustão, decomposição, etc.

Os resultados da análise são mostrados sob a forma de gráficos denominados curvas termogravimétricas, cuja abcissa contém os registros de temperatura (ou do tempo) e a ordenada, o percentual em massa.

\subsubsection{Aplicações da TG}

Dentre as inúmeras aplicações existentes da termogravimetria destacam-se: 
$\checkmark \quad$ Calcinação e torrefação de minerais;

$\checkmark \quad$ Corrosão de materiais em várias atmosferas;

$\checkmark \quad$ Curvas de adsorção e dessorção;

$\checkmark \quad$ Decomposição de materiais explosivos;

$\checkmark \quad$ Degradação térmica oxidativa de substâncias poliméricas;

$\checkmark$ Desenvolvimento de processos gravimétricos analíticos (peso constante);

$\checkmark$ Decomposição térmica ou pirólise de materiais orgânicos, inorgânicos e biológicos;

$\checkmark \quad$ Destilação e evaporação de líquidos;

$\checkmark \quad$ Determinação da pressão de vapor e entalpia de vaporização de aditivos voláteis;

$\checkmark$ Determinação da umidade, volatilidade, e composição de cinzas;

$\checkmark \quad$ Estudo da cinética das reações envolvendo espécies voláteis;

$\checkmark \quad$ Estudo da desidratação e da higroscopicidade;

$\checkmark \quad$ Identificação de polímeros novos, conhecidos e intermediários;

$\checkmark \quad$ Propriedades magnéticas como temperatura Curie, suscetibilidade magnética;

$\checkmark \quad$ Reações no estado sólido que liberam produtos voláteis;

$\checkmark \quad$ Taxas de evaporação e sublimação.

Esta técnica foi utilizada nos eletrólitos poliméricos para estudar as alterações que o aquecimento pode provocar na massa das substâncias, permitindo estabelecer a faixa de temperatura em que elas tem composição química fixa, definida e constante, a temperatura em que começam a se 
decompor, acompanhar o andamento de reações de desidratação, oxidação, combustão, decomposição, etc.

\subsubsection{Cadinhos de TG}

O tipo de cadinho utilizado depende da temperatura máxima de exposição, da natureza química da amostra, da sua quantidade e reatividade.

Em função das características da análise e da amostra a analisar, o material utilizado para confeccionar o cadinho pode ser de: platina, alumina, quartzo ou vidro. Os cadinhos para amostra em pó são achatados, mas, para evitar inchamento ou projeções, é mais indicado o uso de cadinhos com paredes mais altas, conforme a Figura 3-22.

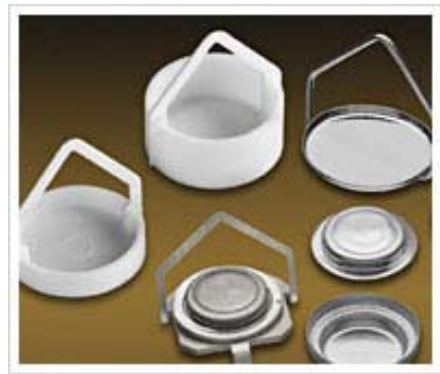

Figura 3-22: Exemplos de cadinhos utilizados na $\mathrm{TG}^{36}$.

As curvas de TG foram obtidas em um equipamento da TA Instruments modelo TGA 2650, em atmosfera de nitrogênio com fluxo de $50 \mathrm{~mL} / \mathrm{min}$, colocou-se aproximadamente $5 \mathrm{mg}$ de amostra em um cadinho/panelinha de alumina. As análises foram efetuadas com uma programação de temperatura controlada de $30^{\circ} \mathrm{C}$ à $800^{\circ} \mathrm{C}$ com um taxa de aquecimento de $10^{\circ} \mathrm{C} / \mathrm{min}$. 


\subsubsection{Calorimetria Exploratória Diferencial (DSC)}

\subsubsection{Histórico}

Dispositivos precisos de medição de temperatura, como termopares, termômetros de resistência, e pirômetro óptico, estavam todos completamente estabelecidos na Europa ao final do século XIX. Como resultado, foi inevitável que eles fossem logo aplicados em sistemas químicos a elevadas temperaturas. Então, Le Chatelier (1887), um estudioso tanto de mineralogia quanto de pirometria, introduziu o uso de curvas apresentando mudanças nas taxas de aquecimento como uma função do tempo, $\mathrm{dT}_{\mathrm{s}} / \mathrm{dt}$ versus $\mathrm{t}$, para identificar argilas.

O método diferencial de temperatura, no qual a temperatura da amostra é comparada a uma amostra inerte de referência, foi concebido por um metalurgista Inglês, Roberts-Austin (1889). Esta técnica eliminava os efeitos da taxa de aquecimento e outros distúrbios externos que poderiam mudar a temperatura da amostra. Ele também suprime a alta temperatura de ambos os materiais, possibilitando a captação e ampliação de sinais menores.

Um segundo termopar foi colocado na substância inerte estando suficientemente afastado da amostra de modo a não sofrer sua influência. A diferença de temperatura, $\Delta \mathrm{T}$ ou $\mathrm{T}$ - Ti, era observada diretamente no galvanômetro enquanto um segundo galvanômetro mostrava a temperatura da amostra. Saladin (1904) aperfeiçoou este método através do desenvolvimento de um gravador fotográfico da $\Delta \mathrm{T}$ versus Ti. Um gravador fotográfico versátil baseado em um cilindro em rotação foi desenvolvido por Kurnakov (1904). Este 
instrumento foi extensivamente utilizado por pesquisadores russos durante muitos anos colaborando para a formação de seu grupo ativo em DTA.

Argilas e minerais de silicato formavam o assunto principal dos estudos iniciais baseados na DTA, entendendo-se pelos próximos 40 anos. Por causa das aplicações predominantemente geológicas a DTA foi desenvolvida primeiramente por ceramistas, mineralogistas, cientistas do solo, e outros geologistas.

A era moderna da instrumentação para a DTA começou com a introdução por Stone (1951) de um instrumento de controle dinâmico de atmosferas. Este sistema permitiu o fluxo de um gás ou vapor através do suporte da amostra durante o processo de aquecimento ou resfriamento. As pressões parciais dos componentes ativos na fase gasosa podiam ser controladas durante o ensaio de DTA. O efeito da atmosfera em relação a uma reação podia agora ser efetivamente estudado.

Vários instrumentos novos e modificações foram desenvolvidos durante a década de 60. A maior inovação foi o desenvolvimento da calorimetria diferencial de varredura (DSC) por Perkin-Elmer Co. (1964). Outros sistemas notáveis foram desenvolvidos por Mettler-Toledo, DuPont, NETZSCH, Setaram, TA Instruments e outras companhias.

Em tempos mais recentes a rápida evolução dos polímeros e plásticos, em particular, foi impulsionada pelo desenvolvimento da técnica e instrumentos. Medidas precisas, rápidas, e simples de fenômenos como temperatura de fusão, transição vítrea, e cristalização, bem como a habilidade de acompanhar processos de cura, degradação, e oxidação de polímeros e materiais associados têm levado a uma ampla aceitação das análises térmicas. 
Não obstante, as análises qualitativas e quantitativas dos gases evolvidos durante todo o processo térmico, nas análises de, como exemplo, TG, DTA e DSC são inteiramente possível.

De fato, esta caracterização e qualificação dos gases envolvidos são classificadas como uma análise térmica, conhecida como EGA (Evolved Gas Analysis) e sua quantificação é possível através da técnica de pulso (PTA Pulse Thermal Analysis) aliada ao sistema de espectrometria de massa (MS Mass Spectrometry) que são acoplados junto à saída dinâmica de gás dos aparelhos de TG, DTA, DSC, STA, etc ${ }^{33}$.

\subsubsection{A Técnica}

A Calorimetria exploratória diferencial (DSC) é uma técnica termoanalítica na qual se mede a diferença de energia fornecida à uma substância e a um material de referência, em função da temperatura enquanto a substância e o material são submetidos a uma programação controlada de temperatura.

O termo calorimetria exploratória diferencial tem sido motivo de confusão em análise térmica, devido aos diferentes tipos de equipamentos que usam o mesmo nome. Estes instrumentos são baseados em condições, que podem ser divididas em dois grandes grupos:

- DSC por compensação de potência: arranjo no qual a referência e a amostra são mantidas na mesma temperatura, através de aquecedores elétricos individuais. O primeiro controla a temperatura média entre a amostra e a referencia, de forma que o aquecimento ou resfriamento possa ser feito à 
velocidade controlada. O segundo garante que se há diferença de temperatura entre amostra e referência, devido a processos endotérmicos ou exotérmicos, a potência nos aquecedores é ajustada de forma a restaurar o equilíbrio, onde é mantida a mesma temperatura para a amostra e para a referência por meio de ajustes contínuos e automáticos de potencia.

- DSC por fluxo de calor: arranjo mais simples no qual a amostra e a referência, contidas em seus respectivos suportes de amostra, são colocados sobre um disco de metal. A troca de calor entre o forno e a amostra ocorre preferencialmente pelo disco. Para uma condição de fluxo de calor de estado estacionário, o sinal medido $\Delta \mathrm{T}$ (diferença de temperatura) é proporcional à diferença nos fluxos de calor $\Delta \Phi$, entre a amostra, $\Phi$ a, e referencia $\Phi$, e é representado pela (Equação 3.17):

$$
\Delta \phi=\phi a-\phi r=-\mathrm{k} \Delta \mathrm{T}
$$

Um processo endotérmico na amostra cria um $\Delta \mathrm{T}<0$ e um $\Delta \phi>0$, ou seja, flui calor do disco para a amostra. No processo exotérmico acontece inverso do que foi descrito acima. A constante $\mathrm{K}$ deve ser determinada por calibração, usando-se padrões com uma constante física conhecida, como por exemplo, entalpia de fusão.

Os limites de temperatura podem variar de um equipamento para outro, mas geralmente se encontram na faixa de $-180^{\circ} \mathrm{C}$ a $725^{\circ} \mathrm{C}$.

Com essa técnica pode-se estudar as transições térmicas de materiais tais como: temperatura de transição vítrea $\left(T_{g}\right)$, temperatura de fusão $\left(T_{f}\right)$ e temperatura de cristalização $\left(T_{x}\right)^{30}$. 


\subsubsection{Fatores que interferem nas curvas DSC}

A confiabilidade e reprodutibilidade dos dados medidos por DSC dependem da eliminação de variáveis, que podem ser divididas em duas categorias: fatores instrumentais e características da amostra.

Alguns fatores instrumentais dependem da construção do equipamento, não podendo ser alterados pelo operador, como por exemplo: o material que compõe o disco suporte dos cadinhos, a geometria do forno, o tamanho dos pontos de solda de junção dos termopares com o suporte das cápsulas de amostra e referência, a localização dos termopares e outros.

Outros fatores também instrumentais, assim como algumas características da amostra, podem, pelo contrário, ser controlados pelo operador $^{32}$.

\subsubsection{Aplicações da DSC}

\footnotetext{
$\checkmark \quad$ Alívio de tensões;

$\checkmark \quad$ Análises de copolímeros e blendas;

$\checkmark \quad$ Catálise;

$\checkmark \quad$ Capacidade calorífica;

$\checkmark \quad$ Condutividade térmica;

$\checkmark \quad$ Controle de qualidade;

$\checkmark \quad$ Determinação de pureza;

$\checkmark \quad$ Diagramas de fase;

$\checkmark \quad$ Entalpia das transições;
} 
$\checkmark \quad$ Estabilidade térmica e oxidativa;

$\checkmark \quad$ Grau de cristalinidade;

$\checkmark \quad$ Intervalo de fusão;

$\checkmark \quad$ Nucleação;

$\checkmark \quad$ Transição vítrea;

$\checkmark \quad$ Transições mesofase;

$\checkmark \quad$ Taxas de cristalização e reações

A técnica de calorimetria exploratória diferencial foi utilizada nas amostras de pectinas em pó e em eletrólitos poliméricos para a determinação da transição vítrea, na qual se inicia o movimento de segmentos da cadeia polimérica. A passagem do estado vítreo para o estado de elástico é uma transição de segunda ordem, portanto um processo acompanhado de variação de capacidade calorífica da amostra, que se manifesta como variação da linha base da curva DSC.

\subsubsection{Equipamento}

A Figura 3-23 mostra o esquema representativo do forno de um calorímetro, o cadinho/panelinha (porta amostra) de referência é colocado do lado esquerdo do forno, sem amostra, e o cadinho/panelinha de amostra é colocado do lado direito; os termopares e os sensores de temperatura e fluxo de calor estão localizados abaixo dos cadinhos e o forno é homogeneizado com gás inerte $\left(\mathrm{N}_{2}\right)$; as paredes internas tem o sistema de aquecimento e resfriamento. 


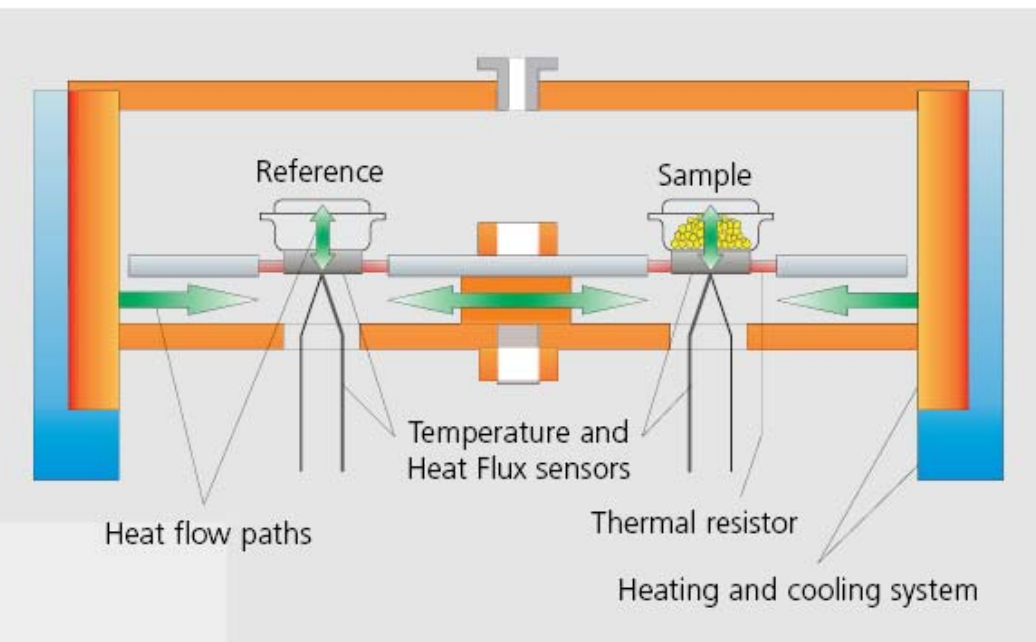

Figura 3-23: Esquema representativo de um Calorímetro ${ }^{37}$.

\section{- Cadinhos de DSC}

Os cadinhos utilizados em DSC são produzidos desde materiais altamente condutores de calor, como platina, até alumina, cerâmica isolante. Estes cadinhos são vulgarmente conhecidos como "panelinha" devido ao seu formato. No DSC por compensação de energia cada cadinho é colocado em um forno, no DSC por fluxo de energia os cadinhos são colocados em cada lado da base de platina, permitindo assim o fluxo de calor entre a amostra e a referência.

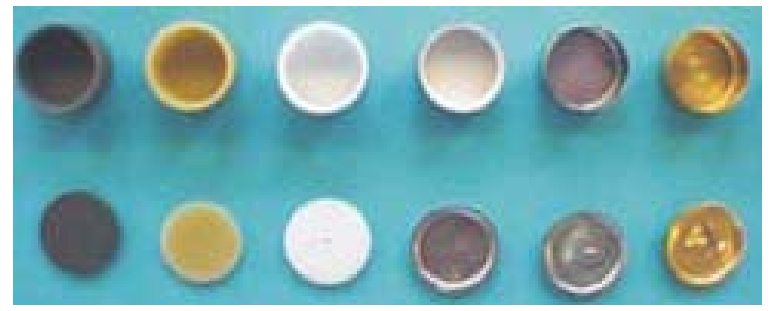

Figura 3-24: Cadinhos utilizado no DSC (grafite, $\mathrm{ZrO}_{2}, \mathrm{Al}_{2} \mathrm{O}_{3}, \mathrm{Pt}+\mathrm{Al}_{2} \mathrm{O}_{3}$ inside layer $\mathrm{Pt}, \mathrm{Au})^{33}$.

As análises de DSC foram realizadas utilizando um equipamento Mettler Toledo DSC $822^{\mathrm{e}}$, cadinho de alumínio tampado com furo, atmosfera dinâmica 
de nitrogênio. Foram programadas 3 (três) dinâmicas de temperatura: a primeira de ambiente até $120^{\circ} \mathrm{C}$ com taxa de aquecimento de $20^{\circ} \mathrm{C} / \mathrm{min}$, com o objetivo de eliminar possíveis solventes ainda presentes na amostra, a segunda e terceira de $-120{ }^{\circ} \mathrm{C}$ à $180{ }^{\circ} \mathrm{C}$ com taxa de aquecimento de 10 ${ }^{\circ} \mathrm{C} / \mathrm{min}$, a fim de se obter a temperatura de transição vítrea; o fluxo de nitrogênio utilizado foi de $50 \mathrm{~mL} / \mathrm{min}$. 


\section{REFERÊNCIAS BIBLIOGRÁFICAS}

${ }^{1}$ DYER, J.R. Aplicações da espectroscopia de absorção aos compostos orgânicos. São Paulo: Edgard Blücher, 1969. 151p.

${ }^{2}$ SILVERSTEIN, R. M.; BASSLER, G. C. Spectrometric identification of organic compounds. New York: John Wiley, 1974. v. 1.

${ }^{3}$ BELLAMY, L. J. The infra-red spectra of complex molecules. London: Chapman and Hall, 1975. 433p.

${ }^{4}$ BOCHEK, A. M.; ZABIVALOVA, N. M.; PETROPAVLOVSKII, G. A. Determination of the esterification degree of polygalactoronic acid. Russian Journal of Applied Chemistry, v. 75, p. 796-799, 2001.

${ }^{5}$ CANTO, L. B. Investigação de novos condutores iônicos sólidos híbridos sílicapolietilenoglicol para utilização em dispositivos eletrocrômicos. 1996. 33 f. Monografia (Bacharelado) - Instituto de Química de São Carlos, Universidade de São Paulo, São Carlos, 1996.

${ }^{6}$ Mc CALLUM, J. R.; VINCENT, A. C. Polymer electrolyte reviews. New York: Elsevier, 1987. $350 \mathrm{p}$.

${ }^{7}$ GIROTTO, E. M.; De PAOLI, M. A. Transporte de massa em polímeros intrinsecamente condutores: importância, técnicas e modelos teóricos. Química Nova, v. 22, n. 3, p. 358-368, 1999.

${ }^{8}$ PROENÇA, M. B.; FILHO COITINHO, J. S.; SALGADO, A. N.; KAVAMURA, E. E. Estudo de metodologias para identificar adsorção e dessorção de hidrogênio por vidros metálicos. Tuiuti: Ciência e Cultura, n. 25, p. 121-134, 2001.

${ }^{9}$ MACDONALD, D. D. Reflections on the history of electrochemical impedance spectroscopy. Electrochimica Acta, v. 51, n. 4, p. 1376-1388, 2006.

${ }^{10}$ EG\&G PRINCETON APPLIED RESEARCH. Basics of electrochemical impedance spectroscopy (EIS). London: Gamry , 2000. 13 p. (Apostila)

${ }^{11}$ RAPHAEL, E. Eletrólitos sólidos poliméricos a base de amidos de mandioca: nativo, acetilado e oxidado - acetilado. 2004. 123 f. Dissertação (Mestrado) Instituto de Química de São Carlos, Universidade de São Paulo, São Carlos, 2004. 
${ }^{12}$ DRAGUNSKI, D. C. Preparação de eletrólitos sólidos a partir de amido. 2003. 163 f. Tese (Doutorado) - Instituto de Química de São Carlos, Universidade de São Paulo, São Carlos, 2003.

${ }^{13}$ GUIMARÃES, K. V. Eletrólitos sólidos poliméricos a base de amido plastificado com etileno glicol, carbonato de propileno e mistura de glicol com poli(etileno glicol). 2003. 101 f. Dissertação (Mestrado) - Instituto de Química de São Carlos, Universidade de São Paulo, São Carlos, 2003.

${ }^{14}$ FERREIRA, H. C. A. Eletrólitos sólidos poliméricos a base de HEC plastificada com glicerol. 2002. 88 f. Dissertação (Mestrado) - Instituto de Química de São Carlos, Universidade de São Paulo, São Carlos, 2002.

${ }^{15}$ MUNICHANDRAIAH, N.;SIVASANKAR, G. Characterization of PEG-PAN hybrid solid polymer electrolytes. Journal of Applied Polymer Science, v. 65, n .11. p. 21912199, 1997.

${ }^{16}$ SKOOG, D. A.; HOLLER, F. J; NIEMAN, T. A. Principles of instrumental analysis. 6.ed. Australia, Brooks/Cole, 2007. 832p.

${ }^{17}$ COSTA, E. Preparação e caracterização de filmes finos sol-gel de Nb2O5- TiO2. 1998. 83 f. Dissertação (Mestrado) - Área Interunidades em Ciência e Engenharia de Materiais da EESC, IQSC e IFSC, Universidade de São Paulo, São Carlos, 1998.

${ }^{18}$ SILVERSTEIN, R.M.; BASSLER, C.G.; MORRIL, T.C. Identificação espectrométrica de compostos orgânicos. 7. ed. Rio de Janeiro: LTC, 2006. 506 p.

${ }^{19}$ SOMMER, L. Analytical absorption spectrophotometry in the visible and ultraviolet: the principles. New York: Elsevier, 1989. $312 \mathrm{p}$.

${ }^{20}$ MICHIGAN STATE UNIVERSITY. Visible and ultraviolet spectroscopy. Disponível em: < http://www.cem.msu.edu/ reusch/VirtTxtJml/Spectrpy/UV-Vis/spectrum.htm> Acesso em: 15 set. 2007.

${ }^{21}$ CULLITY, B. D.; STOCK, S. R. Elements of X-ray diffraction. 3. ed. London: Addison-Wesley, 2001. 664p.

${ }^{22}$ BLEICHER L.; SASAKI J. M. Introdução à difração de raios-X em cristais. Ceará: Universidade Federal do Ceará, 2000. 1 v. (Apostila).

${ }^{23}$ KAHN, H. Difração de raios-X. São Paulo: Universidade de São Paulo, Escola Politécnica, 2007. 1 v. (Apostila). 
${ }^{24}$ CALLISTER W. D. Materials science and engineering: an introduction. New York: John Wiley, 1994. 385 p.

${ }^{25}$ ASKELAND, D. R.; Phulé, P. P. The science and engineering of materials. 5. ed. New York: Thomson Learning, 2005. 863 p.

${ }^{26}$ GONÇALVES, M. C. Microscopia eletrônica de varredura. In: CANEVAROLO, S. V. (Ed.). Técnicas de caracterização de polímeros. São Carlos: Artliber, 2004. p. 168169.

${ }^{27}$ MALISKA, A. M. Microscopia eletrônica de varredura e micro análise. Santa Catarina: UFSC, 2006. 98p. (Apostila).

${ }^{28}$ KITAJIMA, E. W.; LEITE, B. Curso introdutório de microscopia eletrônica de varredura. 2. ed. Piracicaba: ESALQ - USP, 1999. 46p. (Apostila).

${ }^{29}$ KITAJIMA, E. W.; LEITE, B. Curso introdutório de microanálise de raio-X com microscopia eletrônica de varredura. Piracicaba: ESALQ - USP, 1999. 48p. (Apostila)

${ }^{30}$ IONASHIRO, M.; GIOLITO, I. Nomenclatura, padrões e apresentação dos resultados em análise térmica. Cerâmica, 1980. p. 26.

${ }^{31}$ CAVALHEIRO, E. T. G.; BERNAL, C. ;COUTO, A. B.; BREVIGLIERI, S. T. Influência de alguns parâmetros experimentais nos resultados de analises calorimétricas diferenciais - DSC. Química Nova, v. 25, n. 5, p. 849-855, 2002

${ }^{32}$ SALES, A. L. C. Síntese, caracterização e analise térmica dos sais de lítio, sódio e potássio do ácido palmítico e do seu éster etílico. 2006. 75 f. Dissertação (Mestrado) - Instituto de Química de São Carlos, Universidade de São Paulo, São Carlos, 2006.

${ }^{33}$ IONASHIRO, M. ; GIOLITO, I. Nomenclatura, padrões e apresentação dos resultados em análise térmica. Cerâmica, v. 26, n. 121, p. 17-24, 1980.

${ }^{34}$ MATOS, J. R; MACHADO, L. D. B. Análise térmica diferencial e calorimetria exploratória diferencial. In: CANEVAROLO, S. V. (Ed.). Técnicas de Caracterização de Polímeros. São Carlos: Artliber, 2004. p. 229-263.

${ }^{35}$ RODRIGUES, G. V.; MARCHETTO, O. Análises térmicas. Universidade Federal de Santa Catarina. Disponível em: <http://www.materiais.ufsc.br/Disciplinas/EMC 5733/Apostila.pdf>. Acesso em: 26 abr. 2010. 
${ }^{36}$ TA Instruments. Disponível em:

$<$ http://www.tainstruments.com/main .aspx?id=48\&n=2\&siteid=11> Acesso em: 26 abr. 2010.

${ }^{37}$ MANUAL do Equipamento. Disponível em: <http://www.netzsch-thermalanalysis.com/download/DSC 204 F1-Phoenix E $0709 \mathrm{w}$ en 7.pdf>. Acesso em 26 abr. 2010. 


\section{CAPITULO 4 - RESULTADOS E DISCUSSÃO}

\subsection{Caracterização das pectinas utilizadas para preparação dos eletrólitos}

As pectinas em pó, bem como os eletrólitos poliméricos foram caracterizados pelas técnicas de FT-IR, Raios-X, Análise Elementar, e Análises Térmicas, DSC e TG.

\subsubsection{Espectroscopia de Infravermelho (FT-IR)}

As pectinas são macromoléculas compostas por grupamentos de ácidos carboxílicos. Os ácidos carboxílicos existem como dímeros nos estados líquidos ou sólidos, devido à presença de ligações hidrogênio ${ }^{1}$.

Por meio dos espectros de FT-IR (Figura 4-1) foi possível identificar esses dímeros que produzem absorção de deformação axial de O-H intensa e muito larga na região de $3.300-2.500 \mathrm{~cm}^{-1}$.

A banda na região de $2930 \mathrm{~cm}^{-1}$ é atribuída à deformação axial C-H de grupos $\mathrm{CH}_{2}{ }^{2}$ e $\mathrm{CH}_{3}{ }^{3}$. As duas bandas em 1630 e $1420 \mathrm{~cm}^{-1}$ correspondem à deformação $\mathrm{C}-\mathrm{O}-\mathrm{C}$, e às deformações assimétricas e simétricas dos grupos carboxilatos. Os carboidratos tem absorção forte entre 1200 e $950 \mathrm{~cm}^{-1}$, está região é associada ao "fingerprint" característico para cada polissacarídeo. Segundo Gnanasambandam e Proctor ${ }^{4}$, estas bandas são frequentemente difíceis de serem interpretadas, 
entretanto foi observado que esta região independe da origem da pectina e pode ser usada para identificar o ácido galacturônico. A banda na região de $1740 \mathrm{~cm}^{-1}$ corresponde à deformação axial $\mathrm{C}=\mathrm{O}$ do grupo metilcarboxilato (éster de metila). $\mathrm{A}$ banda em $1630 \mathrm{~cm}^{-1}$ é atribuída a deformação assimétrica do grupo $\mathrm{COO}^{-}$, e a banda em $1740 \mathrm{~cm}^{-1}$ corresponde aos grupos carbonila do $\mathrm{COOCH}_{3}$.

$\mathrm{Na}$ Figura 4-1 pode-se observar os espectros idênticos de FT-IR das amostras de pectina pura GENU ${ }^{\circledR}$ BRS-Z e GENU ${ }^{\circledR}$ USP o que implica em composições iguais para as duas amostras. Portanto, a diferença entre elas é somente no controle microbiológico mais restrito para a pectina USP, pois sua aplicação é na indústria farmacêutica, já a BRS-Z é usada na indústria alimentícia.

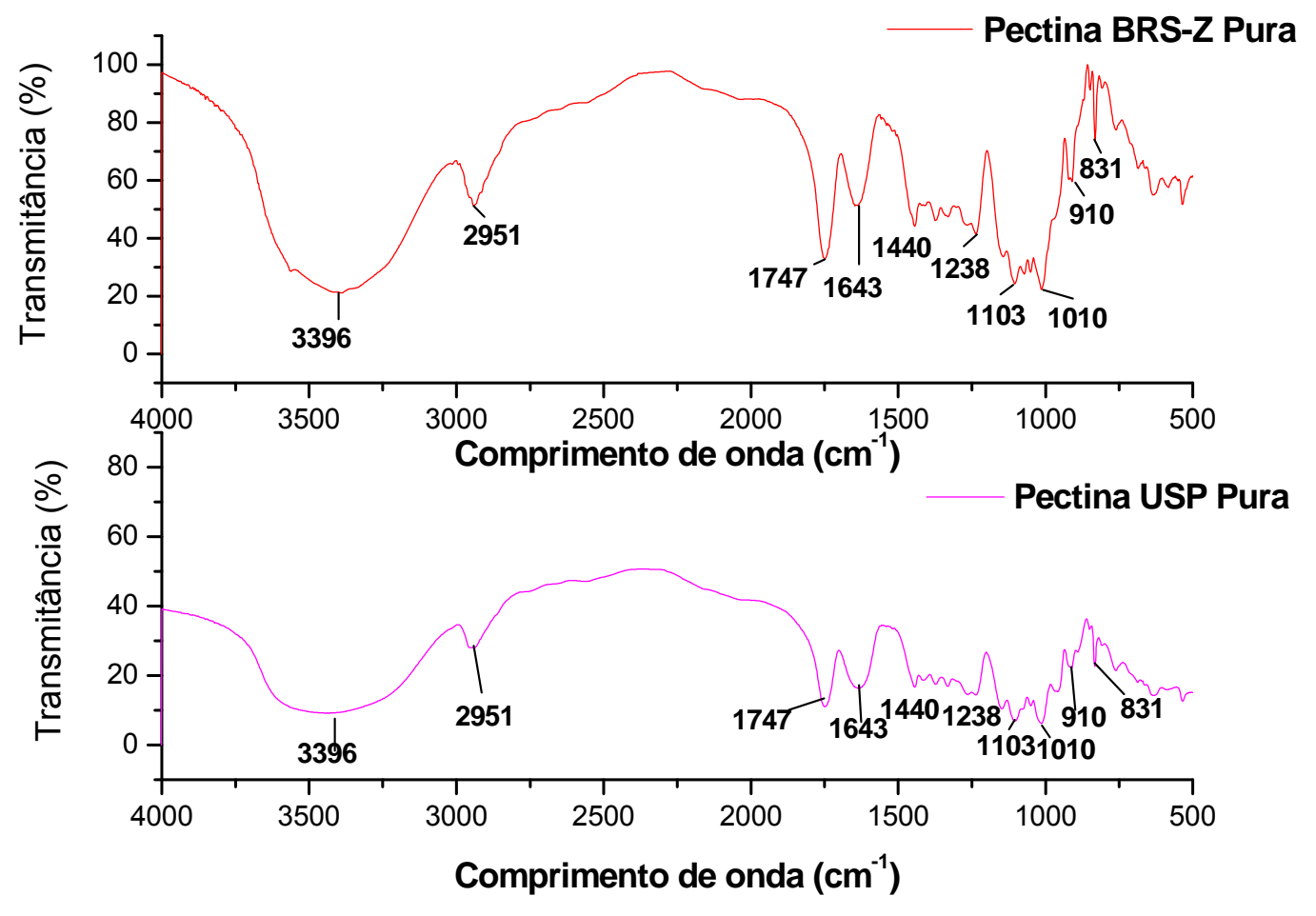

Figura 4-1: Espectros de FT-IR das pectinas USP e BRS-Z pura. 


\subsubsection{Grau de esterificação (DE)}

Na Tabela 4-1 apresenta os valores de DE teórico e DE calculado, obtidos através do método de titulação potenciométrica (seção 3.3.2).

Tabela 4-1: Valores de DE teórico e calculado

\begin{tabular}{c|c|c}
\hline \hline Pectina & $\begin{array}{c}\text { Valor DE } \\
\text { teórico }\end{array}$ & $\begin{array}{c}\text { Valor DE } \\
\text { calculado }\end{array}$ \\
\hline BRS-Z & $72 \%$ & $72 \%$ \\
\hline USP & $72 \%$ & $75 \%$ \\
\hline \hline
\end{tabular}

Analisando a Tabela 4-1 observa-se que a amostra USP apresenta valor calculado de DE superior ao teórico, já a amostra BRS-Z apresenta valor calculado de DE igual ao teórico.

\subsubsection{Difração de Raios -X}

Com a finalidade de observar a eventual presença de arranjos cristalinos nas amostras de pectina, estas foram submetidas a difração de raios-X.

Analisando os difratogramas de raios-X mostrados na Figura 4-2, não se encontra mudanças significativas na cristalinidade das duas amostras. Os difratogramas das amostras apresentam dois picos sobrepostos, um em aproximadamente $2 \theta=14^{\circ}$ e outro em torno de $2 \theta=21^{\circ}$, resultados muito similares aos obtidos por Lutz et $a l^{5}$ para as amostras de pectina obtida de maçã.

Com esses difratogramas pode se classificar a pectina em pó como um polímero semicristalino, o que já era esperado. 


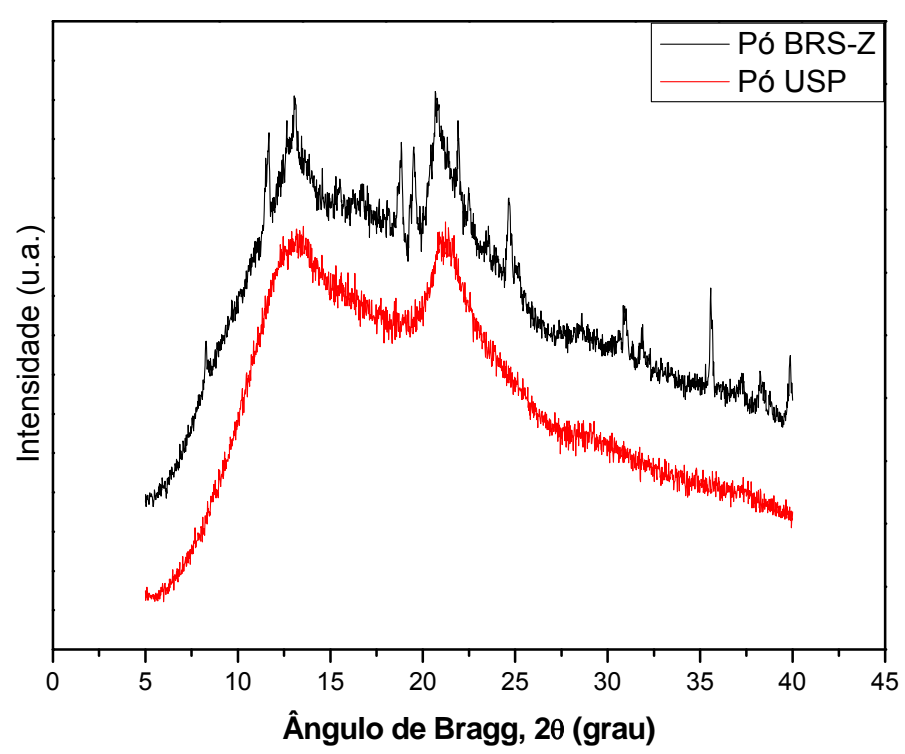

Figura 4-2: Difratogramas de raios-X das pectinas BRS-Z e USP em pó.

\subsubsection{Análise Elementar}

Com o objetivo de quantificar e qualificar os elementos químicos presentes nas amostras de pectina, foi realizada a técnica de análise elementar. Por meio desta técnica foram quantificados os teores de carbono, oxigênio, nitrogênio e enxofre nas amostras de pectina BRS-Z e USP. Os resultados dessas análises são apresentados na Figura 4-3. Estes resultados revelaram valores próximos aos calculados teoricamente. Há pequenas diferenças em relação a quantidade de oxigênio, carbono e hidrogênio que podem ser devido ao ar, o qual influenciou nesta análise como pode ser confirmado pela pequena presença de nitrogênio. 
Análise Elementar

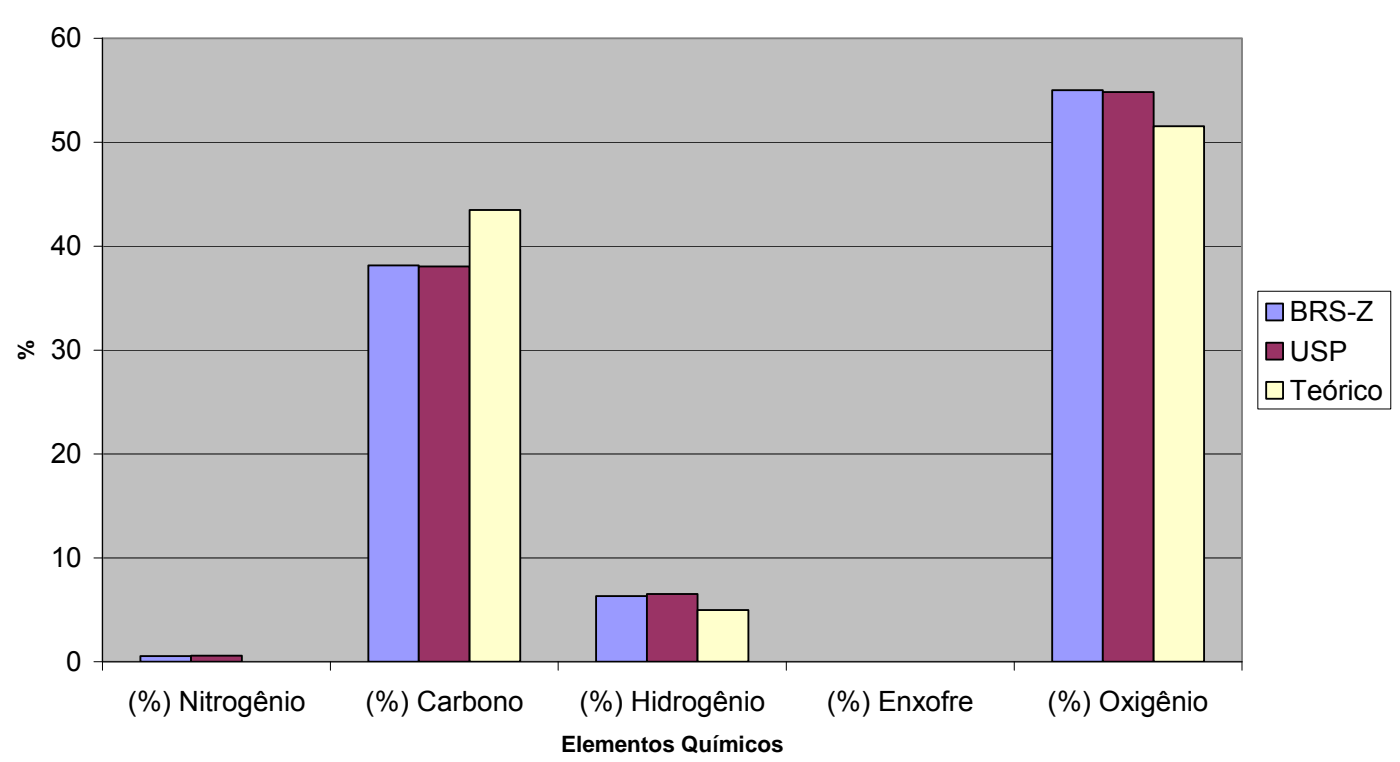

Figura 4-3: Análise elementar das amostras de pectina em pó.

\subsubsection{Análises Térmicas - DSC e TG}

As técnicas de DSC e TG foram utilizadas nas pectinas em pó para a caracterização das transições térmicas. Pode-se observar nas Figuras 4-4 e 4-5 que em temperaturas abaixo de zero não ocorre nenhuma transição. Os picos endotérmicos nos gráficos de DSC em torno de $108^{\circ} \mathrm{C}$ e $124^{\circ} \mathrm{C}$, para BRS-Z e USP, respectivamente, podem ser associados a perda de umidade das amostras, isso pode ser comprovado nos gráficos de TG (Figuras 4-6 a 4-7) onde ocorre uma perda de $12 \%$ e $11,0 \%$, para BRS-Z e USP, respectivamente, na mesma faixa de temperatura dos gráficos de DSC.

Nas Figuras 4-4 e 4-5 é possível observar mudança de linha de base em torno de $53^{\circ} \mathrm{C}$ para $\mathrm{BRS}-\mathrm{Z}$ e $37^{\circ} \mathrm{C}$ para USP, isso pode ser atribuído à $\mathrm{Tg}$ dessas pectinas. 
Não foi possível encontrar as temperaturas de decomposição com a técnica de DSC devido a programação de temperatura realizada na análise. Já plas técnica de TG, Figuras 4-6 e 4-7, foi possível obter a temperatura de degradação é em torno de $230^{\circ} \mathrm{C}$, onde ocorre uma perda de massa de aproximadamente $53 \%$ para a duas pectinas.

Uma ultima perda de massa no intervalo de $350^{\circ} \mathrm{C}$ a $800^{\circ} \mathrm{C}$ é apresentada nos gráficos de TG, perda de $21 \%$ para BRS-Z e em torno de $16 \%$ para USP. O teor de cinzas das amostras é de aproximadamente $14 \%$ para BRS-Z e $20 \%$ para USP. Pode-se inferir através das curvas de análise térmica que os mecanismos de degradação térmica para as duas pectinas estudadas são iguais.

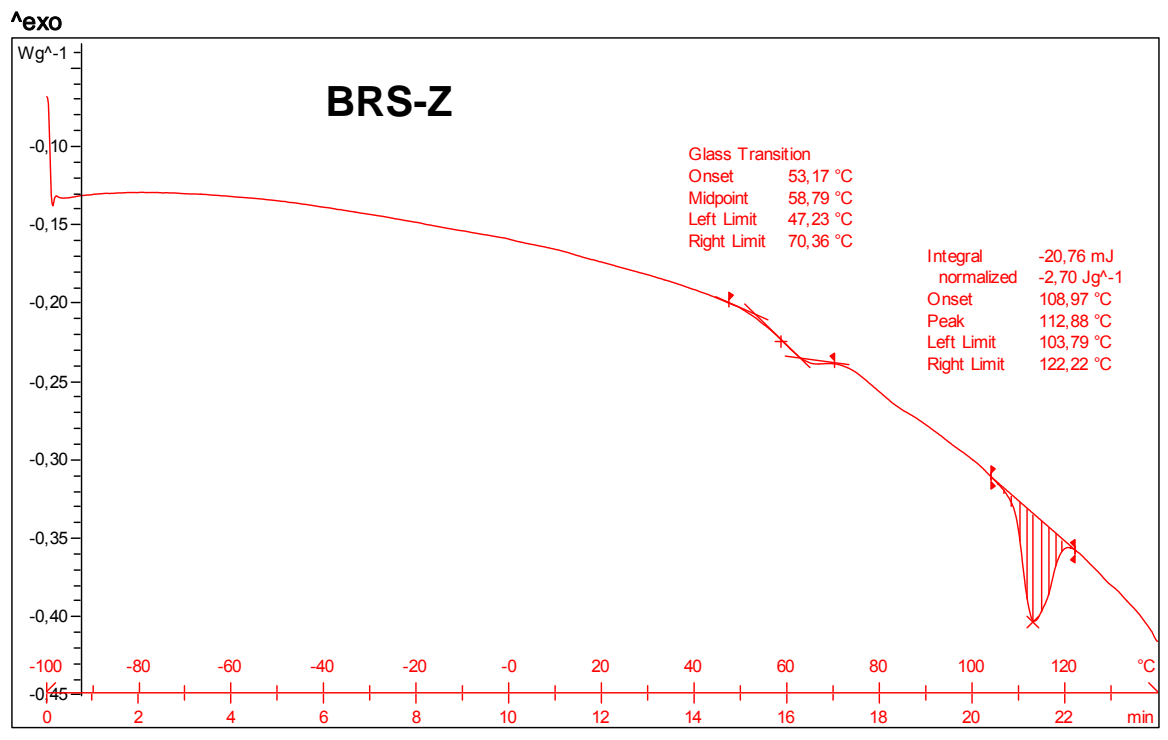

Figura 4-4: Curva de DSC para pectina BRS-Z. 


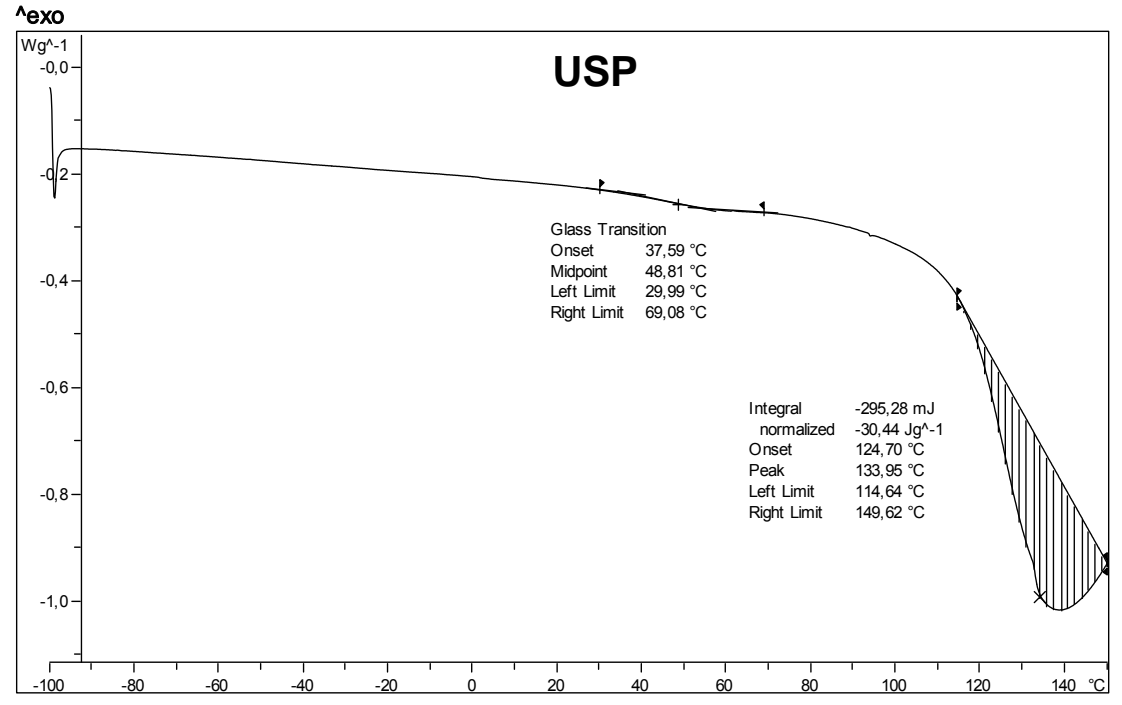

Figura 4-5: Curva de DSC para pectina USP.

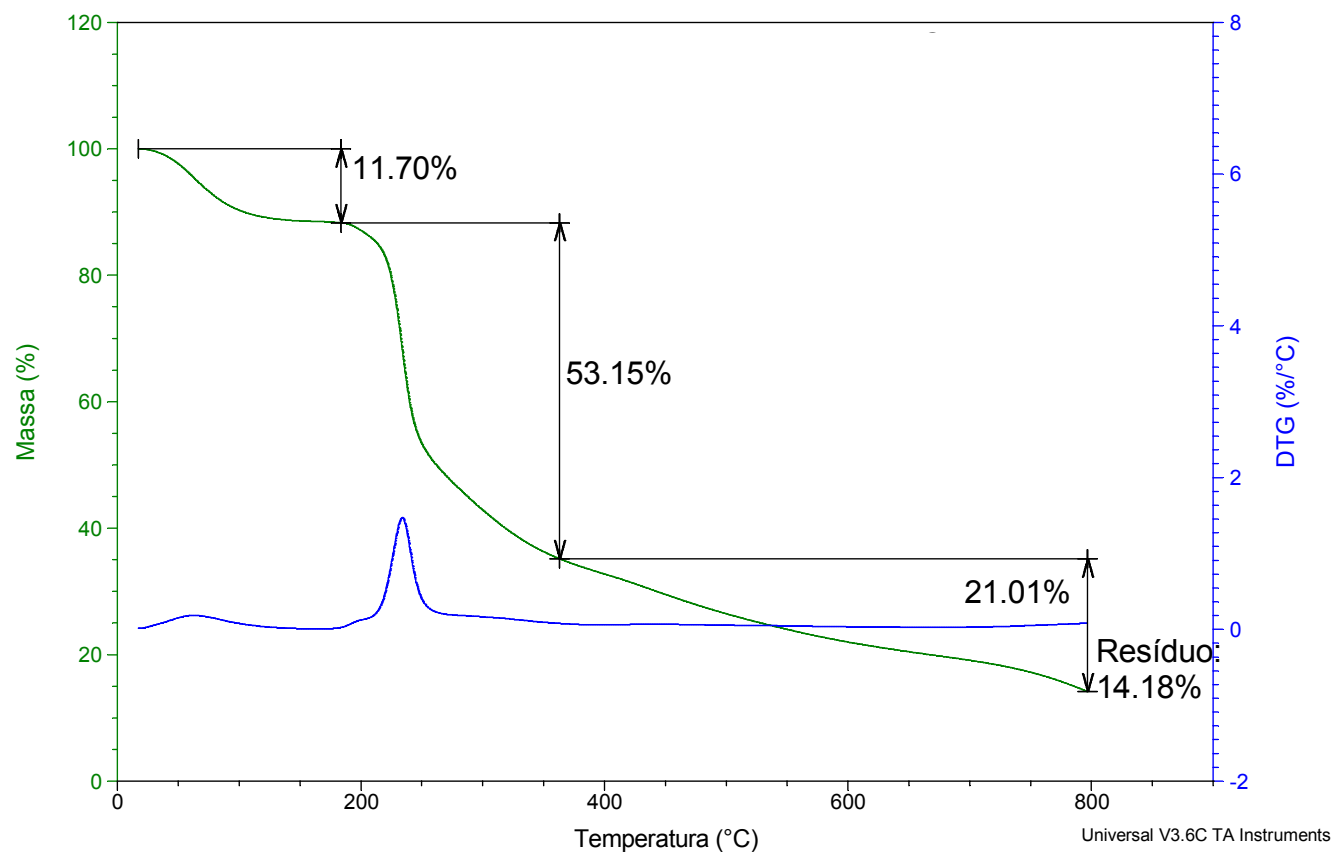

Figura 4-6: Curva de TG para pectina GENU ${ }^{\circledR}$ BRS-Z. 


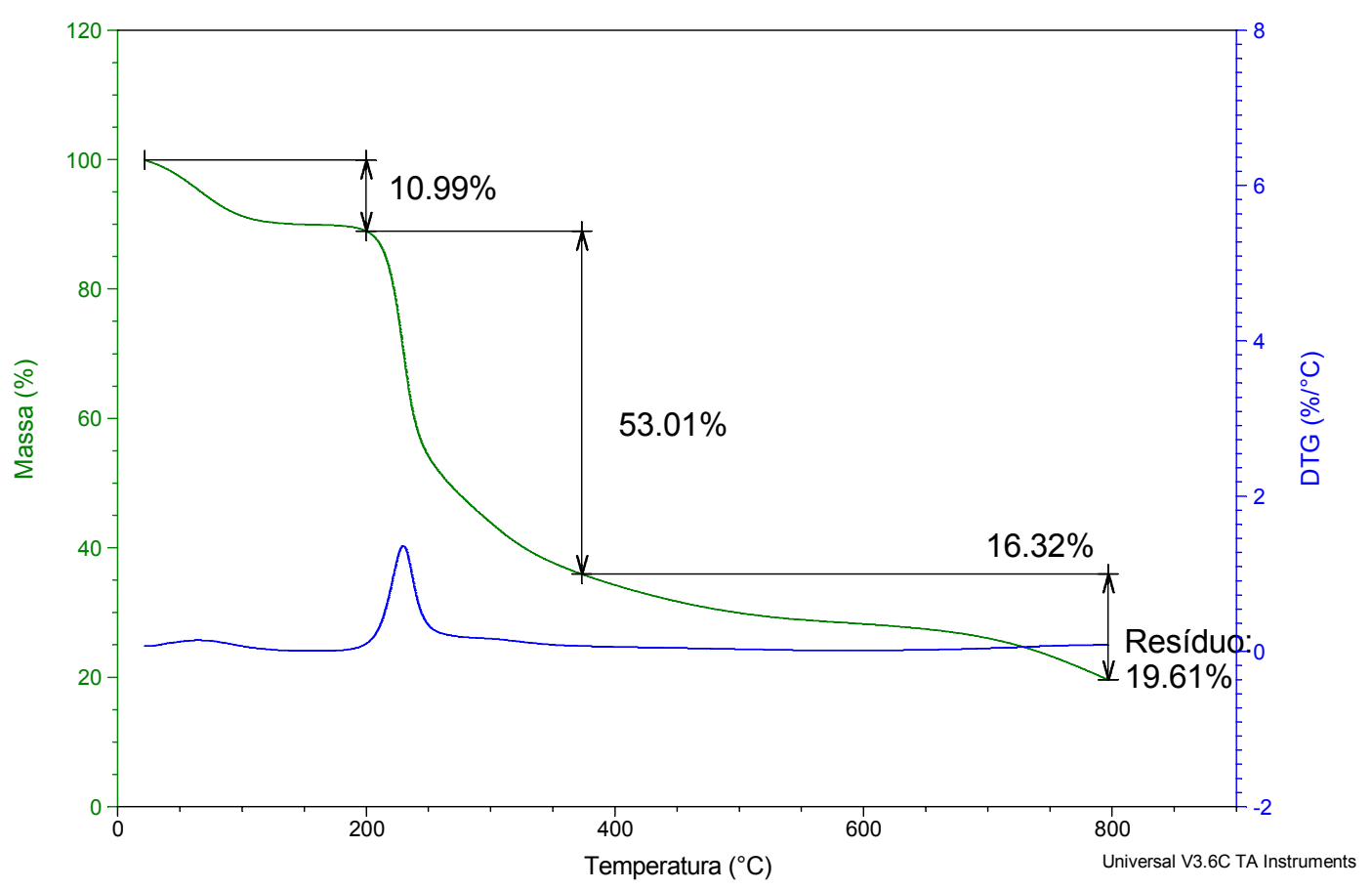

Figura 4-7: Curva de TG para pectina GENU ${ }^{\circledR}$ USP.

As técnicas de caracterização utilizadas para as pectinas USP e BRS-Z, apontam para uma grande similaridade entre as duas pectinas em termos de composição, de estrutura molecular e transição térmica.

\subsection{Eletrólitos Poliméricos Géis (EPG) a base de pectina}

Um eletrólito polimérico sólido ou gel eficiente deve apresentar um bom valor de condutividade iônica, ou seja, acima de $10^{-5} \mathrm{~S} . \mathrm{cm}^{-1}$ à temperatura ambiente, além de ser transparente na região do visível e possuir certa maleabilidade. O filme deve também possuir boa aderência ao substrato para exercer bem a sua função como eletrólito.

Tomando como base as características desejadas em um eletrólito polimérico citadas para o preparo dos EPGs foram realizados vários testes com as pectinas, 
plastificantes e o sal. Assim, os materiais que não tiveram resultados satisfatórios foram excluídos do preparo das membranas.

Para a preparação dos EPGs (seção 3.2), tomou-se como base um trabalho já desenvolvido no grupo, onde se obtiveram boas membranas com $1,5 \mathrm{~g}$ de glicerol, a partir disso realizou-se vários testes com diferentes quantidade de pectina, para se obter um filme maleável e aderente, e o melhor resultado encontrado foi com 0,6 $\mathrm{g}$ de pectina.

Os filmes preparados com sorbitol como plastificante não soltaram da placa de Petri, impossibilitando as medidas de condutividade. Dessa maneira, apesar da transparência e da homogeneidade, o sorbitol foi descartado das análises posteriores.

Para a condução iônica utilizou-se, além do $\mathrm{LiClO}_{4}$ também o sal $\mathrm{KCl}$. Contudo, o filme produzido com este sal não apresentou boa aparência, pois o sal não dissolveu completamente deixando cristais aparente, além de promoverem muita espuma, dessa maneira sua utilização para EPGs destinados a janelas eletrocrômicas não é recomendada.

Os filmes preparados com a pectina GENU ${ }^{\circledR}$ USP-200 apresentavam muitas bolhas em sua superfície, o que interfere nas medidas de condutividade e de transmitância, além de não deixarem a superfície homogênea. Assim, esta pectina também foi desqualificada para futuras análises.

Em outros trabalhos ${ }^{6,7}$, utilizou-se formaldeído para formar as reações das ligações cruzadas no gel. Contudo, devido à estrutura e aos substituintes da pectina, tais ligações são formadas sem a adição de formaldeído.

Após definir a quantidade de $0,6 \mathrm{~g}$ pectina, plastificante como glicerol e água como solvente, realizou-se um estudo com os filmes, Figura 4-8, variando a 
quantidade de plastificante $(0 \%$ a $70 \%)(\mathrm{m} / \mathrm{m})$ e a quantidade de perclorato de lítio $(0,24 \mathrm{~g} \mathrm{e} 30[\mathrm{O}] /[\mathrm{Li}])$.

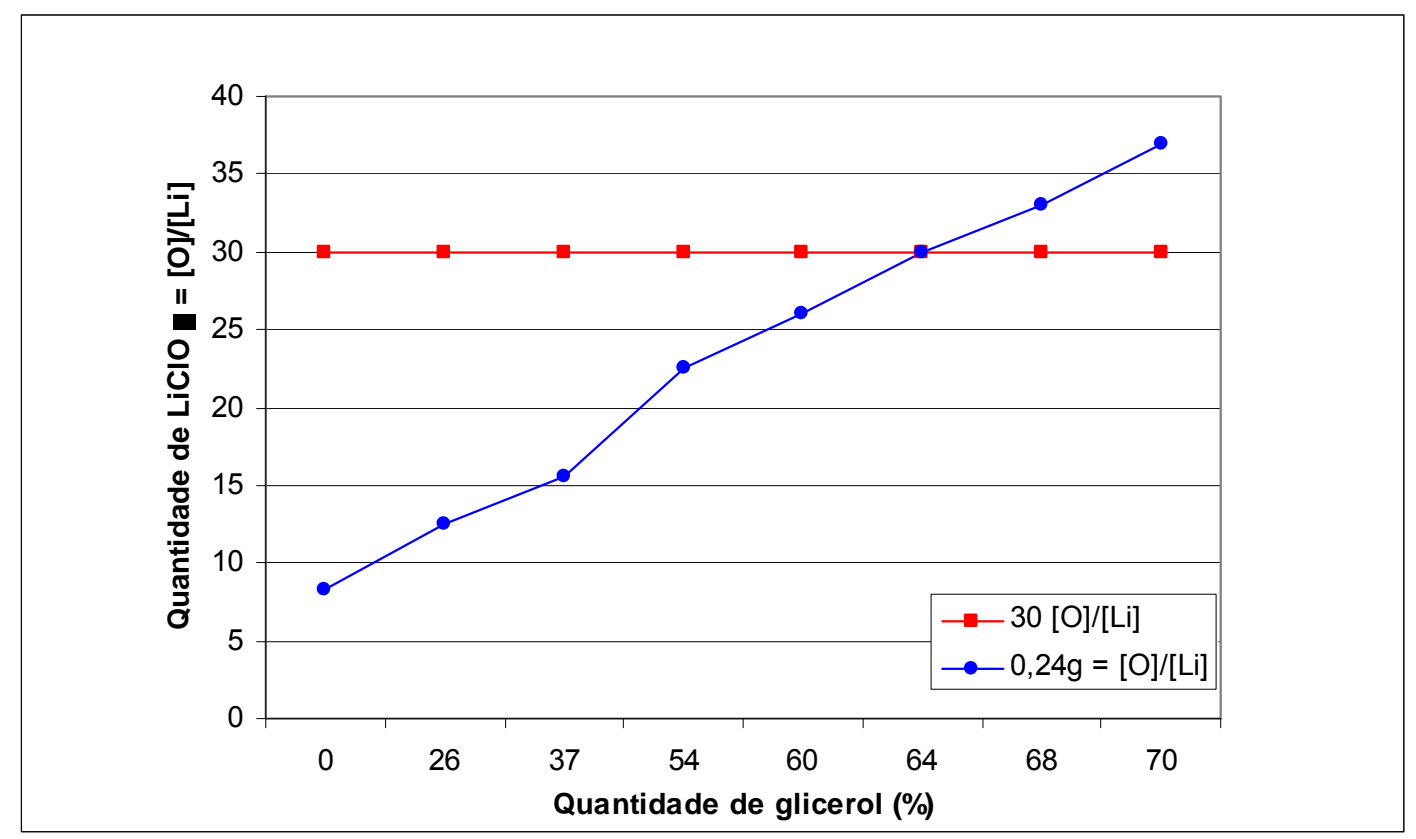

Figura 4-8: Quantidade de glicerol (\%) versus quantidade de $\mathrm{LiClO}_{4}([\mathrm{O}] /[\mathrm{Li}])$

O EPG produzido sem glicerol não apresentou boa maleabilidade nem boa aderência ao substrato. Além disso, a condutividade deste filme é muito baixa, mostrando a importância da adição do plastificante para a produção de um bom eletrólito.

Uma observação empírica foi a de que o sal adicionado como fornecedor de íons ajudou na dissolução da pectina.

O solvente (água) foi extraído dos EPGs por meio da técnica solvent casting, ou seja, evaporação do solvente. Para isso, as soluções foram colocadas em repouso, em temperatura ambiente por 48 horas e em estufa a $60^{\circ} \mathrm{C}$ por mais 48 horas, resultando na formação dos filmes. Tal processo é importante porque a água pode interferir nas medidas de condutividade, resultando em erros experimentais. 
Os filmes, depois de preparados, eram armazenados em dessecador, para evitar a absorção de água da atmosfera em sua superfície.

As medidas de condutividade foram realizadas sob pressão reduzida para evitar, novamente, a interferência da água. Em pressão reduzida, como o ar é rarefeito, não há alterações significativas nas medidas, de maneira que esta técnica conduziu a resultados mais precisos.

\subsubsection{Eletrólitos Poliméricos Géis a base de pectina GENU ${ }^{\circledR}$}

\section{BRS-Z, contendo $0,24 g$ de sal em função da concentração do glicerol.}

A Figura 4-9 mostra os difratogramas de raios-X dos filmes com 3 concentrações de glicerol diferentes e da pectina em pó. Os difratogramas apresentam bandas largas centradas em $2 \theta=21^{\circ}$ com um pequeno ombro em $2 \theta=$ $9^{\circ}$ na amostra com $37 \%$ em massa de glicerol. Com essas características pode se afirmar que a adição dos plastificantes promoveu a diminuição da fase cristalina das amostras e aumentou o seu caráter amorfo de modo análogo aos outros filmes condutores iônicos a base de polissacarídeos. Isso indica que os filmes são promissores para utilização como eletrólitos. 


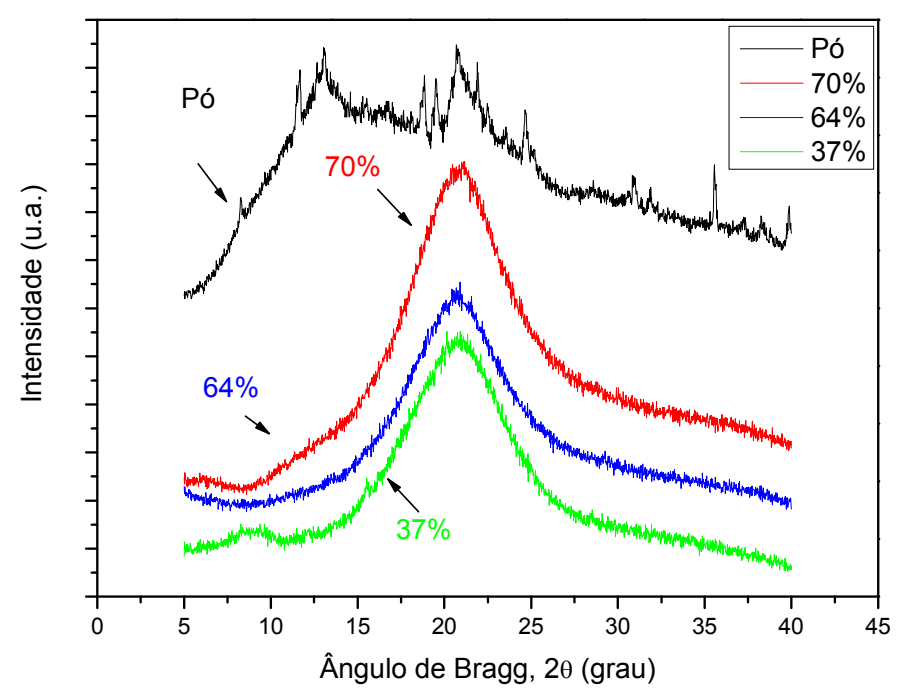

Figura 4-9: Difração de raios-X dos filmes a base de pectina contendo $0,24 \mathrm{~g}$ de $\mathrm{LiClO}_{4}$ e $37 \%$, 64\% e $70 \%$ em massa de glicerol e da pectina em pó.

Como já discutido anteriormente, os ácidos carboxílicos existem como dímeros nos estados líquidos ou sólidos, devido à presença de ligações fortes de hidrogênio. As análises espectroscópicas na região infravermelho (IR) dos dímeros de ácidos carboxílicos revelaram uma absorção de deformação axial de O-H intensa e muito larga na região de $3300-2500 \mathrm{~cm}^{-1}$. Nesta região encontra-se também a deformação axial de $\mathrm{O}-\mathrm{H}$ do glicerol. Portanto, os picos observados nesta região podem ser associados aos grupos $-\mathrm{OH}$ de ambas as moléculas, tanto do ácido quanto do glicerol, presentes nas amostras de EPGs a base de pectina como mostra a Figura 4-10. O aumento da quantidade do plastificante também provoca o aumento da intensidade desta banda. A banda na região em torno de $2930 \mathrm{~cm}^{-1}$ pode ser atribuída à deformação axial $\mathrm{C}-\mathrm{H}$ de grupos $\mathrm{CH}_{2}$ e duas bandas em 1630 e $1420 \mathrm{~cm}^{-1}$ correspondem à deformação C-O-C. Os carboidratos têm absorção forte entre 1200 e $950 \mathrm{~cm}^{-1}$, está região corresponde ao "fingerprint" característico para cada polissacarídeo. A banda na região de $1740 \mathrm{~cm}^{-1}$ é associada à deformação axial 
$\mathrm{C}=\mathrm{O}$ do grupo carboxilato de metila. As bandas em torno de 1629 e $1420 \mathrm{~cm}^{-1}$ correspondem respectivamente à deformação assimétrica e simétrica dos grupos carboxilados como observado nos espectros das pectinas em pó (Figura 4-1). A banda em $1630 \mathrm{~cm}^{-1}$ pode ser atribuída a deformação assimétrica do grupo $\mathrm{COO}^{-}$, e a banda em $1740 \mathrm{~cm}^{-1}$ corresponde aos grupos carbonila do $-\mathrm{COOH}$ e $-\mathrm{COOCH}_{3}$.

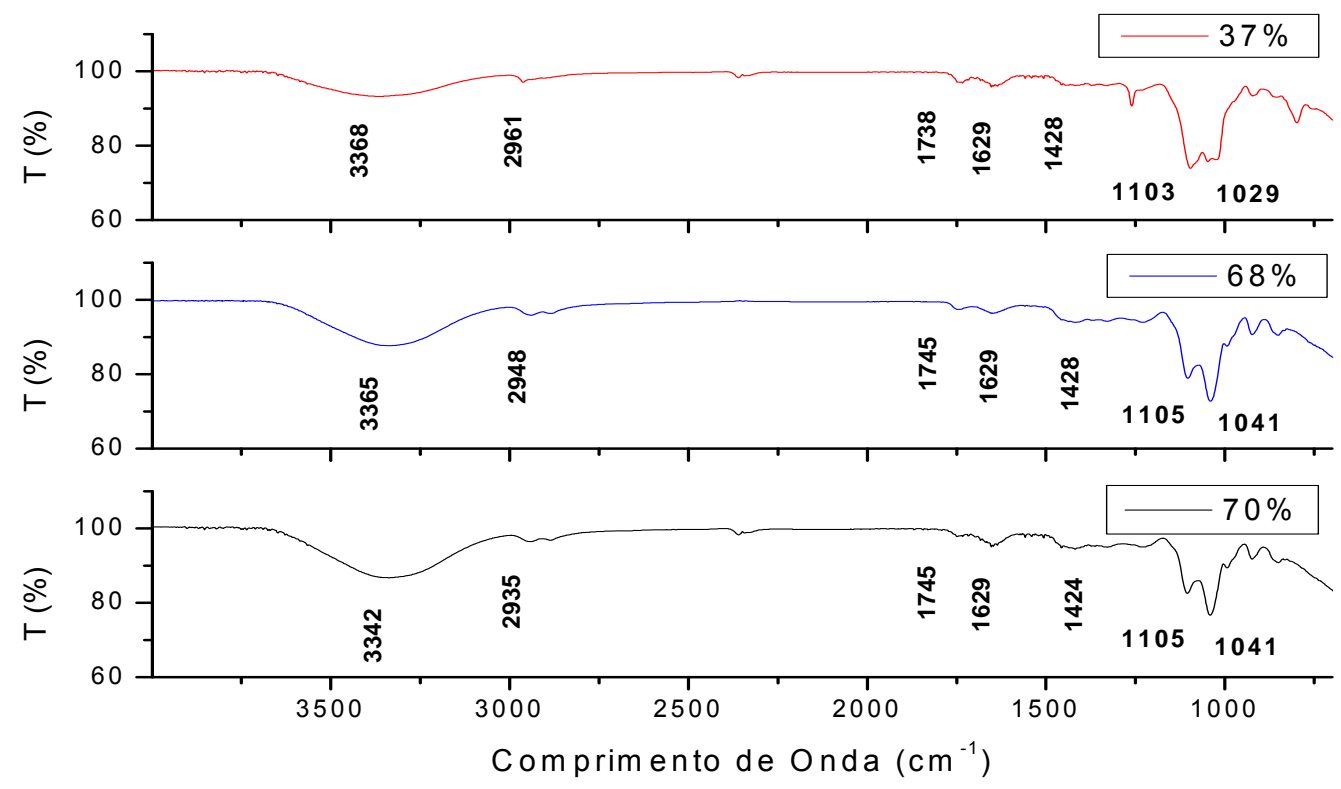

Figura 4-10: Espectros de FT-IR dos filmes a base de pectina com 0,24g de $\mathrm{LiClO}_{4} \mathrm{e}$ $37 \%, 60 \%$ e $70 \%$ em massa de glicerol.

A técnica de calorimetria exploratória diferencial (DSC) foi utilizada na caracterização dos filmes para a identificação da presença da temperatura da transição vítrea, na qual se inicia o movimento de segmentos das cadeias poliméricas. A passagem do estado vítreo para o estado elástico ou de "borracha" é uma transição de segunda ordem, portanto um processo acompanhado de variação de capacidade calorífica da amostra, que se manifesta como mudança da linha base da curva DSC. 
A Figura 4-11 mostra duas mudanças de linha de base, o que se refere a valores de Tg. A primeira mudança de linha de base ocorre em temperatura negativa $\left(-65^{\circ} \mathrm{C}\right)$ e pode ser atribuída a $\mathrm{Tg}$ da pectina plastificada e a segunda $\left(63^{\circ} \mathrm{C}\right)$ referente ao valor de $\operatorname{Tg}$ da pectina ${ }^{8,9}$. Um pequeno pico endotérmico em $111^{\circ} \mathrm{C}$ pode ser devido a evaporação de água absorvida pela amostra. Acima desta temperatura observa se uma grande diminuição na capacidade calorífica o que pode ser indício de começo de degradação da amostra.

A Tabela 4-2 apresenta os valores de Tg dos. Isso pode ser comprovado através das análises de TG e DTA discutidas a seguir, filmes com $60 \%$ e $70 \%$ de glicerol, e pode-se ver que com o aumento da concentração de glicerol ocorre uma diminuição na $\operatorname{Tg}$ o que comprova a diminuição da cristalinidade das amostras e corrobora com as análises cristalográficas apresentadas na Figura 4-9.

Tabela 4-2: Valores de transição vítrea (Tg) das amostras com 60\% e 70\%.

\begin{tabular}{c|c}
\hline \hline \% de glicerol & $\mathbf{T g}\left({ }^{\circ} \mathrm{C}\right)$ \\
\hline $60 \%$ & -55 \\
\hline $70 \%$ & -65 \\
\hline
\end{tabular}




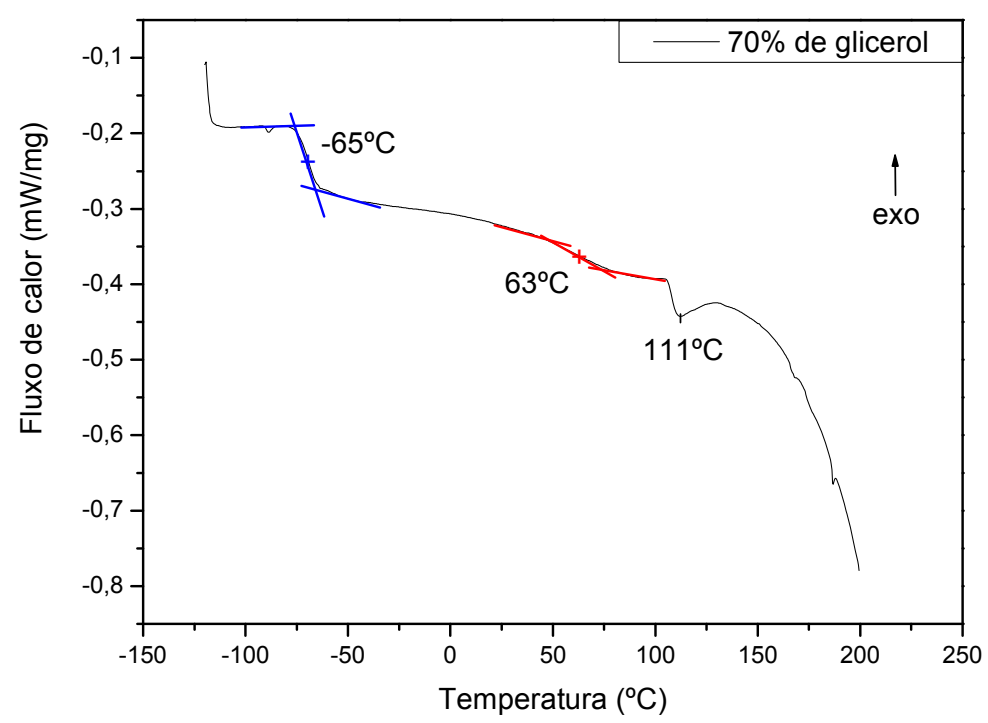

Figura 4-11: Curva de DSC do filme de ESGs a base de pectina com $70 \%$ de glicerol e $0,24 \mathrm{~g}$ de $\mathrm{LiClO}_{4}$.

A Figura 4-12 apresenta as curvas de TG e DTG (derivative weight loss) da pectina em pó, e dos filmes de ESGs com 64 e $70 \%$ de glicerol e 0,24g de $\mathrm{LiClO}_{4}$.
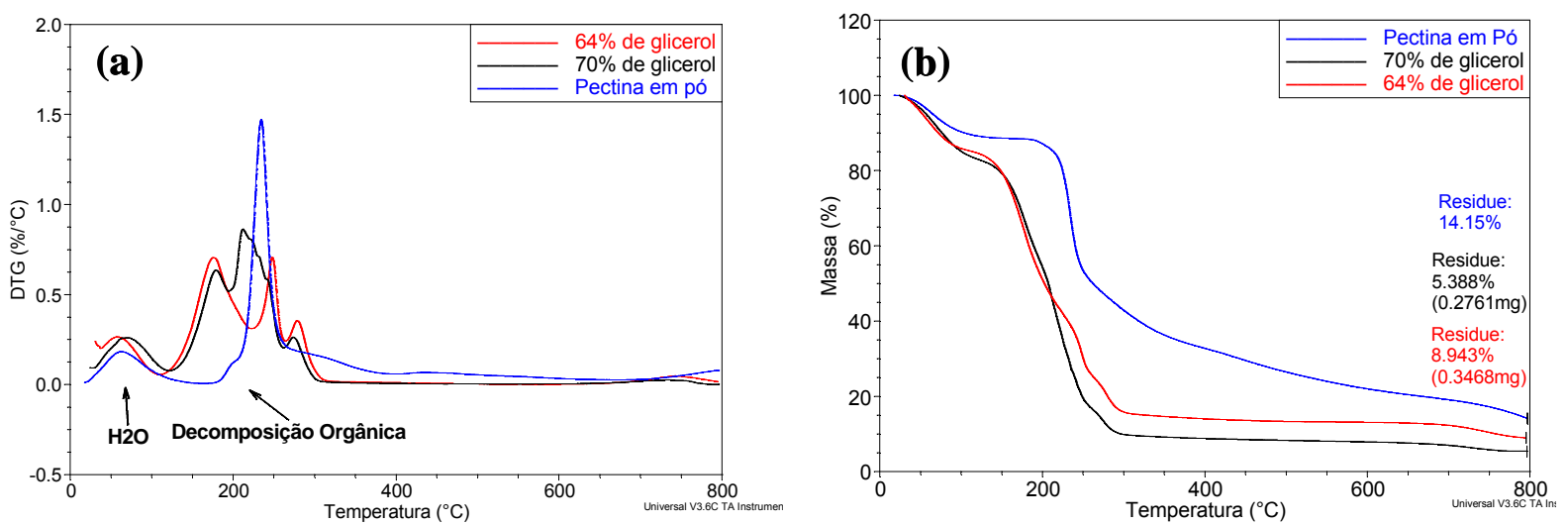

Figura 4-12: Curvas de DTG (a) e TG (b) para a pectina em pó, e para os filmes ESGs a base de pectina plastificada com 64 e $70 \%$ de glicerol e contendo $0,24 \mathrm{~g}$ de $\mathrm{LiClO}_{4}$.

A perda de massa de temperatura ambiente até $120^{\circ} \mathrm{C}$ pode ser atribuída à água livre. A segunda perda de massa de $120^{\circ} \mathrm{C}$ até $\sim 350^{\circ} \mathrm{C}$ é diferente para as três 
amostras, nos filmes ocorrem 3 eventos simultâneos, já na pectina em pó ocorre somente um, essas perdas podem ser atribuídas a decomposição orgânica. O resíduo em torno de 5-8\% é provavelmente devido a formação do carbonato de lítio de modo análogo as amostras de LiCMC além de outras impurezas ${ }^{10}$

A técnica de espectroscopia de UV-vis opera em duas faixas de luz, no ultravioleta de 200 a $400 \mathrm{~nm}$, e no visível de 400 a $800 \mathrm{~nm}$. Os espectros foram obtidos para a maioria dos filmes preparados os quais, variam as espessuras de 0,10 a $0,42 \mathrm{~mm}$, conforme a variação da quantidade de plastificante, e foram fixados diretamente no caminho ótico do aparelho.

Através da Figura 4-13, pode-se perceber que os valores de transmitância variam de 55 a $85 \%$ na região do visível (400 a 800 nm), o que são considerados bons resultados de transmitância, possibilitando a utilização dos eletrólitos em janelas eletrocrômicas.

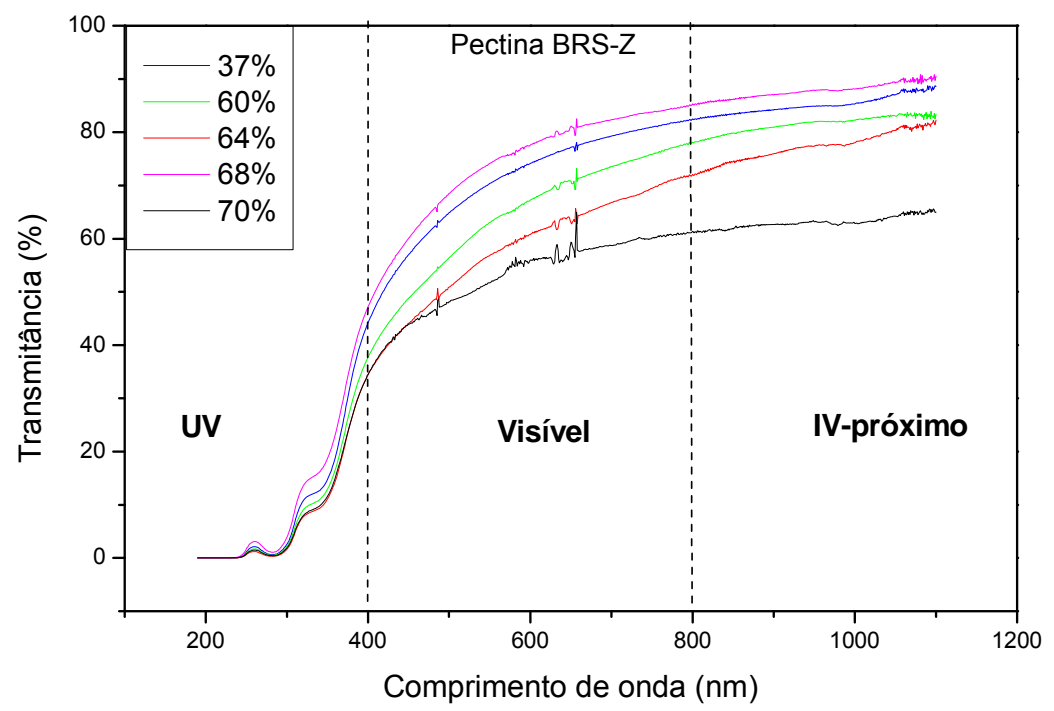

Figura 4-13: Espectro de UV-vis dos ESGs a base de pectina. 
Por meio de microscopia eletrônica de varredura é possível observar a morfologia da superfície do polímero, sua orientação e as possíveis mudanças realizadas, como por exemplo, a plastificação e a dissolução do sal.

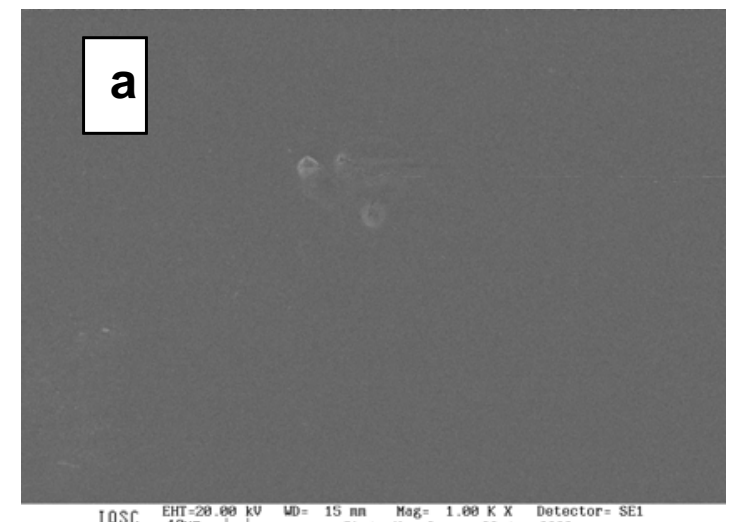

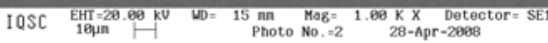

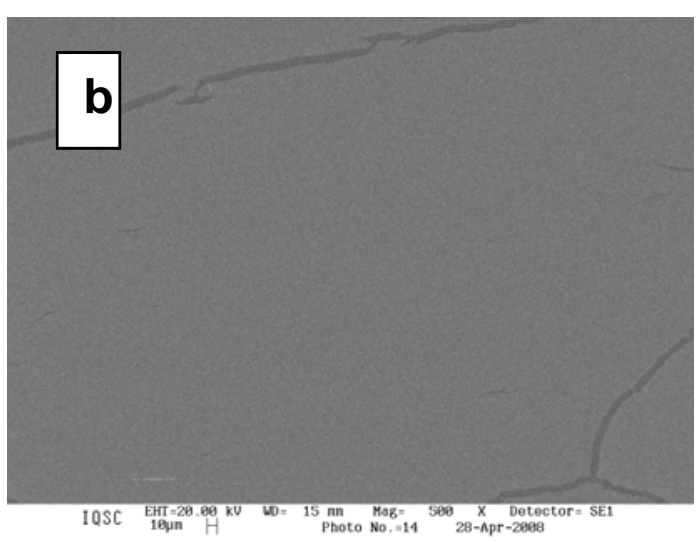

Figura 4-14: Micrografias das amostras com (a) $37 \%$ de glicerol aumento de $1000 \mathrm{X}$ e 5000X e (b) $70 \%$ de glicerol com aumento de 1000X e 5000X (respectivamente).

As Figuras 4-14 (a) são da amostra com 37\% de glicerol, a qual é mais rígida, entretanto como pode ser observado através desta análise não há aparecimento de trincas nem rachaduras em sua superfície.

Observa-se nas micrografias da Figura 4-14 (b) o aparecimento de trincas, isto ocorre porque o filme é maleável e existem nele impurezas ou cristais de sal de onde as trincas provavelmente iniciam quando ocorre sua submissão a pressão reduzida do equipamento. 
A adição de plastificante nos filmes provoca uma diminuição da cristalinidade e da temperatura de transição vítrea do polímero, além disso, permite maior mobilidade dos íons aumentando conseqüentemente a condutividade iônica ${ }^{11}$.

Na Figura 4-15 é possível observar que ocorre um aumento da condutividade

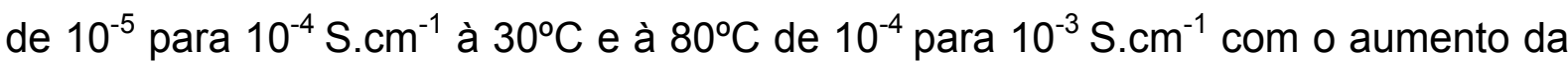
concentração de glicerol.

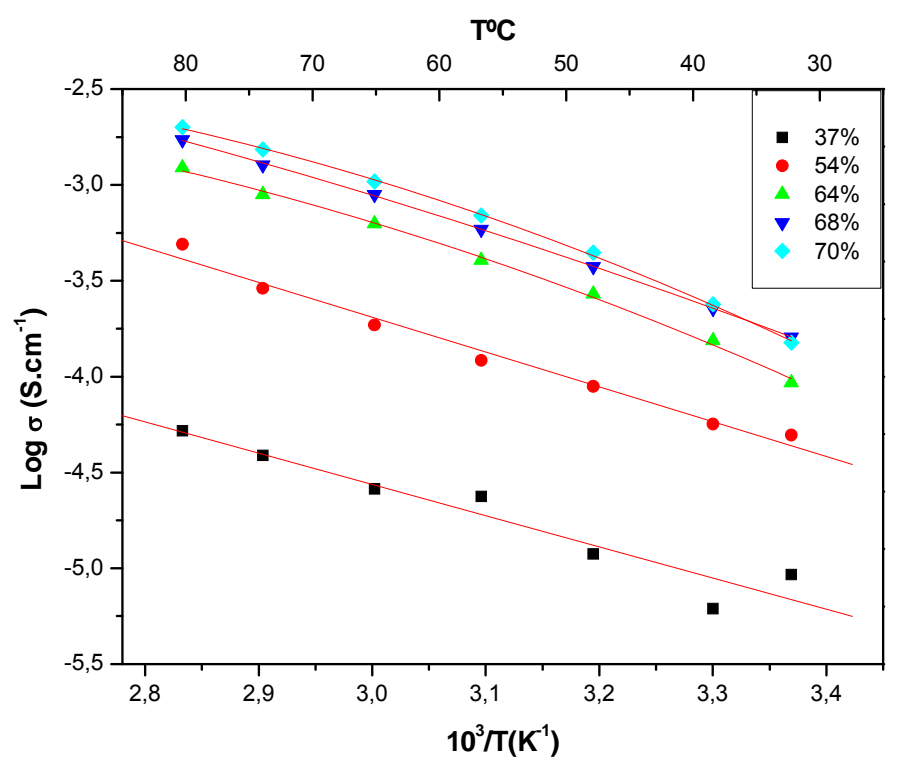

Figura 4-15: Log da condutividade em função do inverso da temperatura para amostras de pectina plastificada com glicerol e contendo $0,24 \mathrm{~g}$ de $\mathrm{LiClO}_{4}$.

As curvas da Figura 4-15 permitem avaliar a maneira com que as espécies migram na matriz polimérica. No gráfico, verifica-se que a condutividade tem uma tendência linear com o aumento da temperatura para as amostras com baixa quantidade de glicerol indicando que não há nenhuma transição de fase nem a formação de domínios pela adição de sal $^{12}$. Os resultados similares foram obtidos com outras membranas condutoras iônicas a base de polissacarídeos.

As amostras com mais de $60 \%$ de glicerol apresentam, contudo, um comportamento distinto, indicando a ocorrência do mecanismo VTF de condução 
iônica. Isso significa que as espécies responsáveis pela condução estão inseridas em uma matriz móvel, e os íons mudam de um sítio de solvatação a outro com o auxílio dos movimentos das cadeias poliméricas. Neste caso a presença de elevada quantidade de plastificante provavelmente proporciona uma melhor separação das cadeias poliméricas e consequentemente o aumento de volume livre o que leva a sua melhor movimentação. Comparando os valores de condutividade iônica desta amostra com as amostras com baixa concentração de glicerol observa-se um aumento de condutividade até $5 \times 10^{-4}$ S.cm ${ }^{-1}$ em $23^{\circ} \mathrm{C}$ e $5.4 \times 10^{-3} \mathrm{~S} . \mathrm{cm}^{-1}$ para $80^{\circ} \mathrm{C}$.

Na Figura 4-16 pode se observar a variação do log da condutividade em função da concentração de glicerol para os EPGs com 0,24g de $\mathrm{LiClO}_{4}$, a temperatura de $30^{\circ} \mathrm{C}$. Nesta figura observa-se que o aumento da quantidade de glicerol promove um aumento nos valores de condutividade a temperatura ambiente

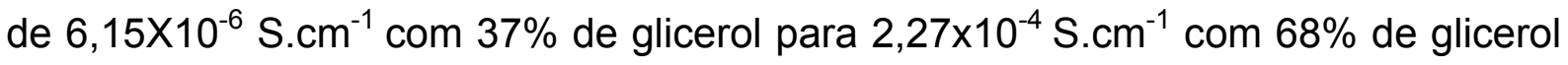
atingindo o máximo de condutividade nesta composição.

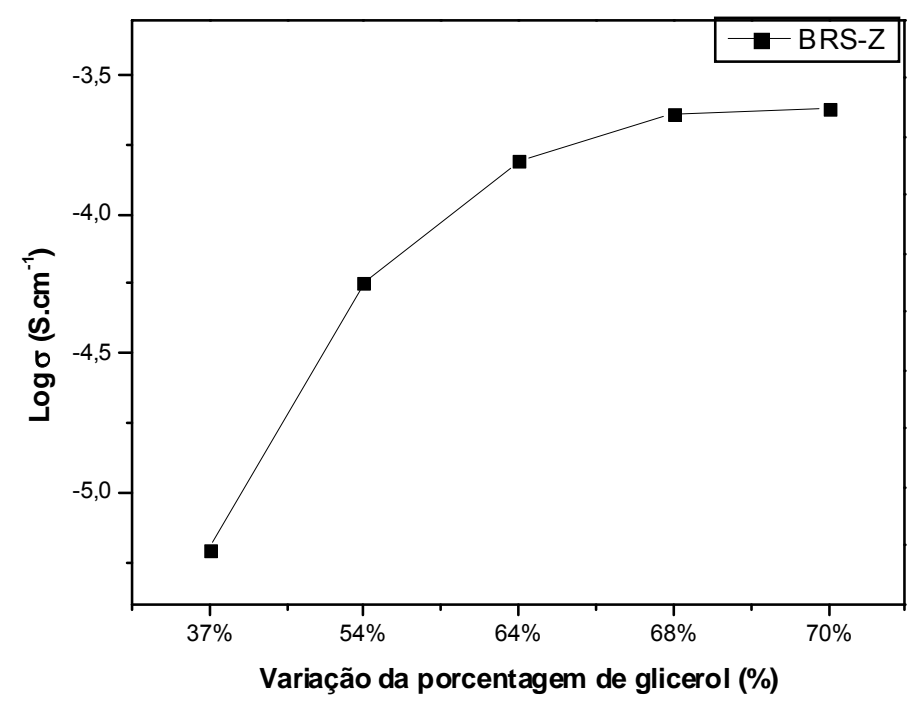

Figura 4-16: Log da condutividade em função da variação da porcentagem de glicerol para amostras de pectina contendo $0,24 \mathrm{~g}$ de $\mathrm{LiClO}_{4}$ a $30^{\circ} \mathrm{C}$. 
Os gráficos de Nyquist foram usados para obter valores de condutividade iônica das amostras plastificadas com diferentes quantidades de glicerol. Nas Figuras 4-17 e 4-18 são apresentados dois destes gráficos com 37 e $70 \%$ de glicerol, em temperatura ambiente e $80{ }^{\circ} \mathrm{C}$, respectivamente. Analisando estas figuras é possível observar a região do semicírculo em altas freqüências no plano complexo que correspondente à resistência do eletrólito, e a partir da qual é possível obter valores de condutividade iônica. No caso da amostra com $37 \%$ de glicerol (Figura 4-17) este semicírculo é muito pequeno e mostra baixíssima resistência real. Outras observações nesta amostra são que ocorre a diminuição do semicírculo com o aumento da temperatura de $23^{\circ} \mathrm{C}$ para $80^{\circ} \mathrm{C}$, e que em altas freqüências os valores Z' vão até zero, o que não é o caso da amostra plastificada com $70 \%$ de glicerol (Figura 4-18). A amostra com $70 \%$ de glicerol apresenta uma pequena resistência em altas freqüências. Munichandraiah et al $^{13}$ observaram uma resposta similar de impedância para a célula $\mathrm{Li} / \mathrm{PEO}_{8}-\mathrm{LiClO}_{4} / \mathrm{Li}$ a $80^{\circ} \mathrm{C}$ e da análise do circuito equivalente afirmaram que a resistência em alta freqüência sem capacitância em alta temperatura é devido ao filme EGPs. Eles também observaram dois semicírculos, à temperatura ambiente e considerando estudos de Thevenin e Muller ${ }^{14}$ descartaram o modelo da resistência do eletrólito sólido (SEI). Os autores deste estudo também apresentaram circuitos equivalentes de uma resistência em série com a resistência do eletrólito com capacitância em paralelo. Ao contrário, Strauss et al $^{15}$, em caso muito semelhante, quando o semicírculo não termina em zero atribuiu uma resposta de média freqüência a SEl, mesmo com dois semicírculos presentes. Como pode se inferir de todas as medidas, os valores de capacitância em uma região de alta freqüência, onde o semicírculo não termina em zero, são muito baixos e, provavelmente existem, no entanto, eles podem ser vistos 
em freqüência $\mathrm{GHz}$, o que não foi possível devido à limitação do equipamento que mede somente até freqüência $\mathrm{MHz}$. No nosso caso, as medidas de impedância para a amostra com 37 e 70 mostram as diferenças em altas frequências, o que é, provavelmente, devido ao contato dos eletrodos com a membrana, como uma conseqüência do processo de exsudação e confirmando os resultados UV-Vis (Figura 4-13). Também neste caso o aumento da temperatura promove uma diminuição da resistência real da membrana, portanto, um aumento na condutividade iônica.

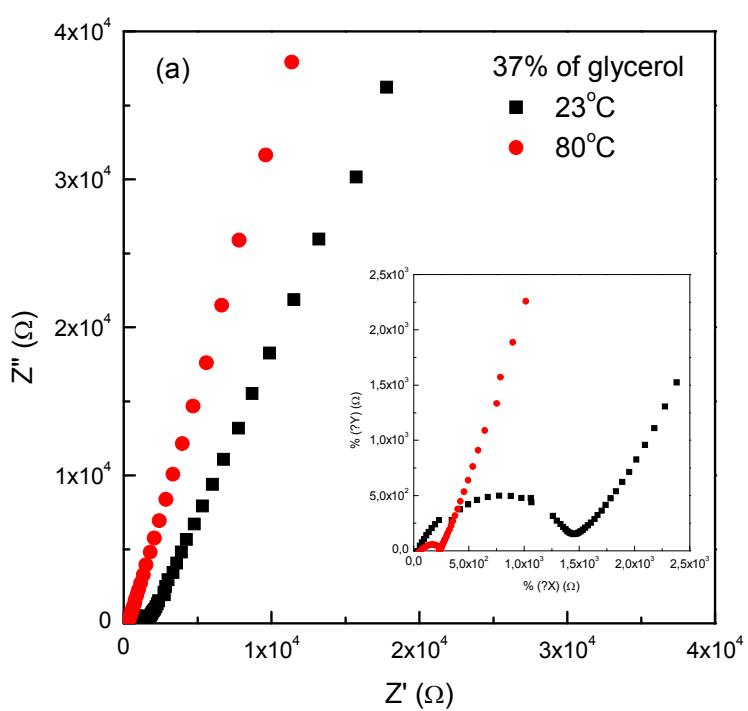

Figura 4-17: Diagrama de Nyquist do filme com $37 \%$ de glicerol e $0,24 \mathrm{~g}$ de $\mathrm{LiClO}_{4}$. 


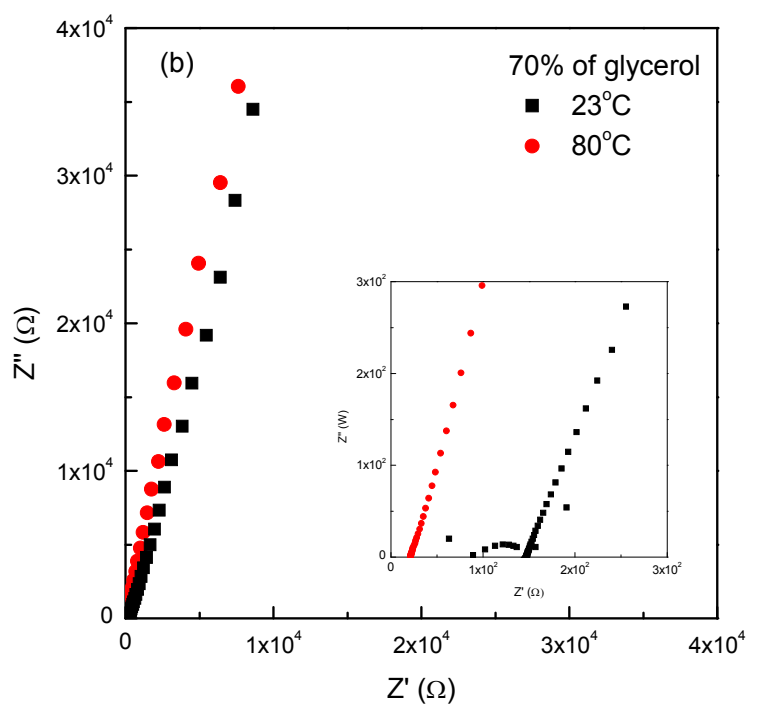

Figura 4-18: Diagrama de Nyquist do filme com 70\% de glicerol e 0,24g de $\mathrm{LiClO}_{4}$.

Quando há o auxílio da cadeia polimérica a condutividade obedece ao modelo VTF de condutividade expresso pela (Equação 4.1):

$$
\sigma(T)=\frac{A}{T^{1 / 2}} \exp \left[-\frac{\Delta E}{\left(T-T_{0}\right)}\right]
$$

Onde $T_{0}=T g-50 K$ é um valor característico do condutor iônico, onde a Tg é a temperatura de transição vítrea. Construindo-se o gráfico de $\ln \left(\sigma \mathrm{T}^{-0,5}\right)$ versus $10^{3} /(\mathrm{T}$ $\mathrm{T}_{0}$ ) determina-se os parâmetros $A$ e $\Delta E$ a partir dos coeficientes linear e angular da reta obtida.

O parâmetro $\Delta \mathrm{E}$ está relacionado com a energia de ativação do processo. Desta forma, a energia de ativação pode ser calculada pelo coeficiente angular da reta, e para o filme com $60 \%$ de glicerol a $\mathrm{Tg}=-62,51^{\circ} \mathrm{C}$.

Já para os outros filmes obteve-se aumento linear da condutividade com o aumento da temperatura, seguindo os parâmetros de $\operatorname{Arrhenius~}^{16}$ (Equação 4.2): 


$$
\log \sigma=\log A+\left(-E_{a} / 2,303 R T\right)
$$

onde A é uma constante que independe da temperatura, e é proporcional ao número de transporte iônico; Ea é a energia de ativação aparente, relacionada a deslocamento do íon e R é a constate dos gases ideais.

A Figura 4-19 mostra a tendência da energia de ativação para os EPGs com variação de glicerol e $0,24 \mathrm{~g}$ de $\mathrm{LiClO}_{4}$.

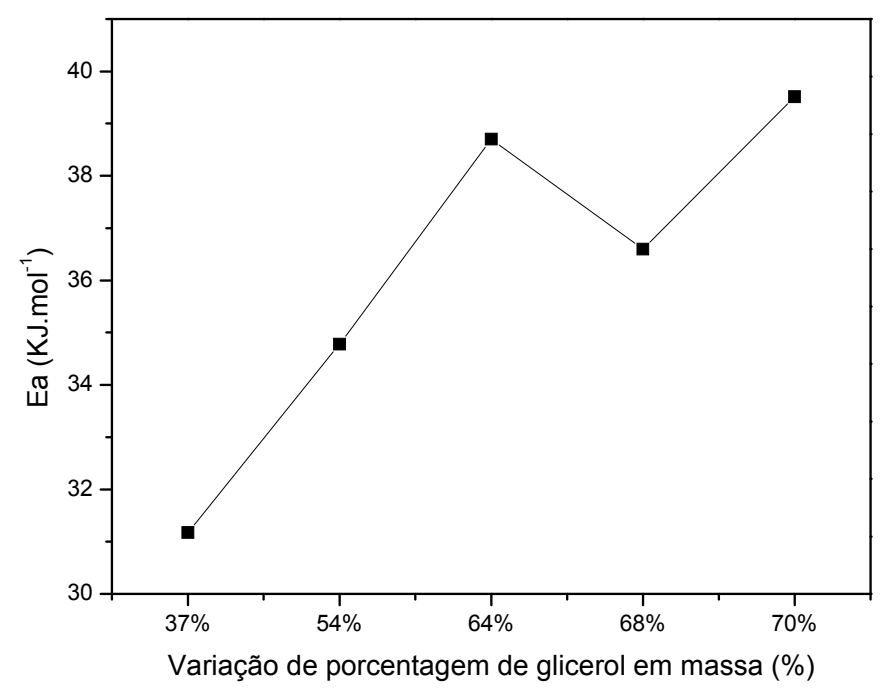

Figura 4-19: Energia de ativação em função da porcentagem de glicerol em massa.

Pode-se observar, pela Figura 4-19 que a energia de ativação aumenta com a quantidade de plastificante de $31 \mathrm{KJmol}^{-1} \mathrm{com} 37 \%$ de glicerol para $39 \mathrm{KJmol}^{-1} \mathrm{com}$ $64 \%$ de glicerol, ocorre um decaimento da energia no filme com $68 \%$ de glicerol para $37 \mathrm{KJmol}^{-1}$, e depois a energia aumenta novamente com $70 \%$ de glicerol para 40 $\mathrm{KJmol}^{-1}$.

Um tipo de representação do ensaio de impedância eletroquímica é através do diagrama de Bode, pelo qual é analisada a impedância absoluta (|Z|) em função da freqüência. 
O diagrama de Bode apresenta algumas vantagens sobre o diagrama de Nyquist. Uma delas é que devido à freqüência estar presente em um dos eixos, é fácil observar como a impedância depende da freqüência. Outra vantagem é a de, pelo fato do diagrama de Bode para $|Z|$ representar a magnitude $|Z|$ em escala logarítmica, pode ser apresentada uma vasta faixa de limites de impedância em um mesmo eixo. Isto é útil quando a impedância depende fortemente da freqüência, como no caso de sistemas eletroquímicos que atuam de forma capacitiva ${ }^{17}$. A Figura 4-20 mostra o diagrama de Bode da amostra com $70 \%$ de glicerol. Segundo o Munihandraiah et $a^{18}$ o decaimento linear do módulo de impedância no gráfico de Bode em baixas e médias freqüências pode ser atribuído a propriedade capacitiva do eletrólito a base de pectina. Em altas freqüências observa-se os valores constantes deste módulo o que pode ser atribuído a propriedade resistiva do filme. A falta de valores constantes em baixas freqüências pode ser comprovada no gráfico de Nyquist que ao invés de semicírculo apresenta um decaimento linear de impedância imaginária versus real. Em altas frequências, acima de $10^{6} \mathrm{~Hz}$ verifica-se novamente uma diminuição ou aumento linear dependendo da temperatura a qual foi submetida a amostras. Este comportamento pode ser explicado pelo comportamento capacitivo ou indutivo da amostra, respectivamente. 


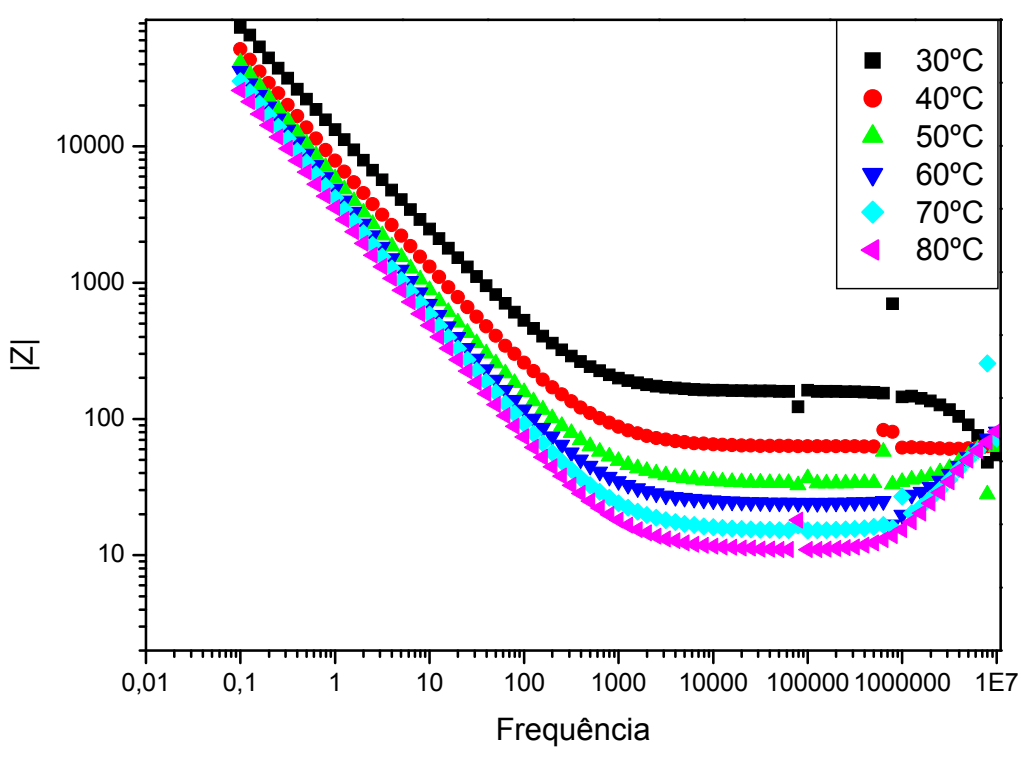

Figura 4-20: Diagrama de Bode do filme a base de pectina plastificada com $70 \%$ de glicerol e contendo $0,24 \mathrm{~g}$ de $\mathrm{LiClO}_{4}$.

Nas Figuras 4-21 e 4-22 apresenta-se o log da condutividade em função do potencial. Nota-se que para uma faixa de potencial que varia de $-1,5$ a $+1,5 \mathrm{~V}$, o valor da condutividade permanece quase constante, indicando que não há nenhuma reação eletrolítica. Entretanto, ao passar para $+2,0 \mathrm{~V}$ ou $-2,0 \mathrm{~V}$ ocorre uma diminuição do valor da condutividade. Desta forma, constatou-se que acima de 2,0V o eletrólito polimérico começa a sofrer alguma mudança estrutural, provavelmente devido à ocorrência de reações eletrolíticas.

Portanto, verificou-se que o eletrólito a base de pectina plastificada com glicerol, possui estabilidade eletroquímica em uma faixa de potencial que varia entre $-1,5 \mathrm{a}+1,5 \mathrm{~V}$. 


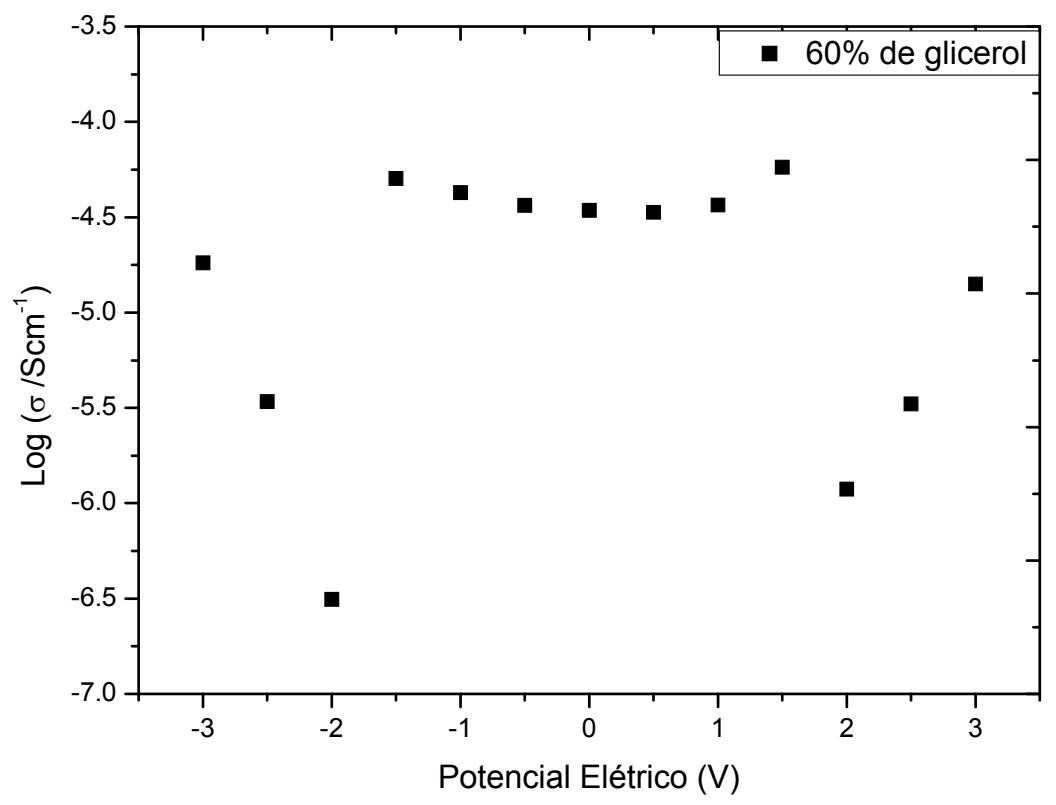

Figura 4-21: Variação de condutividade em função do potencial elétrico aplicado para os filmes com $60 \%$ de glicerol.

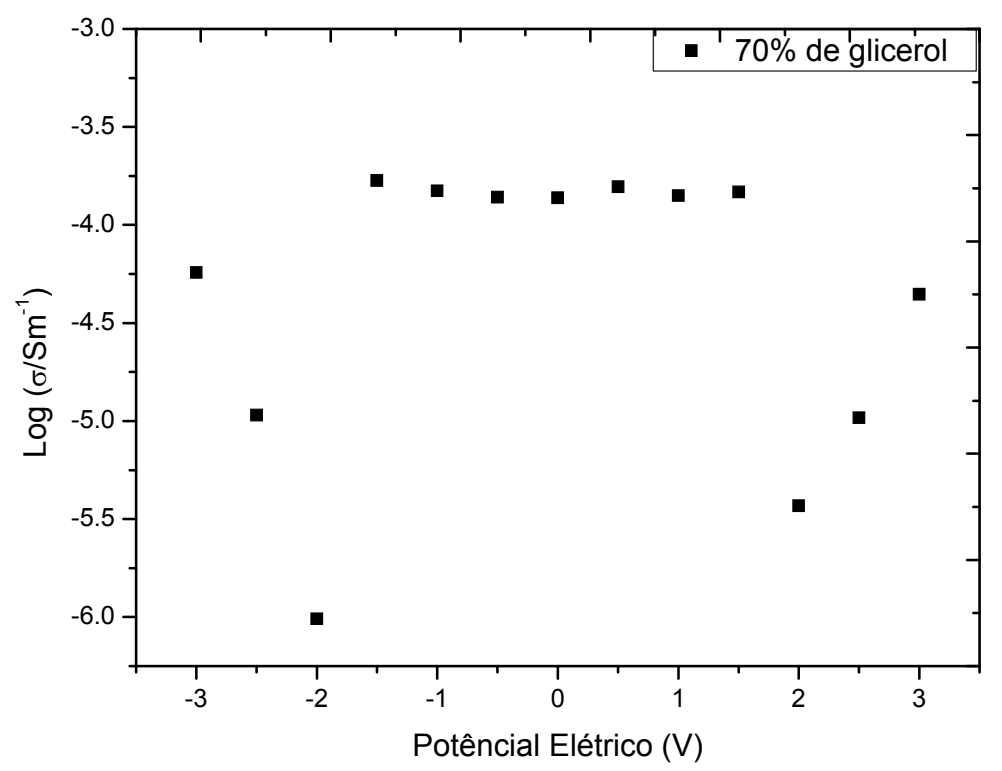

Figura 4-22: Variação de condutividade em função do potencial elétrico aplicado para os filmes com $70 \%$ de glicerol. 


\section{Janelas eletrocrômicas}

A partir da caracterização dos eletrólitos em relação a seus valores de condutividade iônica, fez-se a montagem de janelas eletrocrômicas ITO/ $\mathrm{WO}_{3}$ /eletrólito de pectina/ $/ \mathrm{CeO}_{2}-\mathrm{TiO}_{2} / \mathrm{ITO}$ e aplicou-se potenciais de $-3,5$ a $+3,0 \mathrm{~V}$, para verificar a eficiência desses ESGs.

A Figura 4-23 mostra o gráfico de voltametria cíclica da amostra com $70 \%$ de glicerol e $0,24 \mathrm{~g}$ de $\mathrm{LiClO}_{4}$. O resultado desta análise revelou um pico catódico a ($1,4 \mathrm{~V})$ relativo aos processos de redução e coloração para o azul da camada eletrocrômica de $\mathrm{WO}_{3}$ e um pico anódico correspondente a $(0,6 \mathrm{~V})$ relativo a oxidação desta camada e sua descoloração. Nos mesmos potenciais ocorrem também os processo reversos de oxidação e redução da camada $\mathrm{CeO}_{2}-\mathrm{TiO}_{2}$, chamada de reservatório de íons. Um acentuado aumento de corrente para potenciais abaixo de (-3V) é devido aos processos de redução de ITO e também ao processo de redução de hidrogênio da água do eletrólito. Portanto, os potenciais aplicados não deveriam ultrapassar (-2V). 


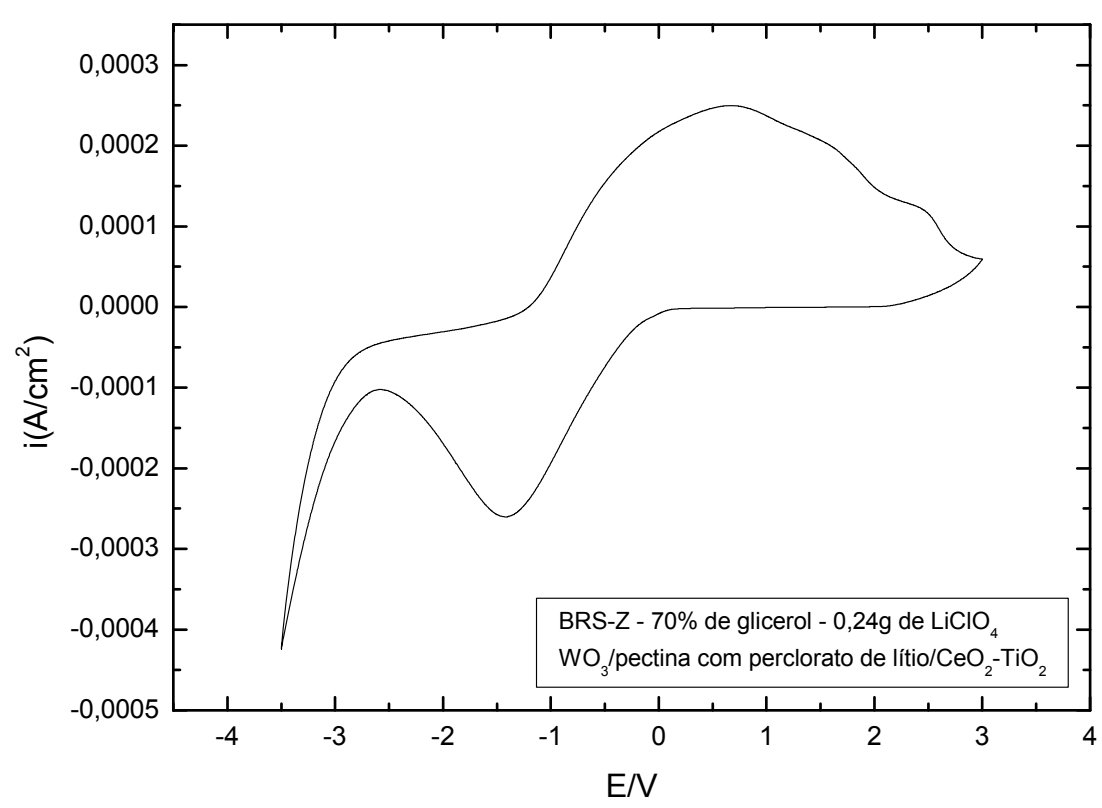

Figura 4-23: Voltametria cíclica da janela eletrocrômica ITO/ $\mathrm{WO}_{3}$ /eletrólito de pectina/ $/ \mathrm{CeO}_{2}-\mathrm{TiO}_{2} / \mathrm{ITO}$ com eletrólito a base de pectina plastificada com $70 \%$ de glicerol e contendo $\mathrm{LiClO}_{4}$ na concentração de $0,24 \mathrm{~g}$ de $\mathrm{LiClO}_{4}$.

\section{Cronoamperometria}

A Figura 4-24 mostra os resultados das cargas inseridas e extraídas durante a coloração e descoloração da janela eletrocrômica contendo eletrólito a base de pectina. Destes ensaios pode se verificar que os processos de inserção ocorrem relativamente rápido atingindo densidade de $8,5 \mathrm{mC} / \mathrm{cm}^{2}$. A extração também é rápida, recuperando o estado inicial também em $15 \mathrm{~s}$, contudo se comparada com resultados de outras janelas eletrocrômicas que descolorem em 2-5 s, esta é um pouco mais lenta ${ }^{19}$. A reversibilidade é de $97 \%$, o que indica que a janela é praticamente totalmente reversível. 


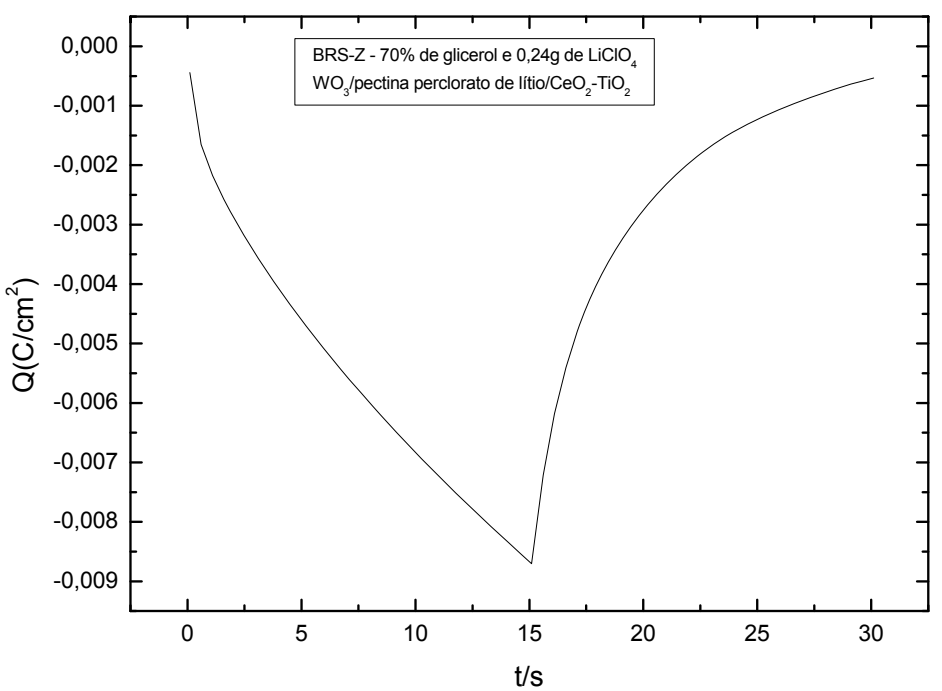

Figura 4-24: Densidade de carga catódica/anódica do eletrólito a base de pectina plastificada $70 \%$ de glicerol e contendo $\mathrm{LiClO}_{4}$ na concentração de $0,24 \mathrm{~g}$ de $\mathrm{LiClO}_{4}$.

\subsection{Eletrólitos Poliméricos a base de pectina BRS-Z, $30[0] /[\mathrm{Li}]$ e contendo diferentes concentrações de glicerol.}

Para investigar a influência da quantidade de portadores de carga nos ESGs foram preparadas e analisadas as amostras contendo $\mathrm{LiClO}_{4}$ na concentração de 30 [O]/[Li]. Também neste caso variou-se a concentração de glicerol de $37 \%$ a $70 \%$ $(\mathrm{m} / \mathrm{m})$.

\subsubsection{Difração de Raios-X}

Como no caso anterior também se verifica que a plastificação de pectina utilizando glicerol modifica a estrutura do filme, uma vez que há a quebra das ligações hidrogênio entre as cadeias poliméricas. Estas ligações são as 
responsáveis pela cristalinidade do polímero. Para analisar a influência do glicerol na estrutura das amostras, utilizaram-se filmes com $37 \%$ e $70 \%$ de glicerol.

A Figura 4-25 mostra que a adição de glicerol resulta em filmes de pectina com predominância do estado amorfo. Isso é confirmado pela presença de linhas de difração largas em cerca de $2 \theta=20^{\circ}$. Estas análises revelam uma modificação na intensidade do pico entre as amostras com $37 \%$ e $70 \%$ de glicerol, contudo como não foi feita a análise quantitativa é difícil de afirmar sobre a mudança de cristalinidade da amostra.

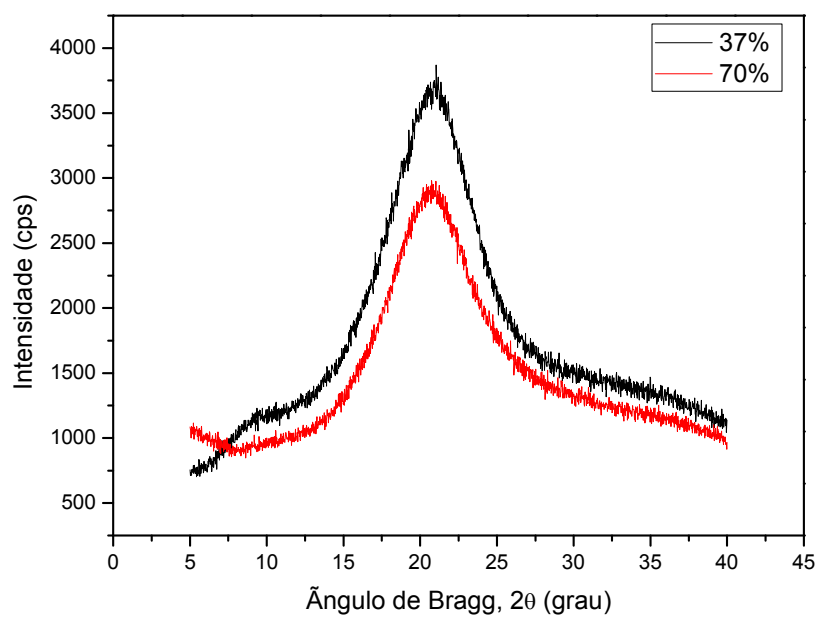

Figura 4-25: Difração de raios-X dos filmes a base de pectina com $\mathrm{LiClO}_{4}$ e com $37 \%$, e $70 \%$ de glicerol.

Entretanto, de um modo geral, o aumento na quantidade de glicerol promove maior afastamento entre as cadeias, tornando o filme mais amorfo e permitindo maior mobilidade dos íons como já observado em outros estudos ${ }^{20}$. Esta também é uma característica muito importante para os eletrólitos poliméricos. 


\subsubsection{Espectroscopia de Infravermelho - FT-IR}

Através dos espectros de FT-IR dos filmes de EPGs, Figura 4-26, pode se observar que com o aumento da quantidade de glicerol a banda na região de 3300$2500 \mathrm{~cm}^{-1}$ referente a deformação axial de $\mathrm{O}-\mathrm{H}$ se intensifica, isso é decorrente da estrutura química do plastificante.

Observa-se também que a região do "fingerprint" característico para cada polissacarídeo entre 1200 e $950 \mathrm{~cm}^{-1}$, não é alterada, com a produção do filme e nem entre as amostras o que significa que a estrutura do polímero não foi alterada.

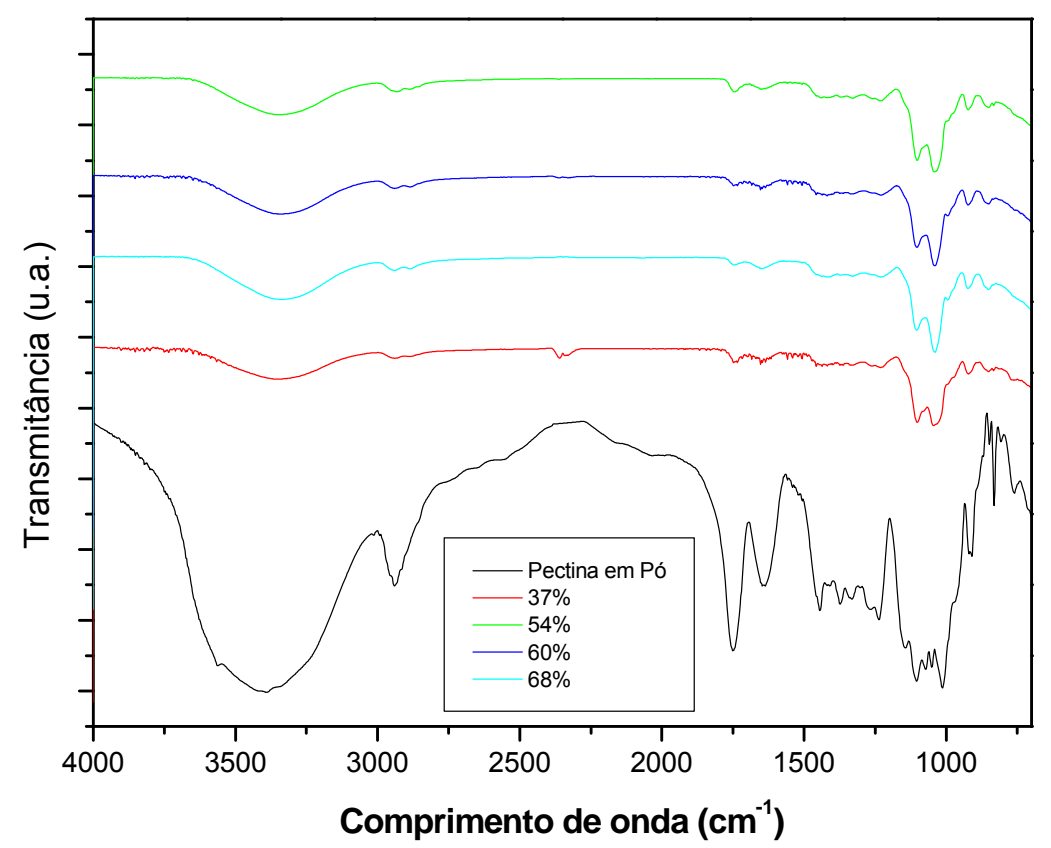

Figura 4-26: FT-IR dos ESGs variando a quantidade de glicerol e com 30[O]/[Li].

O FT-IR não é uma técnica sensível para os sais inorgânicos, portanto não foi observada nenhuma mudança nos espectros referente ao sal incorporado nos filmes. 


\subsubsection{Calorimetria Exploratória Diferencial (DSC)}

A técnica de calorimetria exploratória diferencial (DSC) foi utilizada nos eletrólitos poliméricos para a determinação da transição vítrea $(\mathrm{Tg})$, na qual se inicia o movimento segmental nas cadeias poliméricas. A passagem do estado vítreo para o estado de amorfo (mais flexível) é uma transição de segunda ordem, portanto, um processo acompanhado de variação de capacidade calorífica da amostra. Isso é manifestado pela mudança da linha base da curva DSC.

As Figuras de 4-27 a 4-29 mostram os valores da transição vítrea $(\mathrm{Tg})$ dos filmes. Observa-se que, com o aumento da concentração de glicerol (de 37\% para $70 \%$ ) ocorre uma diminuição na $\mathrm{Tg}$ de $-50^{\circ} \mathrm{C}$ para $-64^{\circ} \mathrm{C}$.

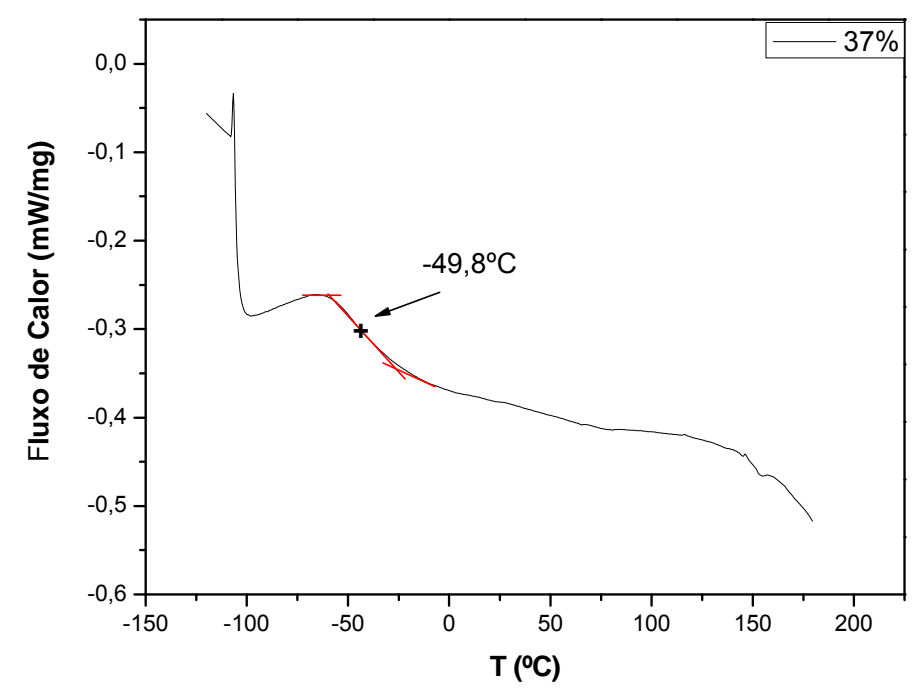

Figura 4-27: Curva de DSC do filme à base de pectina, com $37 \%$ de glicerol e $\mathrm{LiClO}_{4}$ 


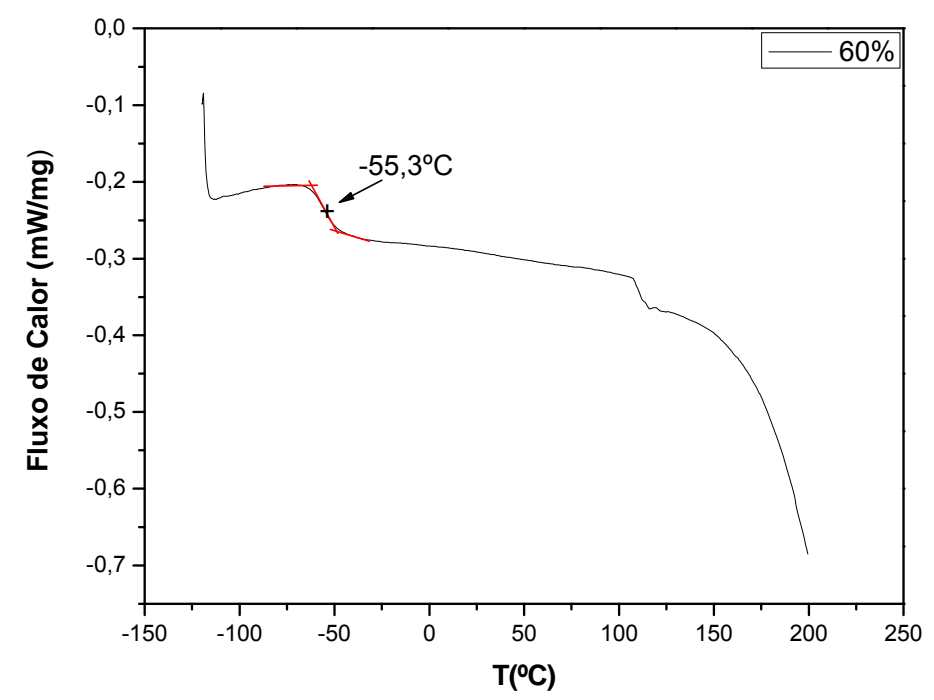

Figura 4-28: Curva de DSC do filme de à base de pectina, com $60 \%$ de glicerol e $\mathrm{LiClO}_{4}$

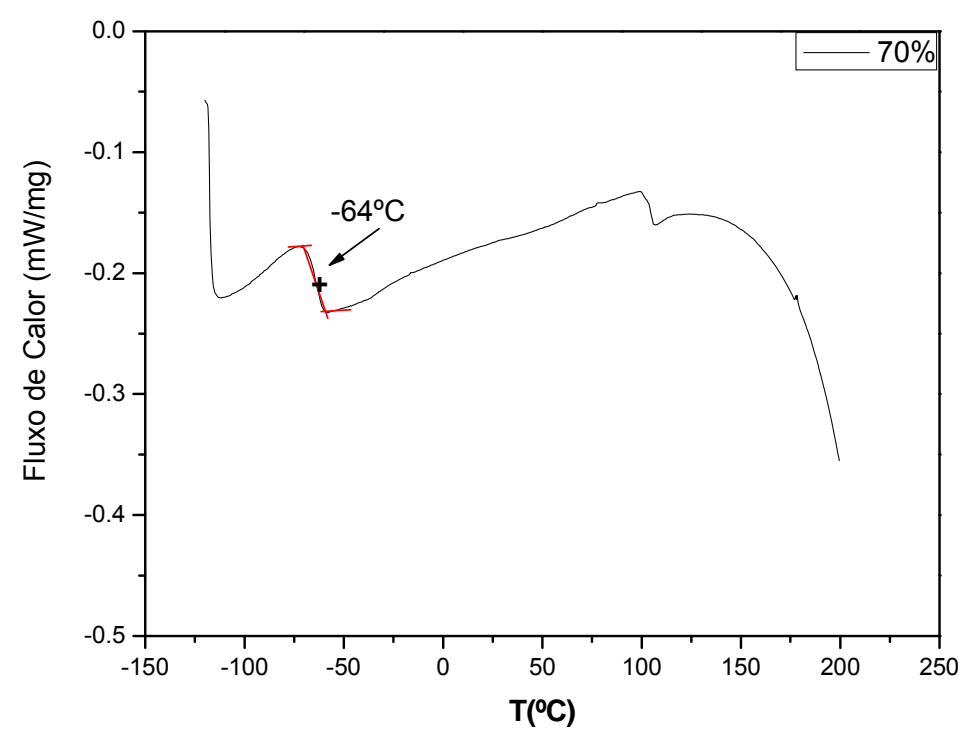

Figura 4-29: Curva de DSC do filme à base de pectina, com $70 \%$ de glicerol e $\mathrm{LiClO}_{4}$

\subsubsection{Termogravimetria (TG)}

As Figuras 4-30 e 4-31 apresentam as curvas de TG e DTG (derivative weight loss), respectivamente, da pectina em pó e dos ESGs com $\mathrm{LiClO}_{4}$ e $37 \%, 60 \%, 64 \%$ e $70 \%$ de glicerol. 


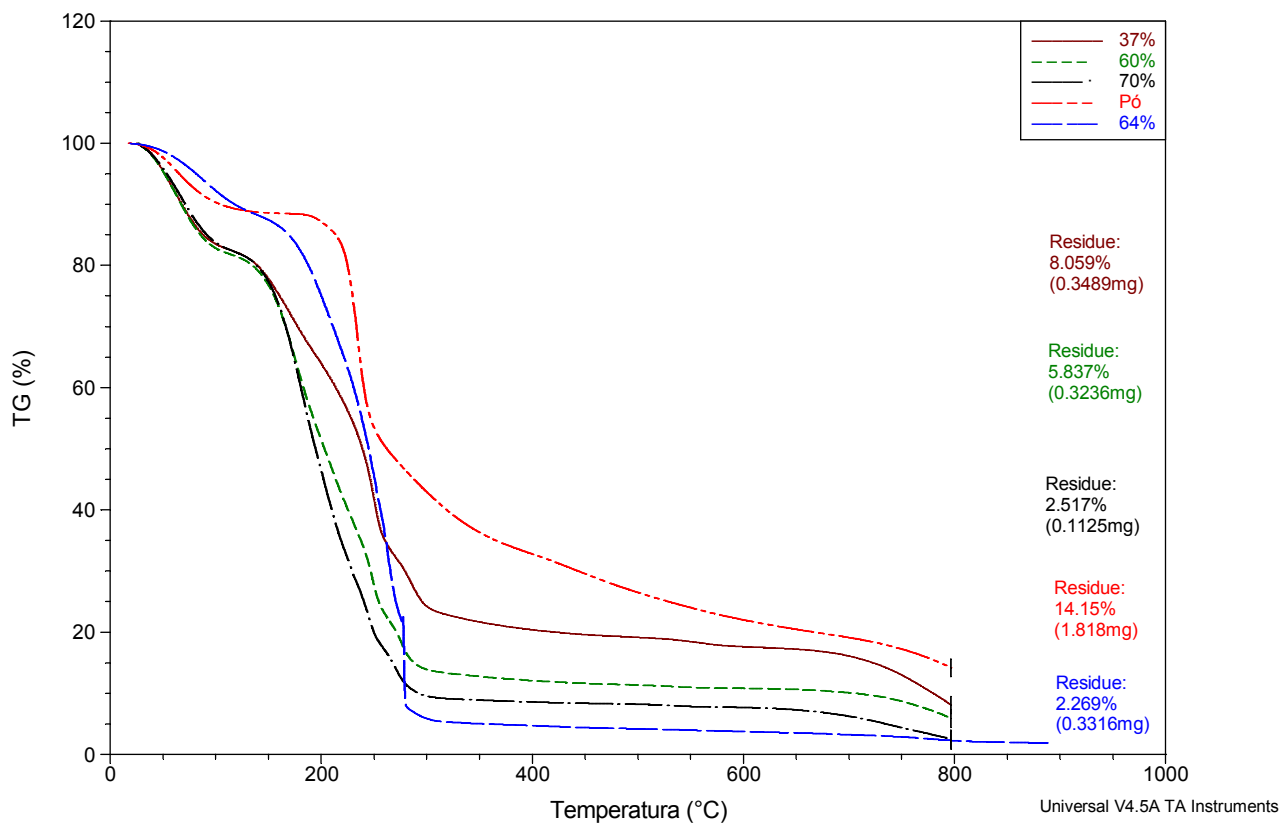

Figura 4-30: Curvas de TG para a pectina em pó, e para os filmes EPGs a base de pectina plastificada com 37\%, 60\%, 64\% e $70 \%$ de glicerol e $30[\mathrm{Li}] /[\mathrm{O}]$.

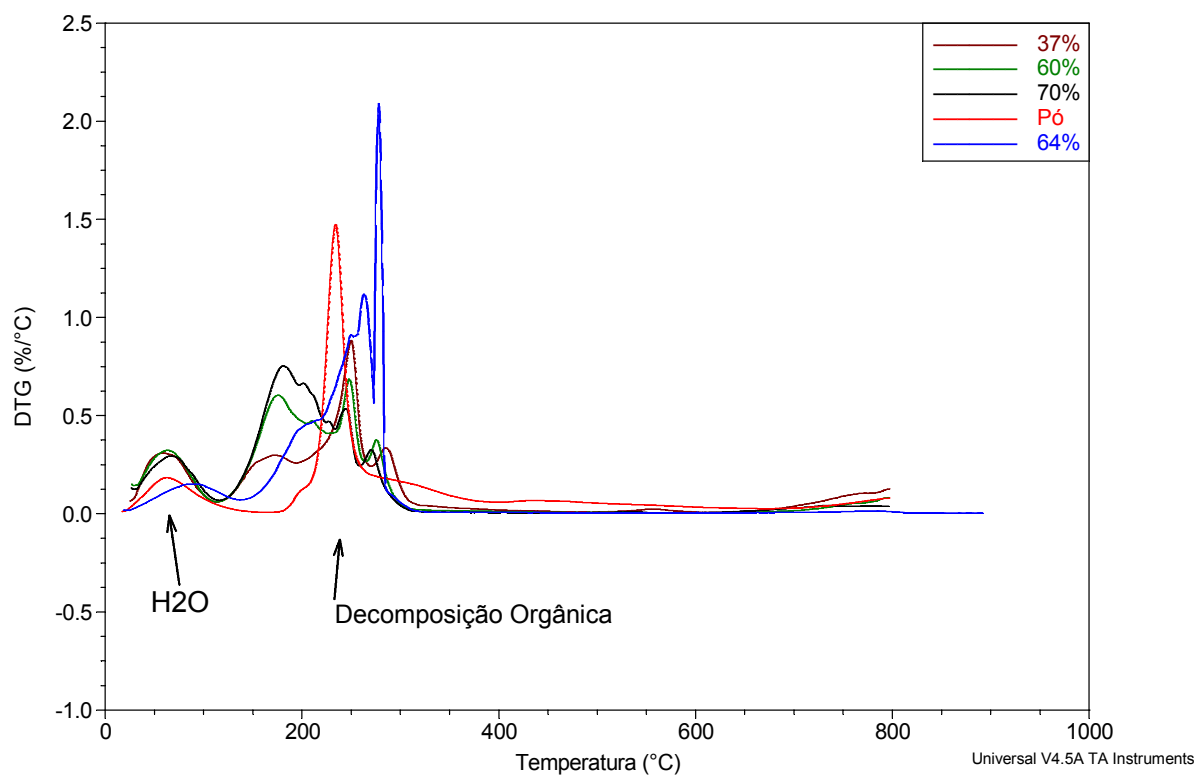

Figura 4-31: Curvas de DTG para a pectina em pó, e para os filmes EPGs a base de pectina plastificada com 37\%, 60\%, 64\% e $70 \%$ de glicerol e 30[O]/[Li].

As medidas termogravimétricas mostradas na Figura 4-30 evidenciam a perda de massa de $11 \%$ para a pectina pura e de 16 a $22 \%$ de massa dos filmes, 
respectivamente, da temperatura ambiente até $100^{\circ} \mathrm{C}$ para os filmes e até $150^{\circ} \mathrm{C}$ para a pectina. Tal fato pode ser atribuído à perda de água livre. É importante ressaltar que o glicerol e o perclorato de lítio são substâncias hidrofílicas, e que suas presenças promovem um aumento da capacidade de absorção de água no filme ${ }^{18}$.

Na região de $150^{\circ} \mathrm{C}$ a $300^{\circ} \mathrm{C}$, a amostra pura de pectina mostrou uma perda de massa muito acentuada de $45 \%$, o que pode ser atribuído à decomposição térmica do material. O resíduo remanescente foi de 14\%. A degradação dos filmes começou em $130^{\circ} \mathrm{C}$ e ocorreu em três fases. Isso pode ser devido à interação do lítio e do glicerol com o polissacarídeo da cadeia. No intervalo de $100^{\circ} \mathrm{C}$ a $300^{\circ} \mathrm{C}$ nos filmes obteve-se perdas de 60 a $74 \%$. Os resíduos variam de 2 a $8 \%$, sendo que a porcentagem de resíduo diminui com o aumento do plastificante. Pode-se notar na Figura 4-30 que os resíduos da amostra de pectina pura são maiores que os resíduos das amostras modificadas, isto é devido a formação do carbonato de lítio e impurezas ${ }^{20}$.

\subsubsection{Medidas de Transmitância na Região do UV-vis}

Os eletrólitos sólidos poliméricos são desenvolvidos com o objetivo de substituir os eletrólitos líquidos em vários dispositivos eletroquímicos. Para a maioria destes dispositivos, uma característica muito importante é a transparência. Esta é facilmente obtida nos eletrólitos líquidos, mas não tão facilmente nos eletrólitos sólidos, principalmente naqueles baseados em polímeros naturais.

Os espectros foram obtidos para a maioria dos filmes preparados, os quais variam suas espessuras conforme a variação da quantidade de plastificante. As 
espessuras obtidas foram de 0,23 a $0,43 \mathrm{~mm}$, e os filmes foram fixados diretamente no caminho ótico do aparelho.

Pela Figura 4-32, pode-se perceber que os valores de transmitância variam de 75 a $78 \%$ na região do visível (400 a 800 nm), o que são considerados bons resultados de transmitância, possibilitando a utilização dos eletrólitos em janelas eletrocrômicas $^{18}$.

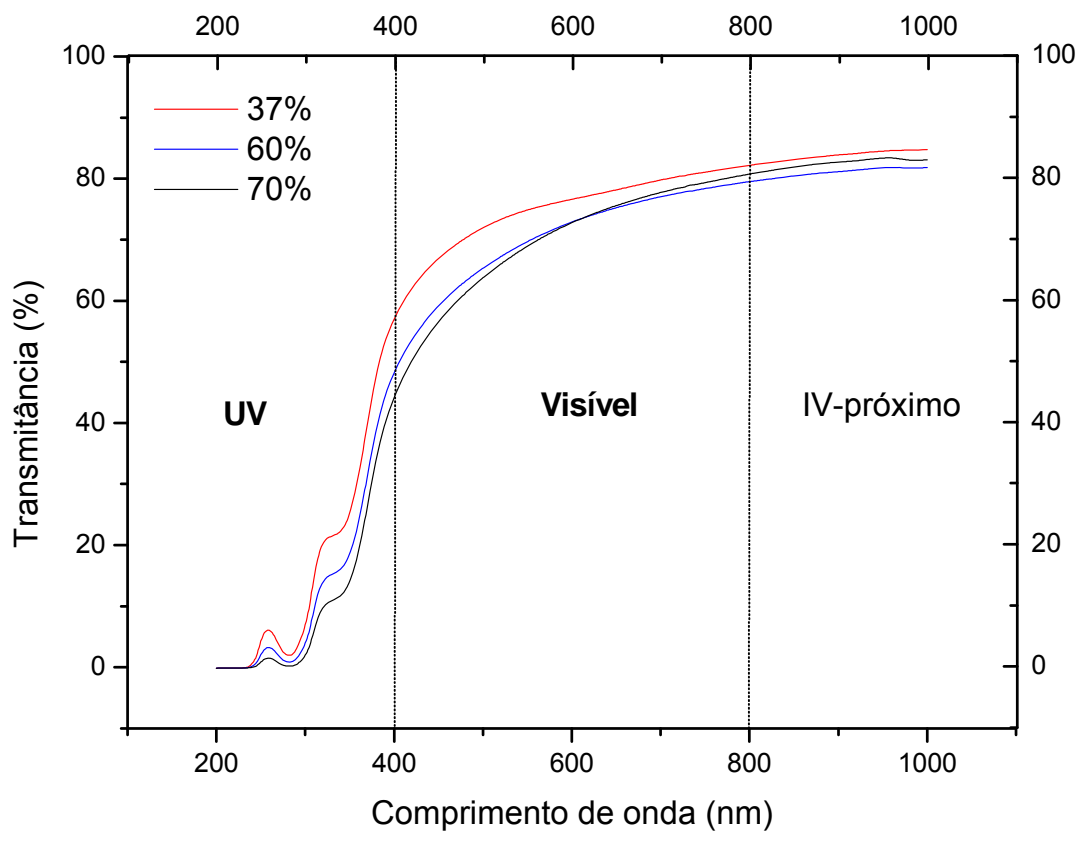

Figura 4-32: Espectro de UV-vis dos ESGs a base de pectina.

Na Figura 4-33, é possível ver a transparência do filme BRS-Z com $60 \%$ de glicerol e $30[\mathrm{O}] /[\mathrm{Li}]$, em uma placa de Petri. 


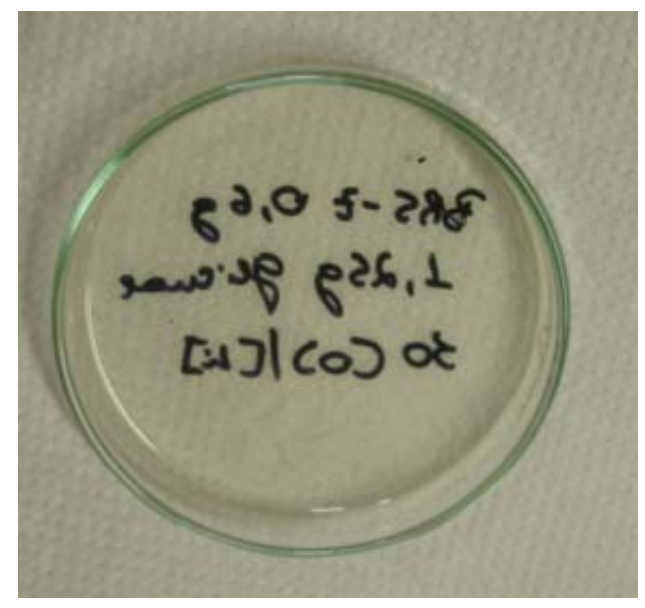

Figura 4-33: Foto do filme a base de pectina com $60 \%$ de glicerol e $30[\mathrm{O}] /[\mathrm{Li}]$.

\subsubsection{Microscopia Eletrônica de Varredura (MEV)}

Para caracterizar a superfície dos filmes, foram realizadas medidas de MEV com o objetivo de visualizar a estrutura e a morfologia do material em estudo.

Nas Figuras 4-34 e 4-35 podem ser observadas as superfícies das amostras contendo diferentes teores de plastificante e concentração de sal de 30 [O]/[Li]. Através das micrografias foi possível verificar que os filmes são homogêneos com presença de alguns agregados incrustados na superfície. Essas incrustações possivelmente são aglomerados do polímero ou, então, impurezas aderidas durante o manuseio das amostras. Em outros trabalhos incrustações semelhantes às aqui apresentadas foram observadas nos eletrólitos à base de amido, verificados por nosso grupo de pesquisa ${ }^{9,21,22}$. Contudo no caso dos eletrólitos feitos a partir de amido, ocorrem picos cristalográficos (difração de raios-X) do sal (perclorato de lítio) em todas as amostras de alta concentração de $\mathrm{LiClO}_{4}$, comprovando a presença desses cristais, mas isso não é observado nos difratogramas dos filmes com pectina (Figura 4-25) reforçando a suposição que as incrustações não são devido ao sal, pois os filmes apresentados neste trabalho tem baixa concentração de sal. 

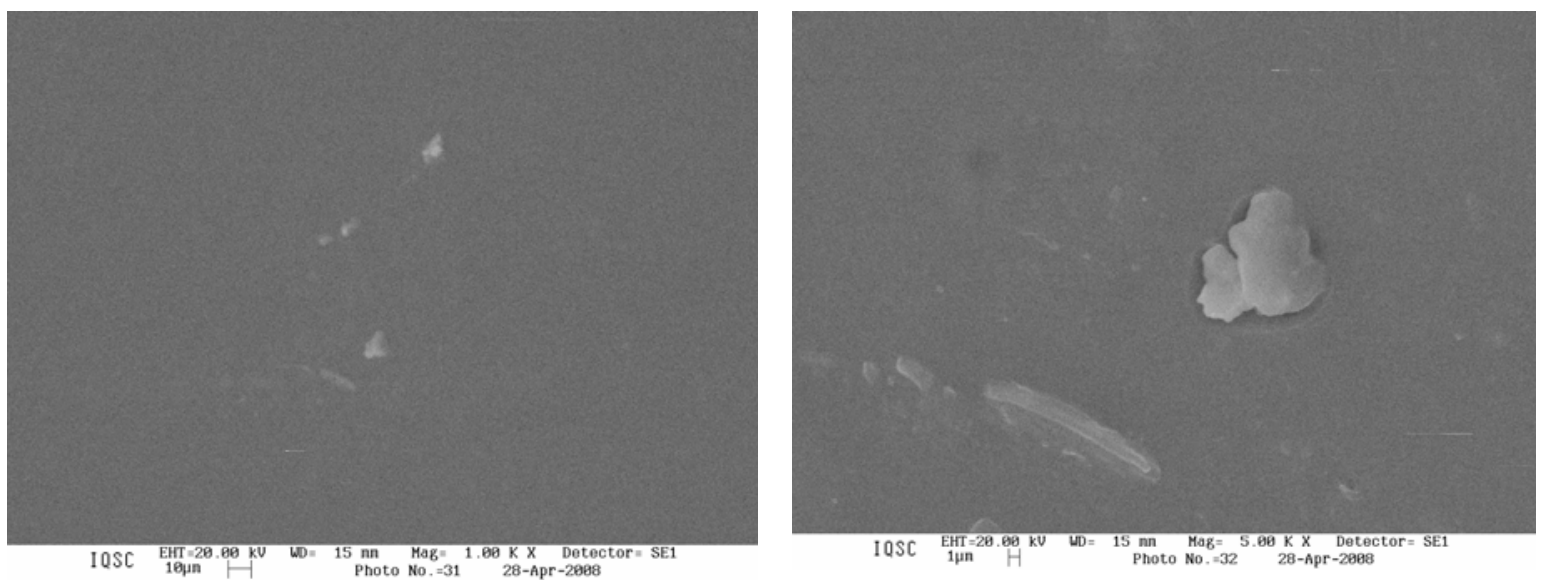

Figura 4-34: Micrografia das amostras com 37\% de glicerol (aumento de 1000X e 5000X).
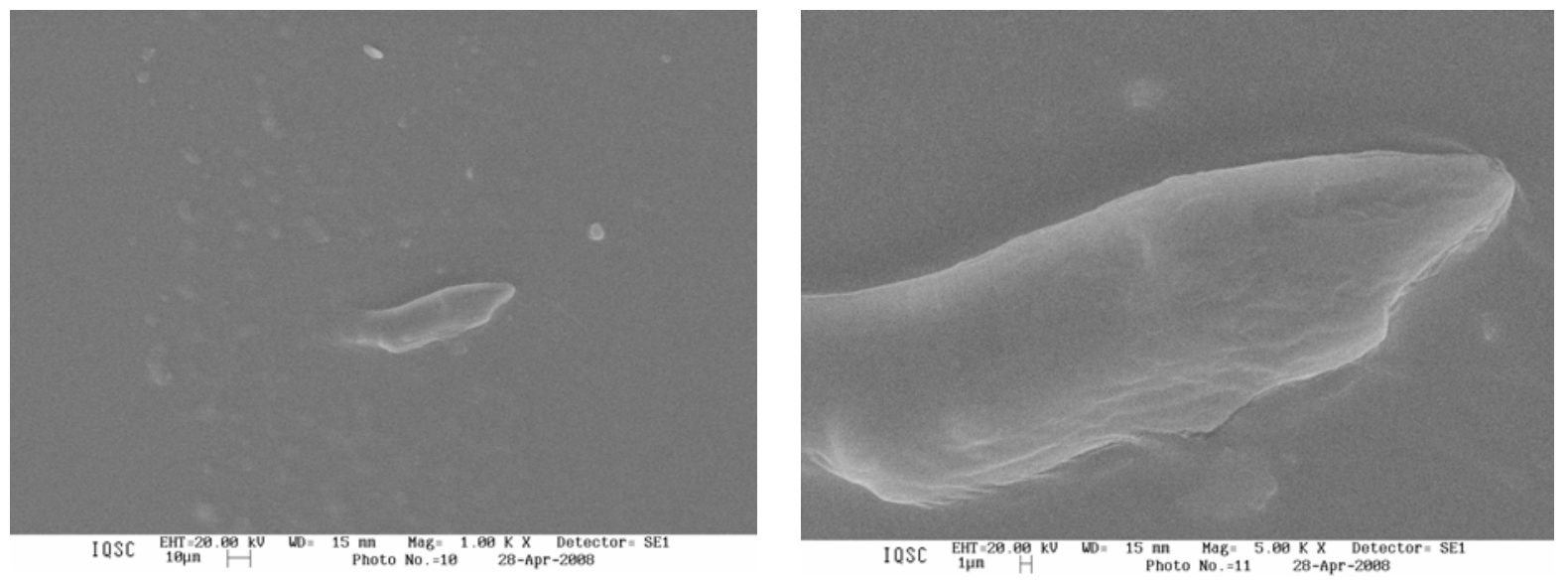

Figura 4-35: Micrografia das amostras com 70\% de glicerol (aumento de 1000X e $5000 X)$.

Segundo Machado ${ }^{23}$ pelos espectros de DSC pode-se evidenciar se as incrustações na superfície do filme seriam devido à presença de sal não dissociado, com o aparecimento de um pico em torno de $65^{\circ} \mathrm{C}$, mas nas curvas de DSC (Figuras 4-27 a 4-28) dos filmes com pectina não apresentam nenhum pico nesta região. Portanto, as alterações nas imagens dos ESGs com pectina provavelmente são provenientes mesmo do polímero, ou impurezas. 
Com essas características as amostras se mostram boas candidatas para aplicação em janelas eletrocrômicas.

\subsubsection{Condutividade lônica dos Filmes à base de Pectina}

Para as medidas de resistência utilizou-se o espectrômetro de impedância. As amostras foram submetidas a variação de temperatura de ambiente à $80^{\circ} \mathrm{C}$, com intervalo de $10^{\circ} \mathrm{C}$, para se obter os valores de condutividade dos filmes à base de pectina com $30[\mathrm{O}] /[\mathrm{Li}]$ e várias concentrações de glicerol.

Como já comentado anteriormente a adição de plastificante nos filmes provoca uma diminuição da cristalinidade e da temperatura de transição vítrea do polímero, além de permitir maior mobilidade dos íons, aumentando a condutividade iônica ${ }^{14}$.

O glicerol, plastificante utilizado neste trabalho, possui grupos $\mathrm{OH}$ que são capazes de formar ligações hidrogênio com a pectina, permitindo um maior distanciamento entre as cadeias tornando os filmes mais maleáveis ${ }^{15}$.

Observa-se, na Figura 4-36, que o aumento de quantidade de glicerol promove uma diminuição de condutividade iônica de $10^{-5} \mathrm{~S}_{\mathrm{cm}} \mathrm{cm}^{-1}$ para $10^{-7} \mathrm{~S}_{\mathrm{cm}} \mathrm{cm}^{-1} \mathrm{e}$ depois um aumento da condutividade para $10^{-4} \mathrm{~S} . \mathrm{cm}^{-1}$ à $30^{\circ} \mathrm{C}$ com uma pequena variação nos resultados da amostra com $68 \%$ de glicerol. 


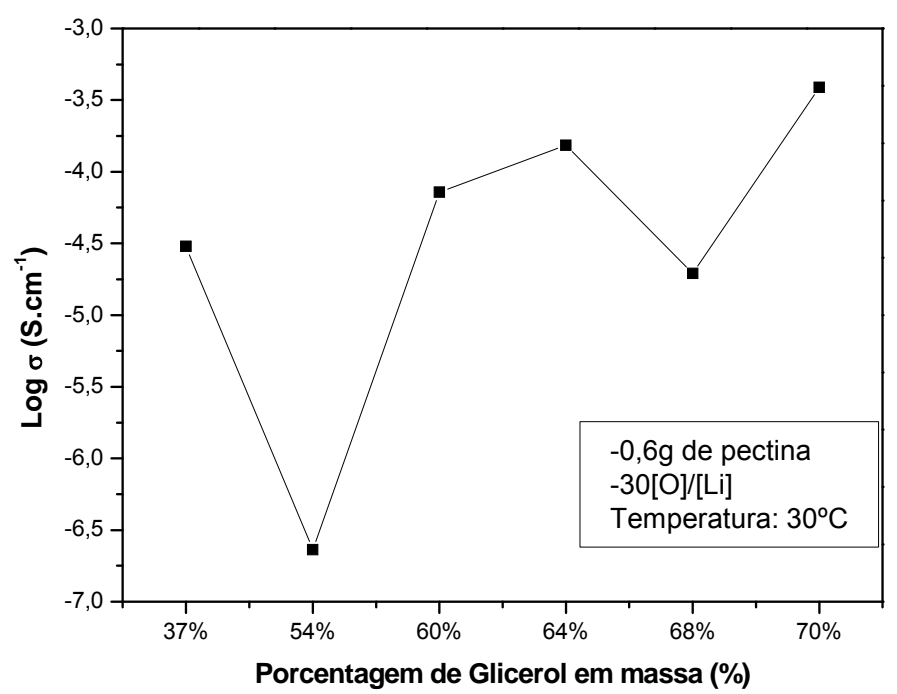

Figura 4-36: Medidas de log da condutividade em função da porcentagem em massa de glicerol a temperatura ambiente para as amostras com 30[O]/[Li] de $\mathrm{LiClO}_{4}$.

Os resultados dos valores de condutividade iônica em função da temperatura estão mostrados na Figura 4-37

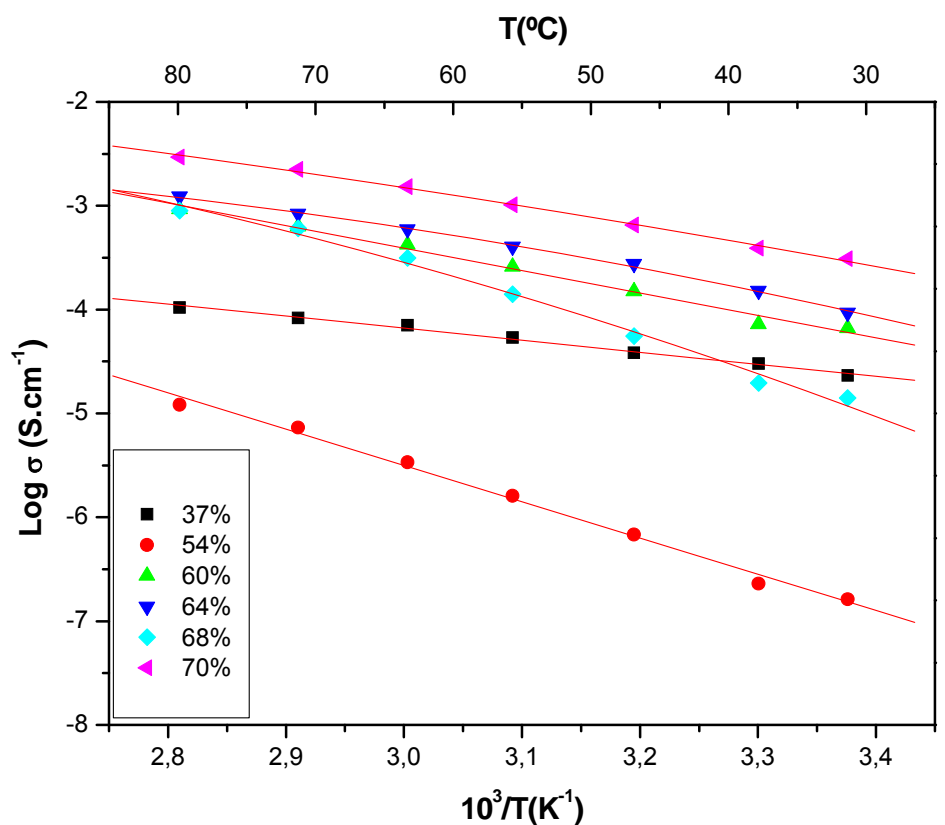

Figura 4-37: Logaritmo da condutividade em função do inverso da temperatura para amostras de pectina plastificada com glicerol, contendo 30 [O]/[Li] 
Pelas curvas da Figura 4-37 pode-se avaliar a forma com que as espécies migram na matriz polimérica. O gráfico mostra que a condutividade tende a ser linear com o aumento da temperatura para os filmes com baixa concentração de glicerol, seguindo os parâmetros de Arrhenius, na equação (4.2). Nos filmes acima de $64 \%$ de glicerol exibem um comportamento do tipo VTF, este leva em conta a movimentação das cadeias poliméricas que auxiliam o transporte iônico e é mias observado em sistemas do tipo de polímeros enxertados, onde o movimento dos íons é auxiliado pelo movimento das cadeias poliméricas. Segundo estudos de Pereira ${ }^{24}$, eletrólitos com baixa concentração de sal tendem para o comportamento do tipo VTF.

A energia de ativação provém da idéia de que as moléculas devem possuir uma quantidade mínima de energia cinética para reagir. Esta energia é aquela necessária para transformar os reagentes em produtos ${ }^{16}$. Neste caso a energia de ativação é ligada a movimentação das espécies condutoras iônicas e da Figura 4-38 pode ser observado que os valores de Ea são inversamente proporcionais aos valores de condutividade iônica das amostras a base de pectina, sendo maior valor de condutividade para a amostra plastificada com $70 \%$ de glicerol. 


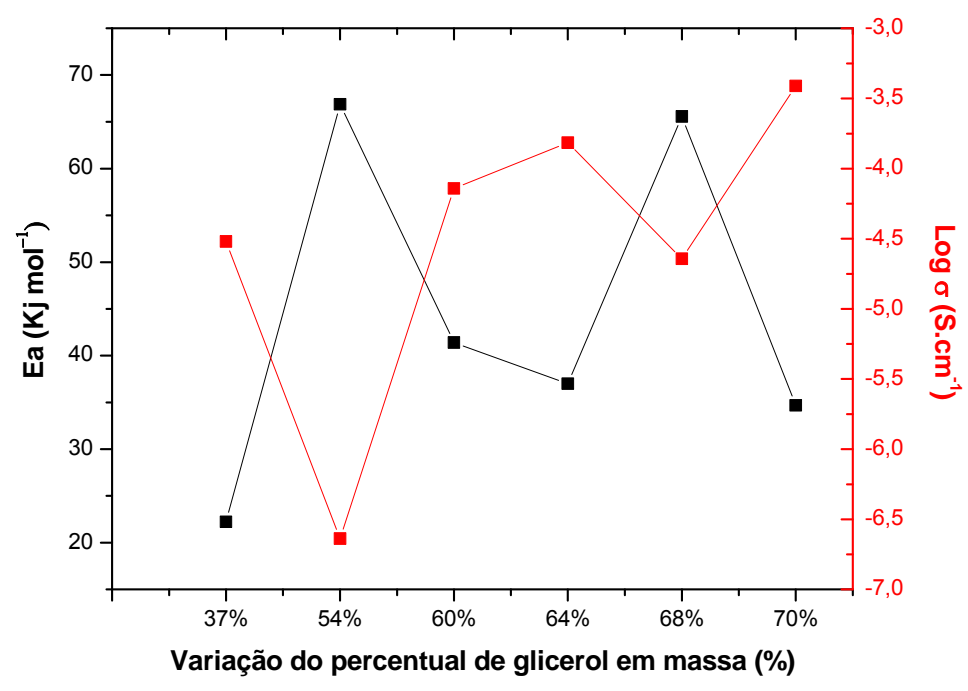

Figura 4-38: Energia de ativação e log da condutividade versus concentração de glicerol.

Um dos formatos mais utilizados para a análise dos ensaios de espectroscopia de impedância eletroquímica é o diagrama de Nyquist apresentado na Figura 4-39 e 4-40, referentes aos filmes com 64\% e $70 \%$ de glicerol $(\mathrm{m} / \mathrm{m})$ nas temperaturas de $30^{\circ} \mathrm{C}$ e $80^{\circ} \mathrm{C}$, respectivamente.

O diagrama de Nyquist é construído lançando-se os valores dos componentes reais e imaginários da impedância, para cada freqüência de excitação aplicada. Pode-se verificar que ocorre o aumento da condutividade com o aumento da temperatura. 


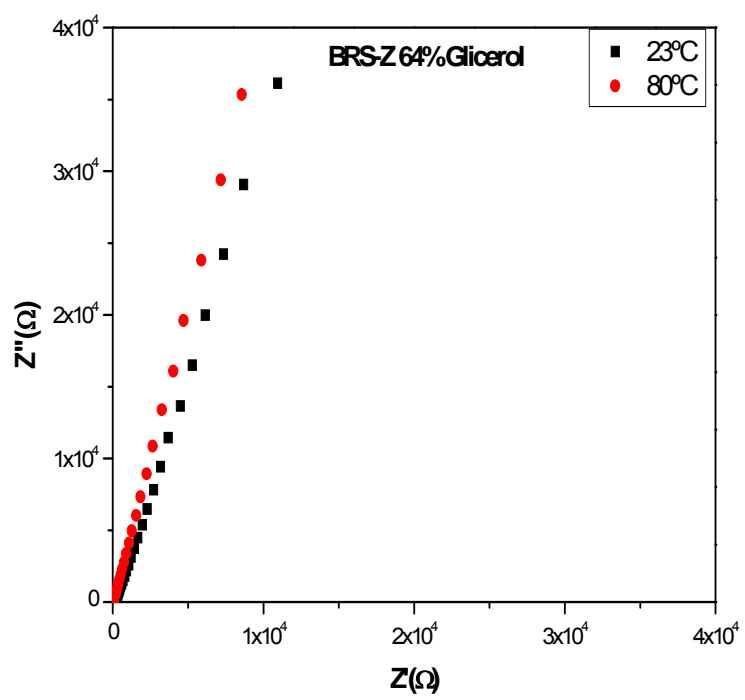

Figura 4-39: Diagrama de Nyquist do filme com 64\% de glicerol, 30[O]/[Li].

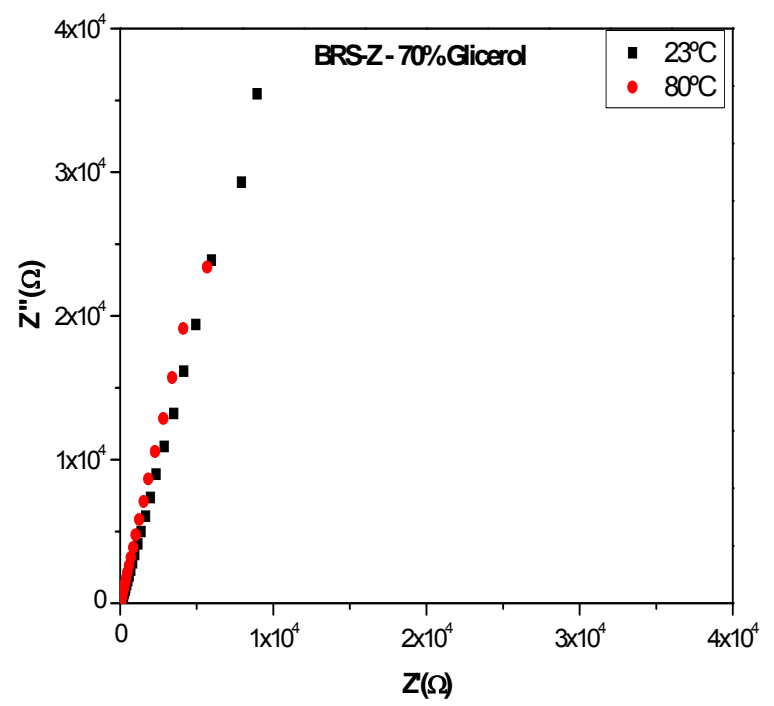

Figura 4-40: Diagrama de Nyquist do filme a base de pectina plastificada com $70 \%$ de glicerol e contendo $\mathrm{LiClO}_{4}$ na concentração de 30[O]/[Li].

Outro tipo de representação do ensaio de impedância eletroquímica é através do diagrama de Bode, pelo qual é analisada a impedância absoluta (|Z|) e/ou o ângulo de fase da impedância $(\theta)$, ambos em função da freqüência. 
Nas Figuras 4-41 e 4-42 são apresentados os diagramas de Bode das amostras contendo $64 \%$ e $70 \%$ de glicerol. Os gráficos são parecidos com os gráficos das amostras com $0,24 \mathrm{~g}$ de sal, onde em baixas freqüências observa se um decaimento linear do módulo de impedância relativo ao comportamento capacitivo da amostra. Em freqüências médias e altas obtêm-se um valor constante deste módulo o que pode ser atribuído a parte resistiva da amostra. Em freqüências muito altas há um início de aumento ou diminuição linear do módulo de impedância relativo novamente a parte capacitiva ou indutiva da amostra.

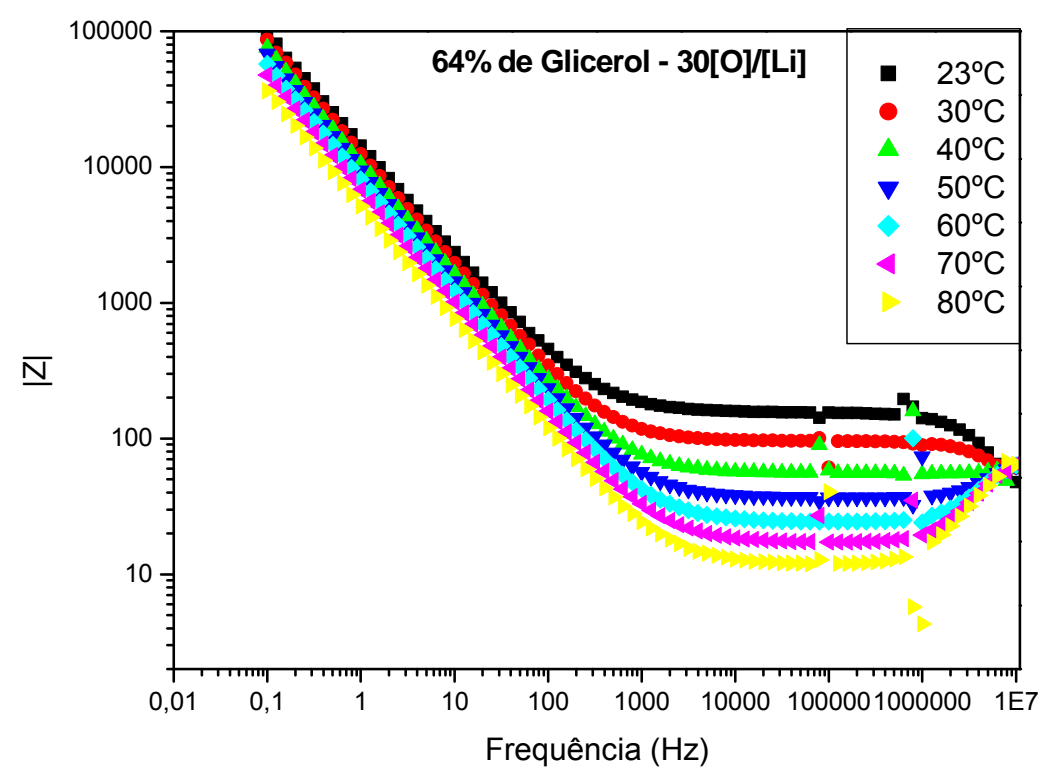

Figura 4-41: Diagrama de Bode do filme a base de pectina, contendo $\mathrm{LiClO}_{4}$, plastificado com $64 \%$ de glicerol. 


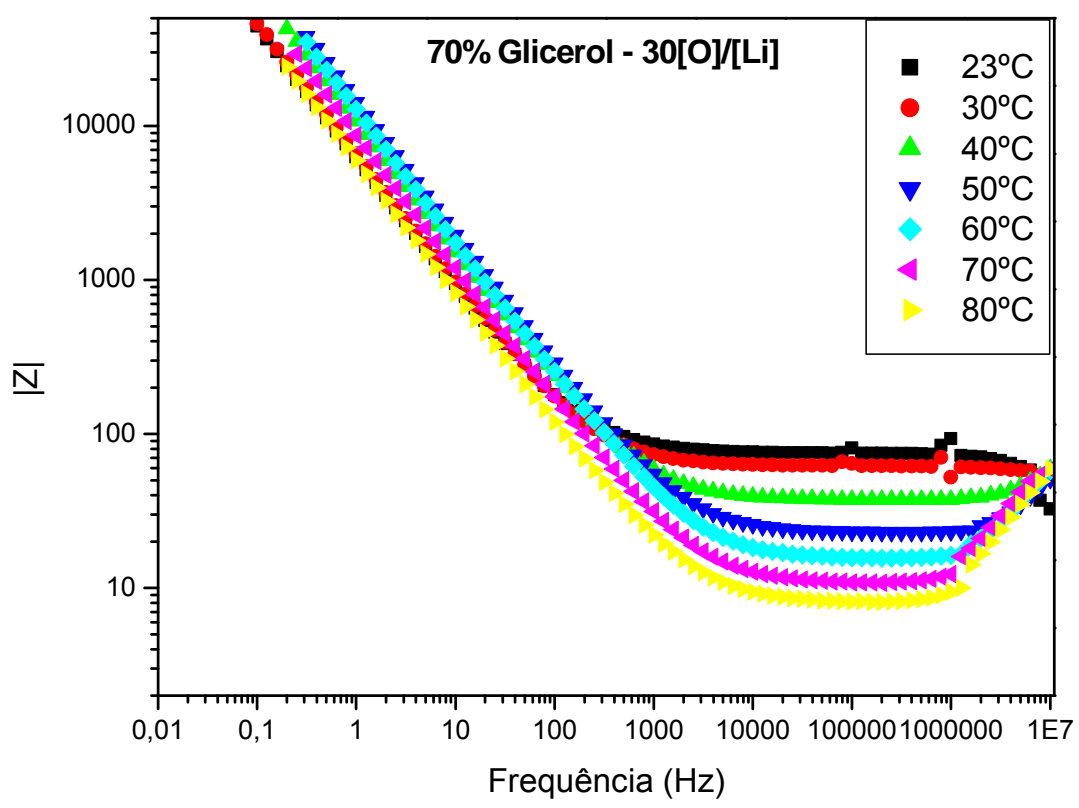

Figura 4-42: Diagrama de Bode do filme a base de pectina, contendo $\mathrm{LiClO}_{4}$ plastificado com $70 \%$ de glicerol.

A partir da caracterização dos eletrólitos, fez-se a montagem de janelas eletrocrômicas ITO/ $\mathrm{WO}_{3} /$ eletrólito de pectina/ $\mathrm{CeO}_{2}-\mathrm{TiO}_{2} / \mathrm{ITO}$ e aplicou-se potenciais de $-2,5$ a $+2,0$, para verificar a eficiência desses ESGs.

A Figura 4-43 mostra o gráfico de voltametria cíclica da amostra de dispositivo contendo eletrólito a base de pectina plastificada com $70 \%$ de glicerol e contendo $\mathrm{LiClO}_{4}$ na concentração de $30[\mathrm{O}] /[\mathrm{Li}]$. Também neste caso verifica-se dois picos relativos aos processos de oxidação e redução de camadas de filmes finos cerâmicos, sendo $\mathrm{O}^{\mathrm{WO}_{3}}$ filme eletrocrômico que muda sua coloração de transparente para o azul em potenciais catódicos $(-1,4 \mathrm{~V})$ e volta para o estado transparente em potenciais anódicos, i.e, $(0,6 \mathrm{~V})$. 


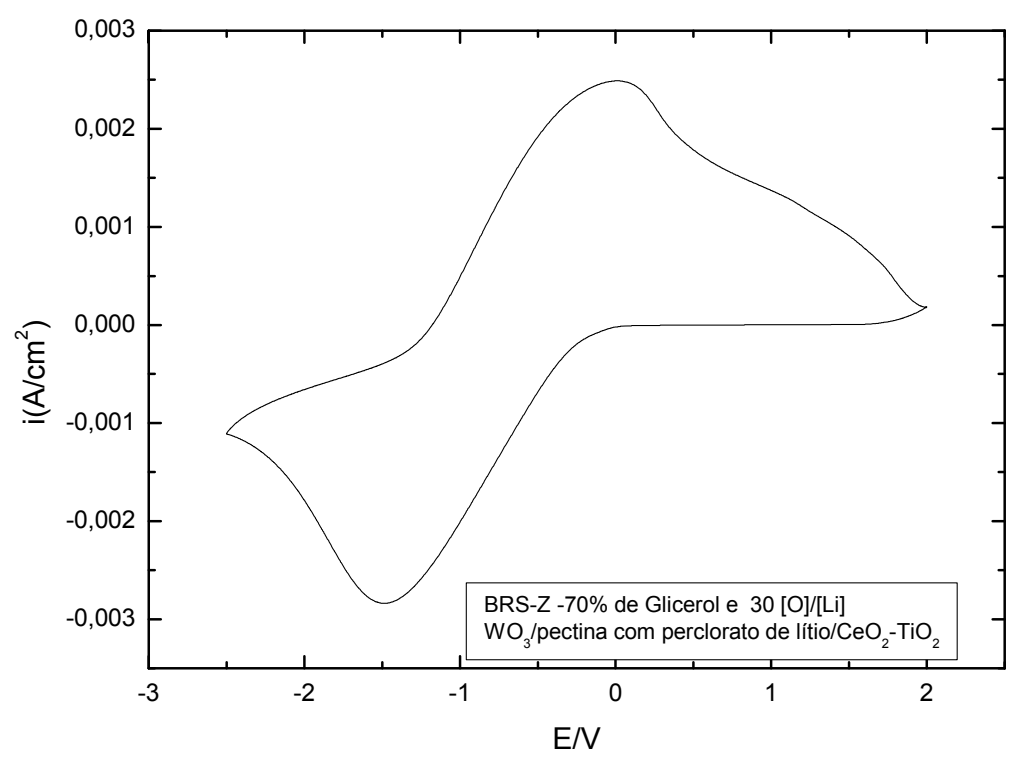

Figura 4-43: Voltametria cíclica da janela eletrocrômica ITO/ $\mathrm{WO}_{3}$ /eletrólito de pectina/ $\mathrm{CeO}_{2}-\mathrm{TiO}_{2} / \mathrm{ITO}$ com eletrólito a base de pectina plastificada com $70 \%$ de glicerol e contendo $\mathrm{LiClO}_{4}$ na concentração de 30 [O]/[Li].

Os resultados de cargas inseridas e extraídas para o sistema descrito acima estão apresentados na Figura 4-44, onde se nota que o processo de inserção/coloração atinge valores de densidade de $85 \mathrm{mC} / \mathrm{cm}^{2}$. Próximos 20 segundos de aplicação de potencial inverso, anódico, promove a descoloração do dispositivo. 


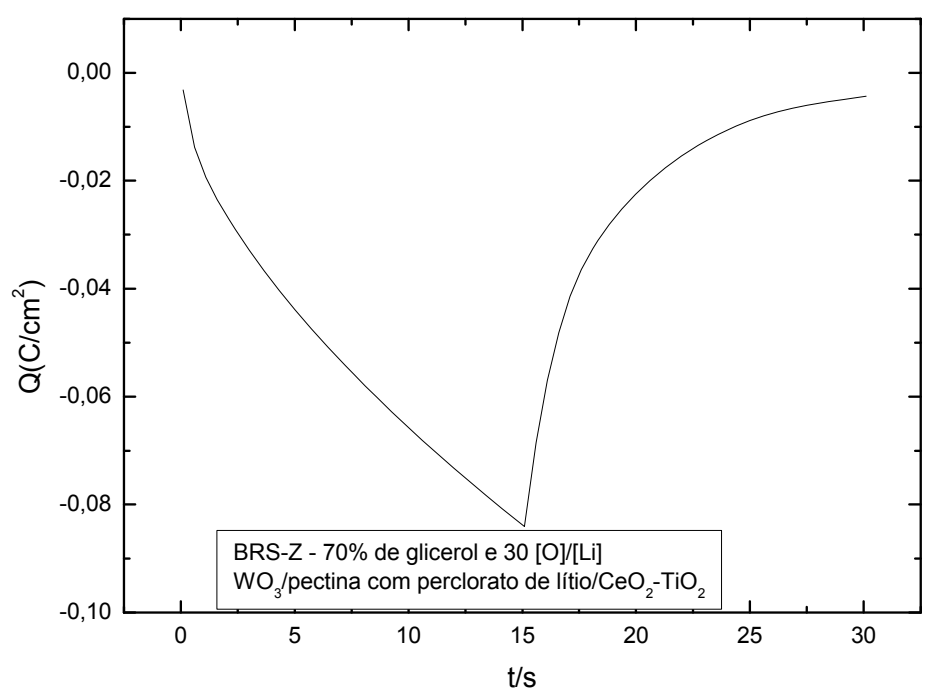

Figura 4-44: Densidade de carga catódica/anódica com eletrólito a base de pectina plastificada $70 \%$ de glicerol e contendo $\mathrm{LiClO}_{4}$ na concentração de 30 [O]/[Li].

A mudança de coloração da janela eletrocrômica estudada foi registrada através de fotografia, cujos resultados estão mostrados na Figura 4-45. Nesta figura pode-se constatar o estado inicial, descolorido da janela, que após o processo de redução muda de coloração para o azul e sua posterior descoloração após a aplicação do potencial anódico.
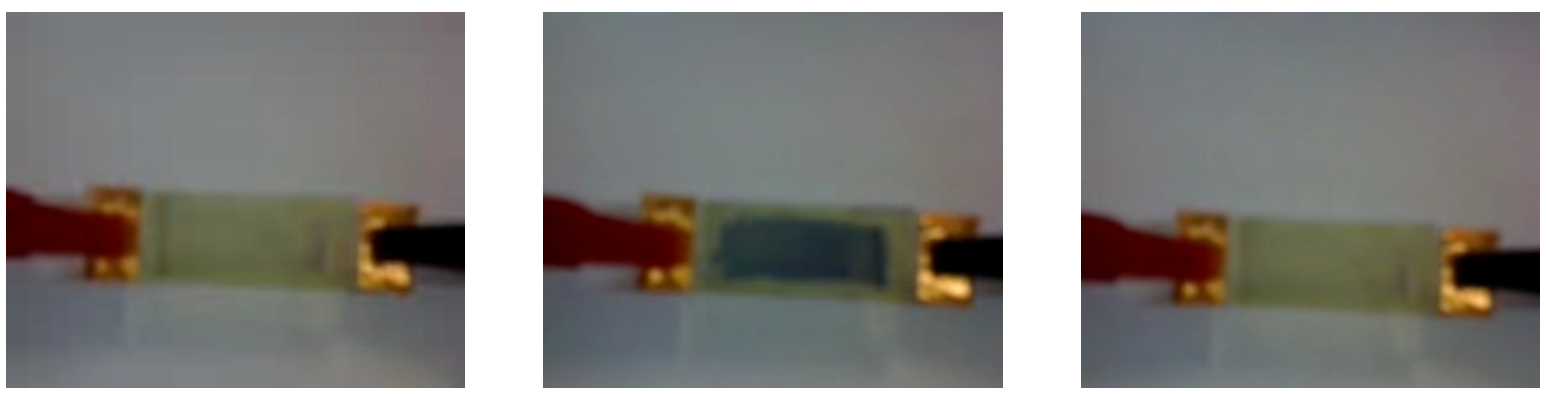

Figura 4-45: Fotos da janela eletrocrômica ITO/ $\mathrm{WO}_{3} /$ eletrólito de pectina/ $/ \mathrm{CeO}_{2}-$ $\mathrm{TiO}_{2} / \mathrm{ITO}$ com eletrólito a base de pectina plastificada $70 \%$ de glicerol e contendo $\mathrm{LiClO}_{4}$ na concentração de 30[O]/[Li]

A mudança de coloração da janela eletrocrômica também foi registrada através de análises espectroscópicas (Figura 4-46) onde há uma mudança de 
transmitância na região visível do espectro eletromagnético de $28 \%$ entre o estado colorido e descolorido.

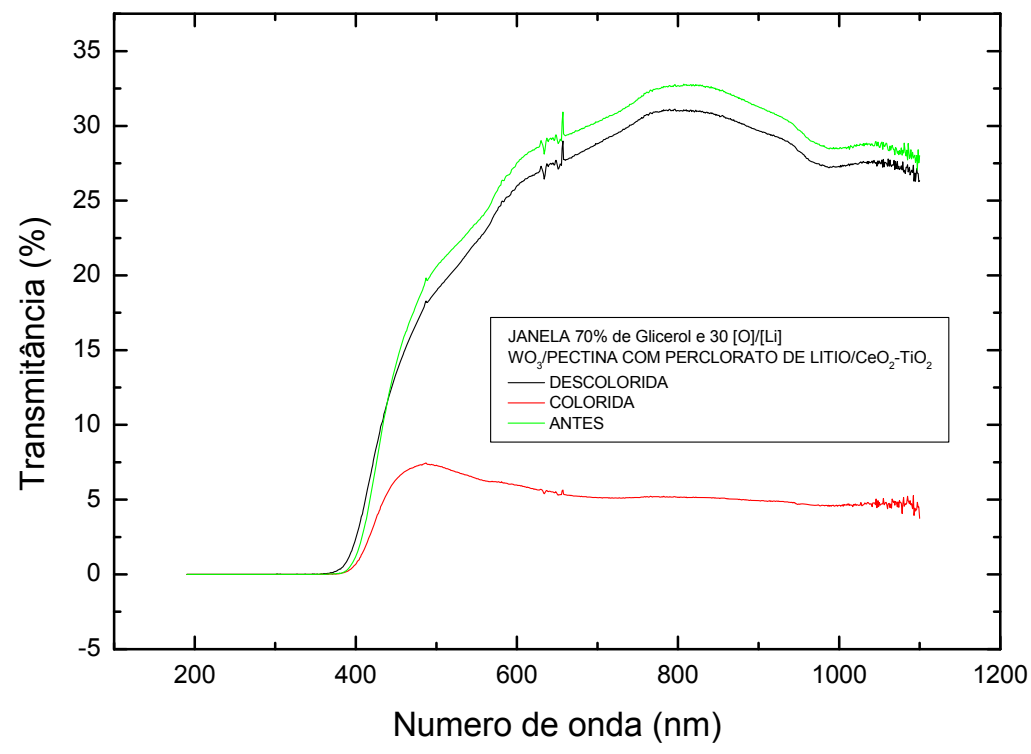

Figura 4-46: UV-Vis da janela eletrocrômica ITO/ $\mathrm{WO}_{3} /$ eletrólito de pectina/ $\mathrm{CeO}_{2}-$ $\mathrm{TiO}_{2} / \mathrm{ITO}$ com eletrólito a base de pectina plastificada $70 \%$ de glicerol e contendo $\mathrm{LiClO}_{4}$ na concentração de $30[\mathrm{O}] /[\mathrm{Li}]$.

Todos os resultados obtidos neste estudo mostraram que a obtenção de eletrólitos poliméricos a base de pectina é um processo simples levando a produção de amostras na forma de géis transparentes que podem ser aplicados em dispositivos eletroquímicos com sucesso. 


\section{REFERÊNCIAS BIBLIOGRÁFICAS}

\footnotetext{
${ }^{1}$ SILVERSTEIN, R. M.; BASSLER, G. C.; MORRILL, T. C. Identificação espectrométrica de compostos orgânicos. 5. ed. Rio de Janeiro: LTC, 1994. 90 p.
}
${ }^{2}$ MANRIQUE, G. D.; LAJOLO, F. M. FT-IR spetroscopy as a tool for measuring degree of methyl esterification in pectins isolated from ripening papaya fruit. Postharvest Biology and Technology, v. 25, p. 99-107, 2002.

${ }^{3}$ MONSOOR, M.A.; KALAPATHY, U.; PROCTOR, A. Determination of polygalacturonic acid content in pectin extracts by diffuse reflectance Fourier transform infrared spectroscopy.

Food Chemistry, v. 74, p. 233-238, 2001.

\footnotetext{
${ }^{4}$ GNANASAMBANDAM, R.; PROCTOR, A. Determination of pectin degree of esterification by diffuse reflectance Fourier transform infrared spectroscopy. Food chemistry, v. 68, p. 327-332, 2000.
}

${ }^{5}$ LUTZ, R.; ASERIN, A.; WICKER, L.; GARTI, N. Structure and physical properties of pectins with block-wise distribution of carboxylic acid groups. Food Hydrocolloids, v. 23, p. 786794, 2009.

${ }^{6}$ VIEIRA, D.F.; AVELLANEDA, C. O.; PAWLICKA, A. Conductivity study of a gelatin-based polymer electrolyte. Electrochimica Acta, v. 53, p. 1404-1408, 2007.

\footnotetext{
${ }^{7}$ PAWLICKA, A.; SABADINI, A. ; RAPHAEL, E.; DRAGUNSKI, D. Ionic conductivity thermogravimetry measurements of starch-based polymeric electrolytes. Molecular Crystals and Liquid Crystals, v. 485, p. 804-816, 2008.
}

${ }^{8}$ LOURDIN, D.; BIZOT, H.; COLONNA, P. Antiplasticization in starch-glycerol films. Journal Applied Polymer Science, v. 63, n. 8, p. 1047-1053, 1997.

${ }^{9}$ RAPHAEL, E. Eletrólitos sólidos poliméricos a base de amidos de mandioca: nativo, acetilado e oxidado - acetilado. 2004. 123 f. Dissertação (Mestrado) - Instituto de Química de São Carlos, Universidade de São Paulo, São Carlos, 2004.

\footnotetext{
${ }^{10}$ MACHADO, G. D.; REGIANI, A. M.; PAWLICKA, A. Carboxymethylcellulose derivatives with low hydrophilic properties. Polimery, v. 48, n. 4, p. 33-39, 2003.

${ }^{11}$ MORITA, M.; ARAKI, F.; KASHIWAMURA, K.; YOSHIMOTO, N.; ISHIKAWA, M. Ionic structure and conductance behavior of plasticized polymeric electrolytes containing multivalent cations. Electrochimica Acta, v. 45, n. 8-9, p. 1335-1340, 2000.
} 
${ }^{12}$ ANDRADE, J. R.; RAPHAEL, E.; PAWLICKA, A. Plasticized pectin-based gel electrolytes. Electrochimica Acta,v. 54, p. 6479-6483, 2009.

${ }^{13}$ MUNICHANDRAIAH, N.; SCANLON, L.G.; MARSH, R.A., J. Surface films of lithium: an overview of electrochemical studies. Power Sources, v. 72, p. 203-210, 1998.

${ }^{14}$ THEVENIN, J.G.; MULLER, R. H. Impedance of Lithium Electrodes in a Propylene Carbonate Electrolyte. J. Electrochem. Soc., v. 134, p. 273-280,1987.

${ }^{15}$ STRAUSS, E.; GOLODNITSKY, D.; ARDEL, G.; PELED, E. Charge and mass transport properties of Lil-P(EO)n-Al $\mathrm{O}_{3}$-based composite polymer electrolytes. Electrochimica Acta, v. 43, p. $1315,1998$.

${ }^{16}$ AVELLANEDA, C. O.; VIEIRA, D. F.; PAWLICKA, A. All solid-state electrochromic devices with gelatin-based electrolyte. Solar Energy Materials and Solar Cells, v. 92, n. 2, p. 228233, 2008.

${ }^{17}$ PROENÇA, M. B.; COUTINHO, J. S.; SALGADO, A. N., KAVAMURA, E. E. Estudo de metodologias para identificar adsorção e dessorção de hidrogênio por vidros metálicos, Ciência e Cultura, n. 25, p. 121-134, 2001.

${ }^{18}$ MUNICHANDRAIAH, N.; SIVASANKAR, G.; SCANLON, L. G.; MARSH, R. A. Characterization of PEG-PAN hybrid solid polymer electrolytes. Journal of Applied Polymer Science, v. 65, n. 11, p. 2191-2199, 1997.

${ }^{19}$ A., AL-KAHLOUT; VIEIRA, D.; AVELLANEDA, C.; LEITE, E.R.; AEGERTER, M. A.; PAWLICKA, A. Gelatin-based protonic electrolyte for electrochromic windows. Ionics, v. 16, p. 13-19, 2010.

${ }^{20}$ PAWLICKA, A.; DANCZUK, M.; WIECZOREK, W.; ZYGADTO-MONIKOWSKA E. Influence of plasticizer type on the properties of polymer electrolytes based on chitosan. Journal of Physical Chemistry A, v. 112, n. 38, p. 8888-8895, 2008.

${ }^{21}$ DRAGUNSKI, D. C. Preparação de eletrólitos sólidos poliméricos apartir de amido. 2003. 163 f. Tese (Doutorado) - Instituto de Química de São Carlos, Universidade de São Paulo, São Carlos, 2003.

${ }^{22}$ GUIMARÃES, K. V. Eletrólitos sólidos poliméricos a base de amido plastificado com etileno glicol, carbonato de propileno e mistura de glicol com poli(etileno glicol). 2003. 101 f. Dissertação (Mestrado) - Instituto de Química de São Carlos, Universidade de São Paulo, São Carlos, 2003. 
${ }^{23}$ MACHADO, G. O. Preparação e caracterização de eletrólitos sólidos poliméricos a partir dos derivados de celulose - hidroxietilcelulose e hidroxipropilcelulose. 2004. 127f. Tese (Doutorado) - Instituto de Química de São Carlos, Universidade de São Paulo, São Carlos, 2004.

${ }^{24}$ FERREIRA, H. C. A. Eletrólitos sólidos poliméricos a base de HEC plastificada com glicerol. 2002. 88 f. Dissertação (Mestrado) - Instituto de Química de São Carlos, Universidade de São Paulo, São Carlos, 2002. 


\section{CAPITULO 5 - CONCLUSÕES}

As pectinas e as membranas foram caracterizadas por técnicas espectroscópicas, térmicas, análises estruturais e microscópicas.

As análises espectroscópicas na região do infravermelho possibilitaram identificar a absorção entre 1200 e 950 cm${ }^{-1}$, região considerada correspondente ao "fingerprint" característico para cada polissacarídeo. Estas bandas são difíceis de serem interpretadas, entretanto foi observado que esta região independe da origem da pectina e pode ser usada para identificar 0 ácido galacturônico. Os espectros de FT-IR revelaram que não há diferença de composição entre as pectinas USP e BRS-Z, sendo a diferença entre elas somente no controle microbiológico que é mais restrito na pectina USP, utiliza em indústrias farmacêuticas.

O grau de esterificação encontrado para as amostras de pectina foi próximo ao teórico característico, em torno de $72 \%$.

Pela técnica de raios- $X$, não se observou pequenas diferenças na cristalinidade entre as amostras de pectina USP e BRS-Z.

As análises químicas elementares demonstraram que as amostras de pectinas utilizadas neste trabalho têm teores de carbono, oxigênio, nitrogênio e enxofre próximos aos calculados teoricamente.

Com as análises térmicas das amostras em pó, observou-se que a temperatura de degradação das pectinas é em torno de $230^{\circ} \mathrm{C}$, sobrando o resíduo em torno entre 15 e $20 \%$. 
As membranas fabricadas são características de eletrólitos poliméricos géis (EPG).

Os eletrólitos poliméricos foram preparados com pectina GENU® BRSZ, plastificados com diferentes concentrações de glicerol e adição de diferentes quantidades de sal $\mathrm{LiClO}_{4}(0,24 \mathrm{~g}$ ou $30[\mathrm{O}] /[\mathrm{Li}])$.

Os resultados da condutividade iônica em função da temperatura obedecem à relação Arrhenius e VTF, dependendo da quantidade de plastificante adicionado.

Os difratogramas de raios- $X$ dos eletrólitos evidenciaram que a adição de plastificantes promoveu a diminuição da fase cristalina das amostras e aumentou o seu caráter amorfo de modo análogo aos outros filmes condutores iônicos a base de polissacarídeos.

Observou-se pela técnica de DSC, que o aumento de quantidade do plastificante nas amostras promoveu a diminuição dos valores de $\operatorname{Tg}$ até $-70^{\circ} \mathrm{C}$.

Os valores de transmitância das membranas obtidos pela técnica de espectroscopia de UV-vis, variam de 55\% a 85\% na região do visível ( 400 a $800 \mathrm{~nm})$, o que pode-se considerar bons resultados de transmitância, possibilitando a utilização destes eletrólitos em janelas eletrocrômicas.

As micrografias apresentaram filmes homogêneos e maleáveis, características importantes para os eletrólitos.

Os valores de condutividade iônica para os filmes com $0,24 \mathrm{~g}$ de $\mathrm{LiClO}_{4}$ variam de $6,15 \times 10^{-6}$ S.cm ${ }^{-1}$ com $37 \%$ de glicerol para $2,27 \times 10^{-4} \mathrm{~S}^{-\mathrm{cm}^{-1} \mathrm{com}}$ $68 \%$ de glicerol à $30^{\circ} \mathrm{C}$ atingindo o máximo de condutividade nesta composição. Portanto, os filmes com $68 \%$ de glicerol apresentam os melhores valores de condutividade iônica que variam de $1,61 \times 10^{-4}{\mathrm{~S} . \mathrm{cm}^{-1}}^{\mathrm{em}}$ 
temperatura ambiente para $1,72 \times 10^{-3} \mathrm{~S} . \mathrm{cm}^{-1}$ à $80^{\circ} \mathrm{C}$, e apresentaram uma transmitância de $80 \%$ no intervalo do visível. Os valores da energia de ativação para este filme é em torno de $37 \mathrm{KJmol}^{-1}$. Também foi verificada a estabilidade eletroquímica evidenciando bons resultados em uma faixa de potencial que varia entre $-1,5 \mathrm{a}+1,5 \mathrm{~V}$

A partir da caracterização dos eletrólitos em relação a seus valores de condutividade iônica, fez-se a montagem de janelas eletrocrômicas $\mathrm{ITO} / \mathrm{WO}_{3}$ /eletrólito de pectina/ $/ \mathrm{CeO}_{2}-\mathrm{TiO}_{2} / \mathrm{ITO}$ e aplicou-se potenciais de $-3,5 \mathrm{~V}$ a +3,0V, e -2,5V a 2,0 V para verificar a eficiência desses ESGs, com o filme com $70 \%$ de glicerol. O resultado desta análise revelou um pico catódico a $1,4 \mathrm{~V}$ relativo aos processos de redução e coloração para o azul da camada eletrocrômica de $\mathrm{WO}_{3}$ e um pico anódico correspondente a $0,6 \mathrm{~V}$ relativo à oxidação desta camada e sua descoloração. Nos mesmos potenciais ocorrem também os processo reversos de oxidação e redução da camada $\mathrm{CeO}_{2}-\mathrm{TiO}_{2}$, chamada de reservatório de íons. Um acentuado aumento de corrente para potenciais abaixo de -3V observado foi considerado como sendo devido aos processos de redução de ITO e também ao processo de redução de hidrogênio da água do eletrólito. Portanto, os potenciais aplicados não deveriam ultrapassar $+/-2 \mathrm{~V}$. Os resultados das cargas inseridas e extraídas durante a coloração e descoloração da janela eletrocrômica contendo eletrólito a base de pectina, pode se verificar que os processos de inserção ocorrem relativamente rápido atingindo $8,5 \mathrm{mC} / \mathrm{cm}^{2}$ em $15 \mathrm{~s}$. A extração também é rápida, recuperando o estado inicial também em 15 s, contudo se comparada com resultados de outras janelas eletrocrômicas que descolorem em 2-5 s, esta é 
um pouco mais lenta. A reversibilidade é de $97 \%$, o que indica que a janela é praticamente totalmente reversível.

Os valores de condutividade iônica para os filmes com $[\mathrm{O}] /[\mathrm{Li}]=30$

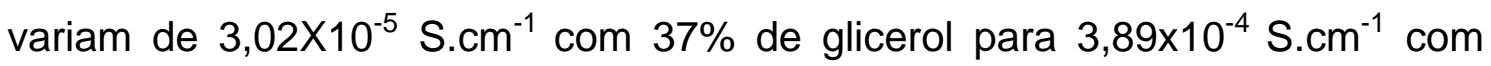
$70 \%$ de glicerol à $30^{\circ} \mathrm{C}$ atingindo o máximo de condutividade nesta composição. Portanto, os filmes com $70 \%$ de glicerol apresentam os melhores valores de condutividade iônica que variam de $3,08 \times 10^{-4} \mathrm{~S} . \mathrm{cm}^{-1}$ em temperatura ambiente para $2,94 \times 10^{-3} \mathrm{~S}_{\mathrm{cm}} \mathrm{cm}^{-1}$ à $80^{\circ} \mathrm{C}$, e energia de ativação em torno de $35 \mathrm{KJmol}^{-1}$. Estes filmes também possuem uma transmitância de $75 \%$ no intervalo do visível.

A técnica de voltametria cíclica da amostra de dispositivo contendo eletrólito a base de pectina plastificada com $70 \%$ de glicerol e contendo $\mathrm{LiClO}_{4}$ na concentração de 30 [O]/[Li]. Nota-se também dois picos relativos aos processos de oxidação e redução de camadas de filmes finos cerâmicos, sendo $\mathrm{o}_{\mathrm{WO}_{3}}$ filme eletrocrômico que muda sua coloração de transparente para o azul em potenciais catódicos $(-1,4 \mathrm{~V})$ e volta para o estado transparente em potenciais anódicos, i.e, (0,6V). O processo de inserção/coloração atinge valores de $85 \mathrm{mC} / \mathrm{cm}^{2}$ em $20 \mathrm{~s}$. Próximos 20 segundos de aplicação de potencial inverso, anódico, promove a descoloração, a reversibilidade é de 98\%, o que indica que a janela é reversível.

Com os resultados expostos, concluí-se que há viabilidade de se preparar eletrólitos poliméricos géis a partir de pectina. E que o melhor filme encontrado neste estudo é membrana contendo $0,6 \mathrm{~g}$ de pectina GENU ${ }^{\circledR}$ BRSZ, $70 \%$ de glicerol em massa e concentração de $\mathrm{LiClO}_{4}$ de 30 [O]/[Li], sendo promissor para a aplicação como eletrólitos em janelas eletrocrômicas. 